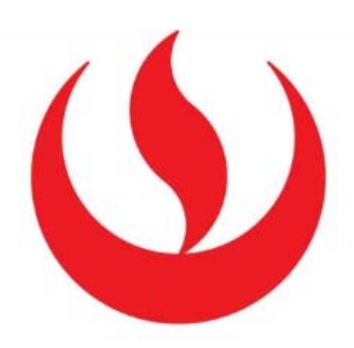

UNIVERSIDAD PERUANA DE CIENCIAS APLICADAS

FACULTAD DE INGENIERÍA

CARRERA DE INGENIERÍA INDUSTRIAL

\title{
PROPUESTA DE MEJORA EN LA GESTIÓN DE INVENTARIOS PARA LA REDUCCIÓN DE VENCIMIENTOS EN UNA EMPRESA DE CONSUMO MASIVO
}

\author{
TESIS \\ Para optar por el título profesional de: \\ INGENIERO INDUSTRIAL \\ AUTOR: \\ Vilela Vera, Joselyn Eilen (0000-0002-5444-645) \\ ASESOR: \\ Salas Castro, Rosa (0000-0002-8297-1104)
}

Lima, 29 de enero 2018 


\section{Resumen}

Las empresas manufactureras en la actualidad cuentan con diversos sistemas o herramientas informáticas que apoyan en la gestión logística. En el consumo masivo, donde se cuenta con una gran variedad de almacén SKUS (unidades de mantenimiento de almacén) y poco margen para los errores logísticos, es primordial contar un modelo logístico que reduzca los excesos o escazes de inventario, reduciendo costos. Este trabajo presenta una propuesta de modelo logístico como solución a los problemas de excesos de inventarios de una empresa de consumo masivo. Para esto inicialmente se muesta el proceso de análisis para la identificación de la causa raíz con data histórica de un año. Se detallan diversos modelos teóricos, así como la situación actual de la empresa para la elección de metodología más adecuada. Es así, que la propuesta seleccionada basada en la mejora de procesos y el DDMRP (Demand Driven Material Requirements Planning) se aplica en un plan piloto soportado en simulaciones de la herramienta informática de la empresa. Finalmente, se muestran los resultados satisfactorios de los indicadores y la inversión necesaria para llevar a cabo la propuesta.

Palabras clave: Inventarios, Política de inventarios, DDMRP, excesos de inventarios, logística, manufactura, modelo de control, punto de abastecimiento, sistema de toma de decisiones 


\begin{abstract}
The business of consumer goods has its core in handling a great number of stock keeping units. Therefore, it is essential to have a logistic model that reduces the excesses or shortages of inventory. Nowadays, manufacturing companies have many computer softwares or tools for logistics management. However, not all of them are supported on a logical process that achieves cost reduction. This work presents a proposal of a logistic model as a solution to the problems of out of day inventories of a consumer goods company. It starts with the analysis to identify the root cause with historic data. Then, prevalent theoretical logistic models are explained, as well as the current situation of the company. Aligning these concepts, the most appropriate methodology is chosen. The selected model is based on process improvement and DDMRP (Demand Driven Material Requirements Planning). A pilot programme is implemented in the company's logistic software. Finally, the results of the indicators and the investment necessary to carry out the proposal are shown with satisfying numbers.
\end{abstract}

Keywords: Inventory, inventory policy, DDMRP, Inventory excess, logistics, manufacture, control model, reorder point, decision making system 


\section{ÍNDICE DE CONTENIDO}

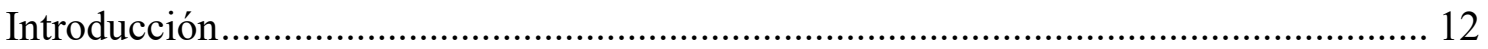

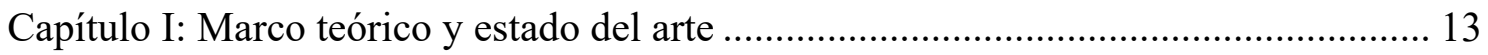

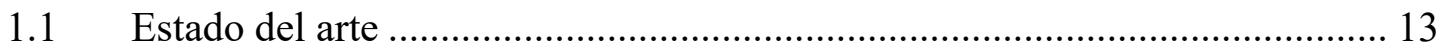

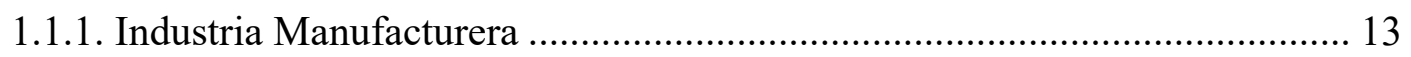

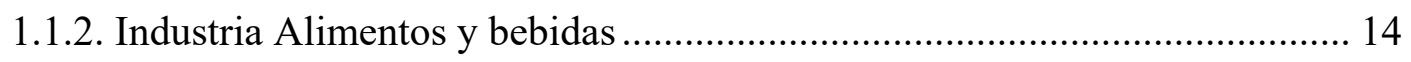

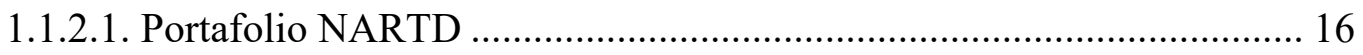

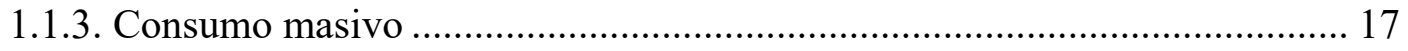

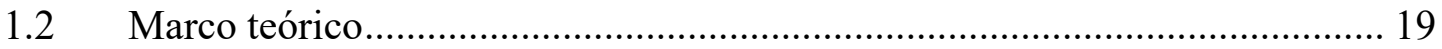

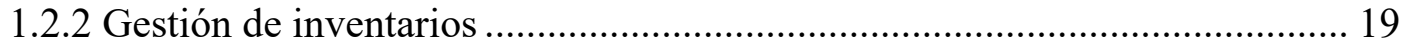

1.2.3 Modelos de gestión de inventarios .......................................................... 21

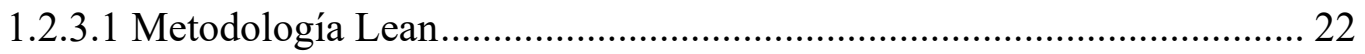

1.2.3.2 Sistemas de control de Inventarios ..................................................... 26

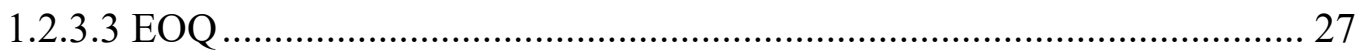

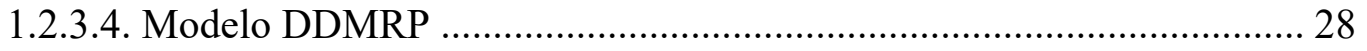

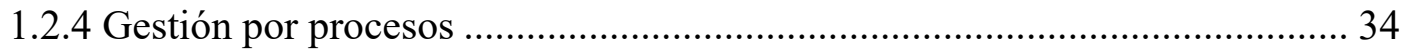

1.2.4.1 Definición de Gestión por procesos...................................................... 34

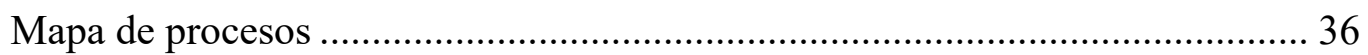

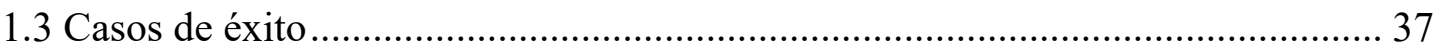

1.3.1. Marco de Referencia para el desarrollo de un sistema de apoyo para la toma

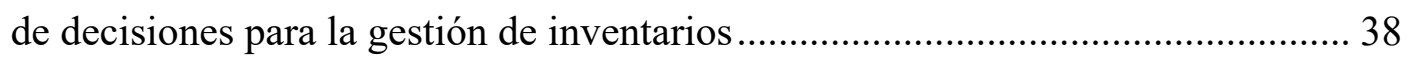

1.3.2. Comparación de MRPII y DDMRP ............................................................. 40

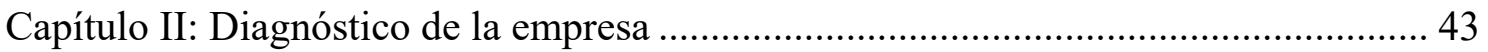

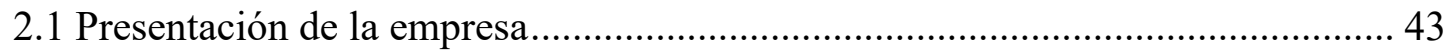

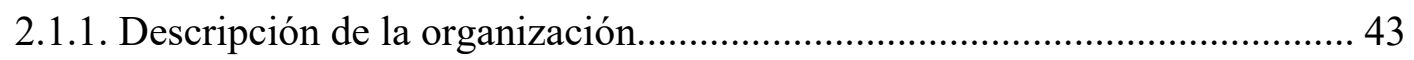

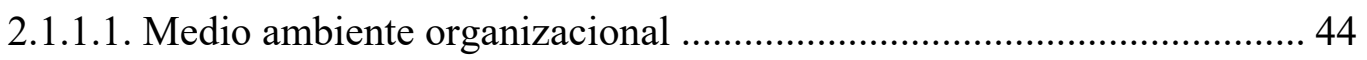

2.1.1.1.1. Misión, Visión y Valores............................................................... 44

2.1.1.1.2. Portafolio de productos............................................................... 44

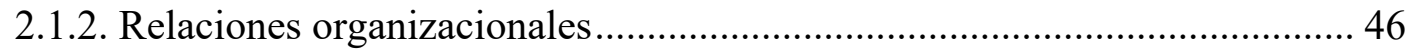

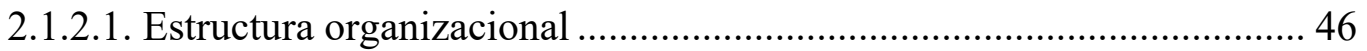

2.1.2.2. Clientes, Socios y Proveedores................................................................ 48

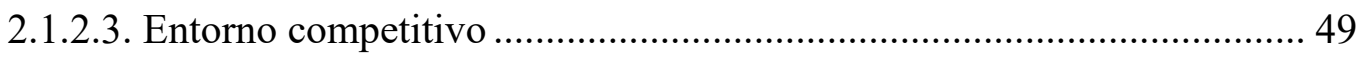

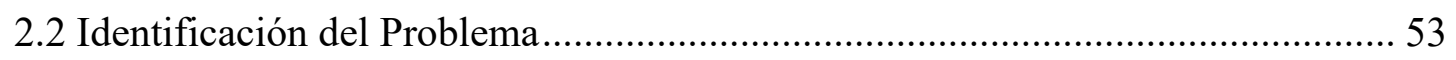




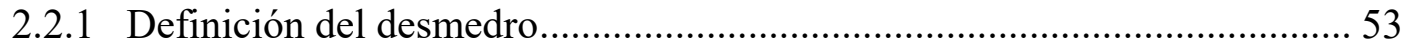

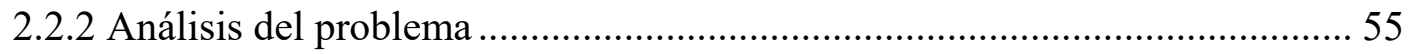

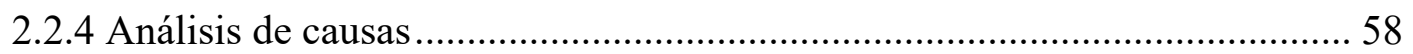

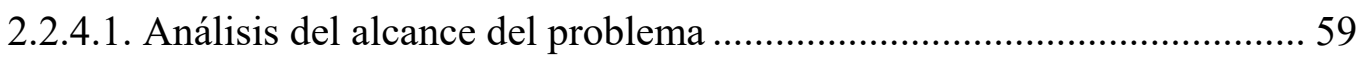

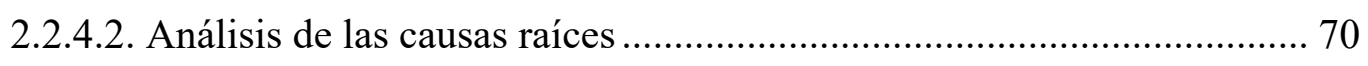

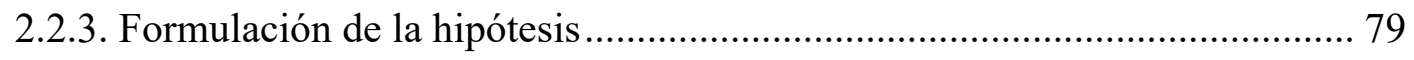

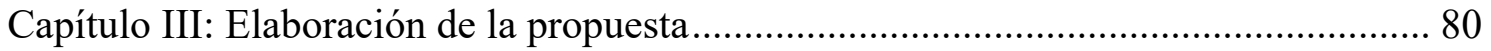

3.1. Objetivos de la propuesta de solución ......................................................... 80

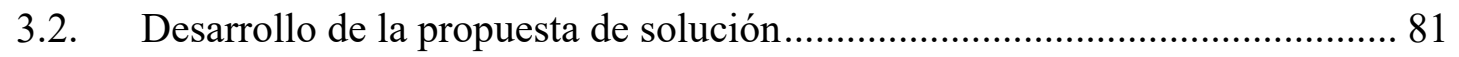

3.2.1. Propuesta para mejora del proceso definición de política de stocks ............ 81

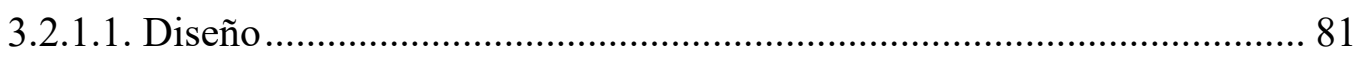

3.2.1.2. Desarrollo del modelo ..................................................................... 83

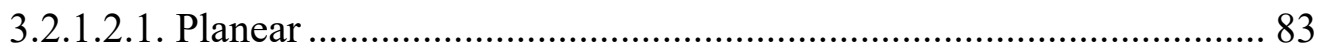

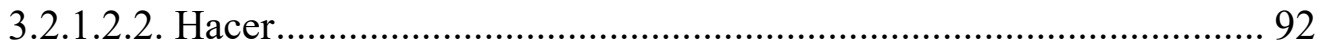

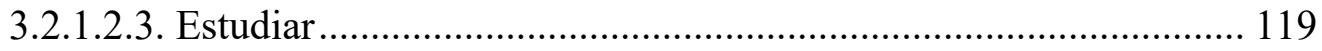

3.3. Plan de implementación................................................................................. 124

Capítulo IV: Evaluación y validación de la propuesta ............................................... 125

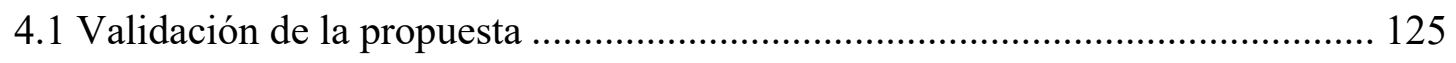

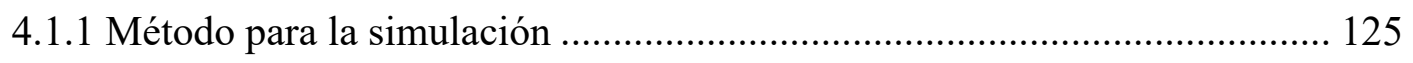

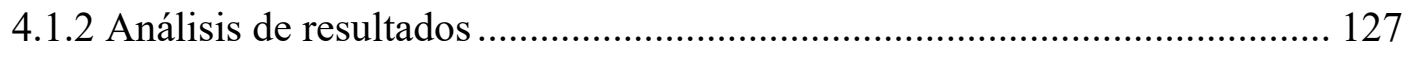

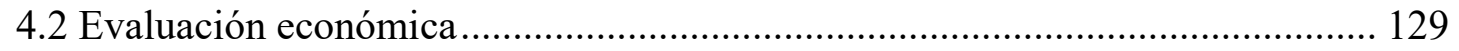

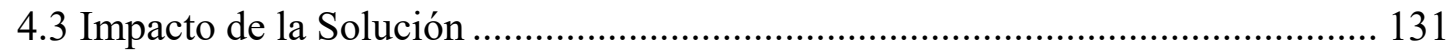

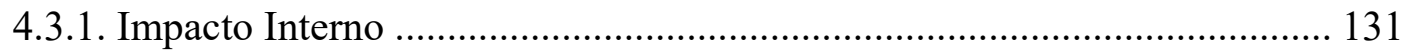

4.3.1.1 Impacto en los trabajadores ......................................................... 131

4.3.1.2 Impacto en la compañía................................................................... 132

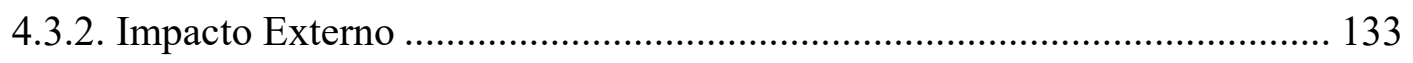

4.3.1.1 Impacto en los clientes .................................................................. 133

4.3.1.2 Impacto en el ambiente................................................................... 133

4.3.1.3 Impacto en los competidores ............................................................ 134

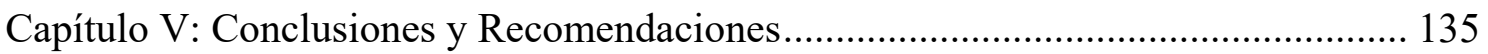

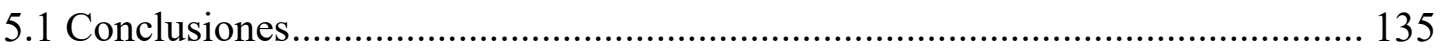

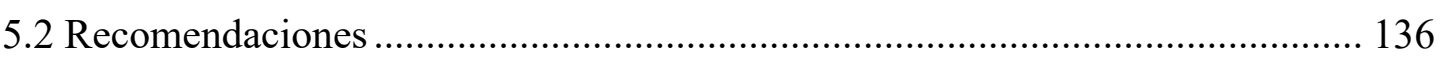

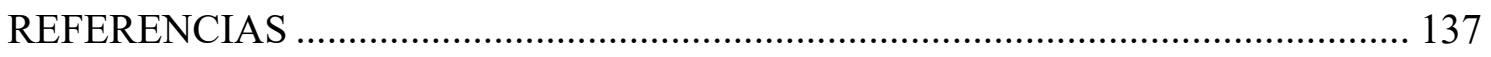

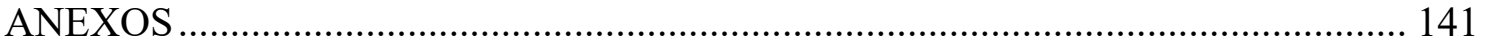




\section{ÍNDICE DE TABLAS}

Tabla 1. Tipos de desperdicio en manufactura ......................................................... 22

Tabla 2

Participación de mercado de la empresa botellas en el rubro de bebidas del año 2017

Tabla 3 Comparación de volumen de desmedro 2017 vs 2016 al mismo periodo .......... 57

Tabla 4 Indicador de gastos de desmedros en miles de S/. .......................................... 58

Tabla $5 \%$ Participación por tipo de desmedro en los últimos 12 meses en Almacén MEPA

Tabla 6 \% Participación por origen del volumen total de vencimientos del Almacén MEPA en los últimos 12 meses 60

Tabla 7 Criterios de clasificación de vencimiento en almacén ...................................... 64

Tabla 8 Criterios de clasificación por tipo de causa .................................................... 67

Tabla 9. Clasificación de causa raíz de planificación deficiente .................................. 67

Tabla 10. Asertividad del pronóstico del SKU 251393 .................................................. 69

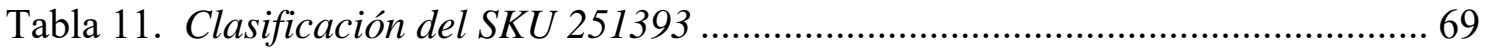

Tabla 12. Clasificación final de skus vencidos en MEPA por tipo de causa ................. 69

Tabla 13 Causas de vencimiento de los almacenes de la empresa ............................... 70

Tabla 14. Diferencias en stock seguro para un SKU de un CDA................................. 74

Tabla 15. Matriz de prioridades para la deficiencia de política de stocks ................... 77

Tabla 16. Metodologías de solución para política de stocks ....................................... 77

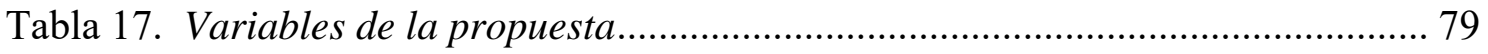

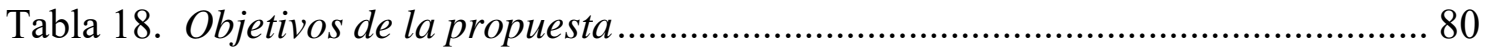

Tabla 19. Cronograma de la propuesta de definición del proceso de política de stocks 83

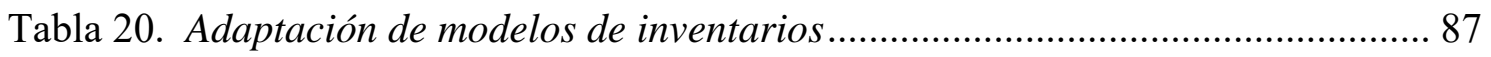

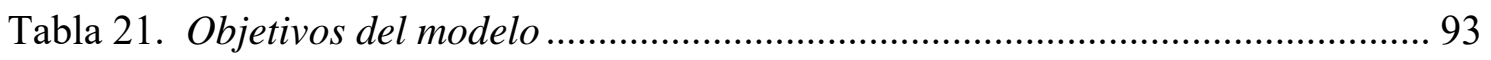

Tabla 22. Asignación de valores $A B C$ por indicador ................................................... 97

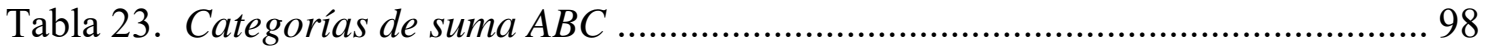

Tabla 24. Resultados de la clasificación ABC multicriterio ......................................... 98

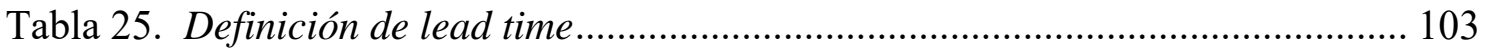

Tabla 26. Definiciones para los factores de lead time …............................................. 103 


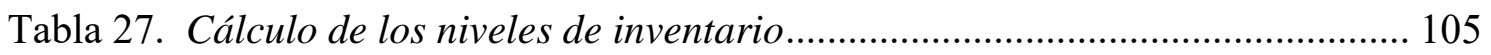

Tabla 28. Ejemplo de cálculo de niveles de inventario para SKU 251291 ................. 106

Tabla 29. Inputs para el cálculo de necesidades........................................................ 113

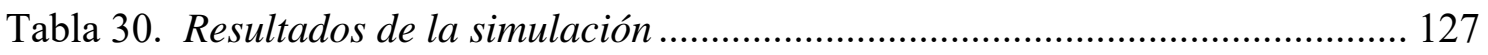

Tabla 31. Comparación de niveles de servicio promedio .......................................... 129 


\section{ÍNDICE DE FIGURAS}

Figura 1. Estructura empresarial del perú según actividad económica 2015-2016. ...... 13

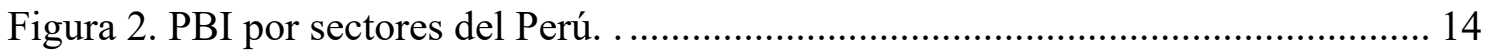

Figura 3. Estructura empresarial de la industria de manufactura. ................................. 14

Figura 4. Ingreso por personal ocupado por empresas manufactureras. . ...................... 15

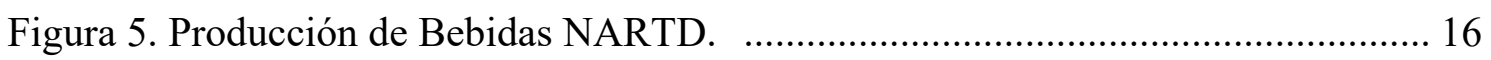

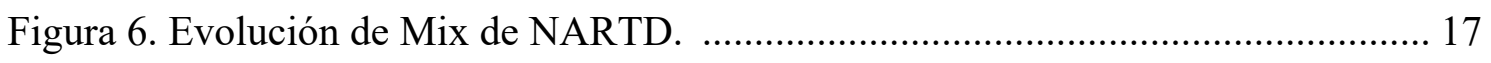

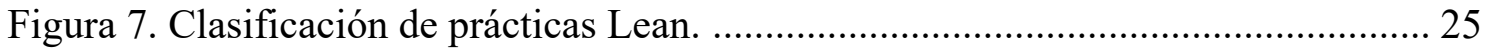

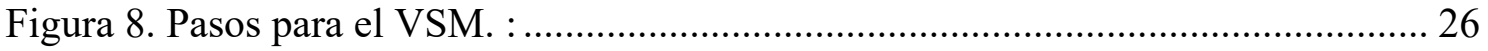

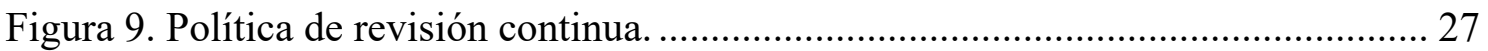

Figura 10. Modelos de control de inventarios, ........................................................... 27

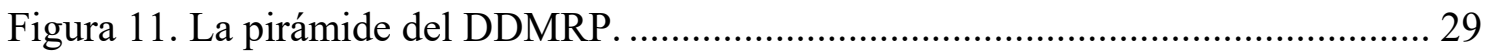

Figura 12. De estratificación zonal a buffer de stocks. ............................................. 30

Figura 13. Rango de impacto de la variabilidad........................................................ 30

Figura 14. Rango del lead time para cálculo de las zonas buffer................................. 31

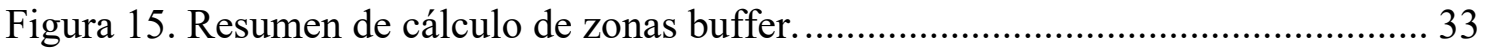

Figura 16. Realineación de las posiciones de inventario con la metodología DDMRP. 34

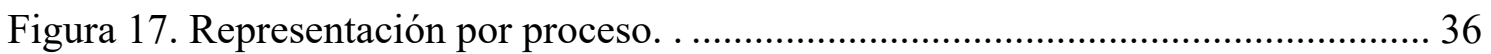

Figura 18. Modelo para la agrupación de procesos en el mapa de procesos.................. 37

Figura 19. Layout de modelo DSS para stocks. ........................................................ 39

Figura 20. Comportamiento del inventario en simulación final................................... 40

Figura 21. Tamaño del reabastecimiento para las órdenes del escenario $7 \ldots \ldots \ldots \ldots \ldots \ldots \ldots . . . . . . .41$

Figura 22. Distribución del inventario con MRPII y DDMRP ..................................... 42

Figura 23. Participación en ventas por categoría y agrupación del 2016. ..................... 45

Figura 24. Evolución de ventas de los últimos 5 años. ................................................ 46

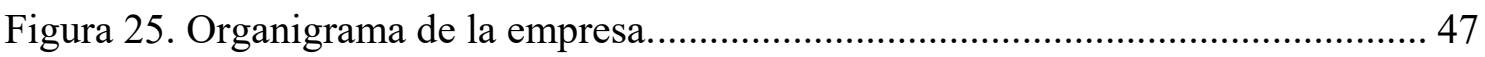

Figura 26. Participación de regiones en el volumen de ventas acumulado del 2016 .... 48

Figura 27. Mapa de procesos de "Botellas"................................................................. 50

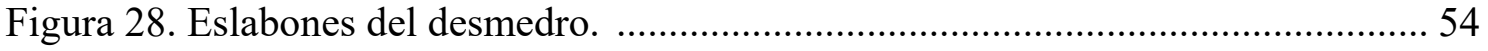

Figura 29. Indicador de Desmedro operativo 2017 .................................................... 55

Figura 30. Desmedro vs Desabastecimiento 2017 ...................................................... 56 
Figura 31.Tendencia del desmedro 2016 vs 2017. 56

Figura 32. Comparación de crecimiento de volumen de venta mes año 2017 vs 2016.. 57

Figura 33. Pareto de participación en volumen de desmedro por almacenes en Lima del año 2017. 58

Figura 34. Evolución del desmedro por tipo en los último 12 meses (Julio 2016 - Julio 2017).

Figura 35. Evolución de la participación en el desmedro por origen en el año 2017 del Almacén MEPA 61

Figura 36. Mapa de calor de días de almacenamiento en plantas de Lima según tipo de producto para Enero - Julio 2017

Figura 37. Salida de lotes del sku 254733

Figura 38. Secuencia de procesos de la planificación de la cadena de abastecimiento. 65

Figura 39. Comparación de planeamiento entre abastecimiento, producción y distribución para el SKU 250068 para el sistema. 66

Figura 40. Comparación de abastecimiento, distribución y producción para 251393 en Lima. 68

Figura 41. Mapa de procesos principales actual del área de Supply Chain...... 71

Figura 42. Macro proceso actual del planeamiento operativo de cadena de suministro 72

Figura 43. Diagrama de Ishikawa de política de stocks .............................................. 73

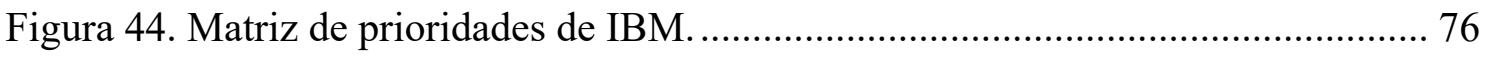

Figura 45. Diagrama de árbol de causa raíz. ................................................................ 78

Figura 46. Perfil de modelo de Castro para DSS........................................................... 85

Figura 47. Perfil de modelo propuesto para niveles de inventario .................................. 86

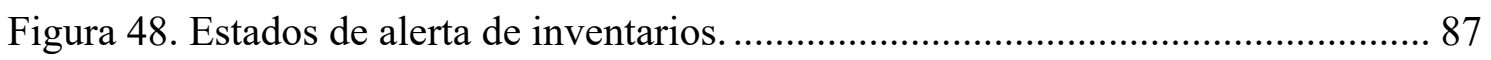

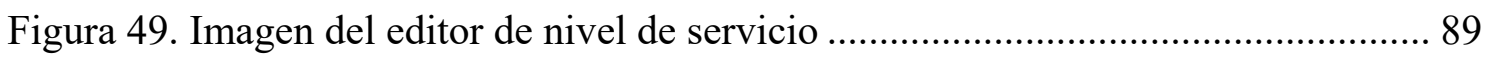

Figura 50. Mapa de procesos principales propuesto para el área de Supply Chain. ..... 94

Figura 51. SIPOC del proceso de definición de la política de inventarios ...................... 95

Figura 52. Pautas para el procedimiento ABC …......................................................... 96

Figura 53. Curva de nivel de servicio de un SKU ......................................................... 99

Figura 54. IP Flat Editor para niveles de servicio ........................................................ 99

Figura 55. Instructivo para cálculo de curvas de nivel de servicio. ............................ 100

Figura 56. Muestra de tabla de niveles de servicio. .................................................. 101

Figura 57. Procedimiento para el cálculo del consumo promedio diario .................... 101

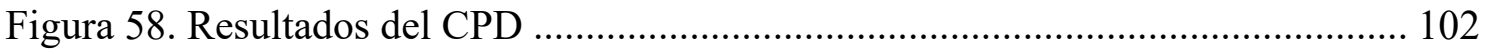


Figura 59. Muestra resultado de factor de variabilidad .............................................. 103

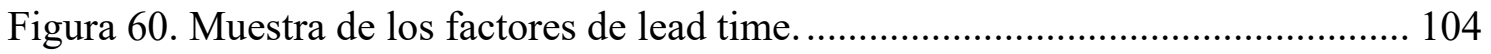

Figura 61. Procedimiento de actualización de costos. ................................................. 104

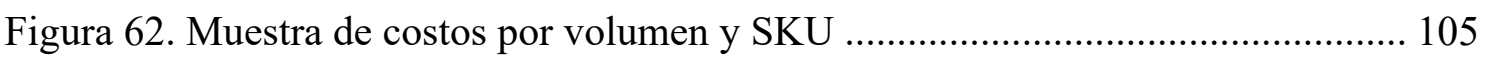

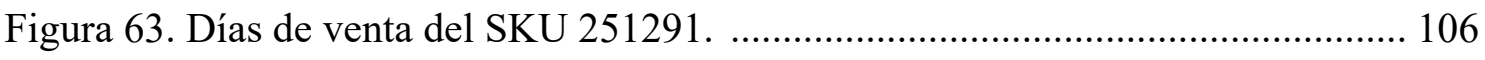

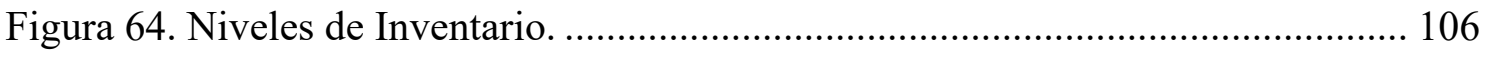

Figura 65. Checklist para mantenimiento del Programa AV en el Modo Test ............ 107

Figura 66. Edición de inventario en sistema.............................................................. 107

Figura 67. Resultado de simulación en el sistema. .................................................... 108

Figura 68. Muestra simulación con costos y niveles de servicio en la herramienta..... 108

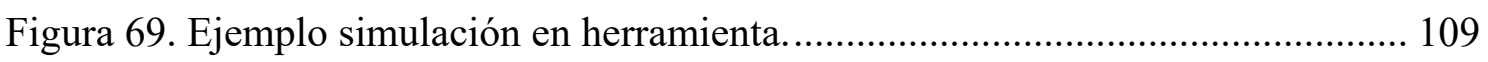

Figura 70 Checklist para clasificación ABC …...................................................... 109

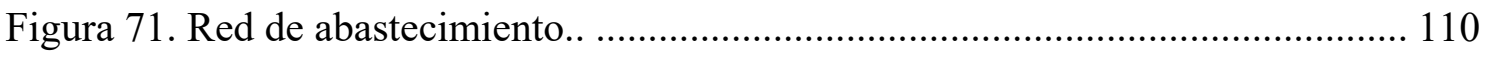

Figura 72. Diagrama de flujo de la nueva planificación de la cadena de abastecimiento

Figura 73. Diagrama de bloques para establecer necesidades de abastecimiento........ 112

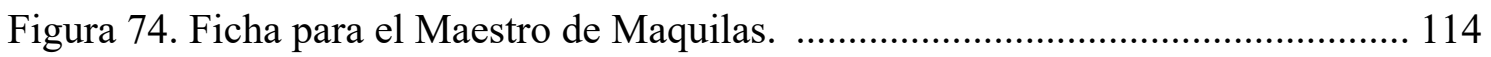

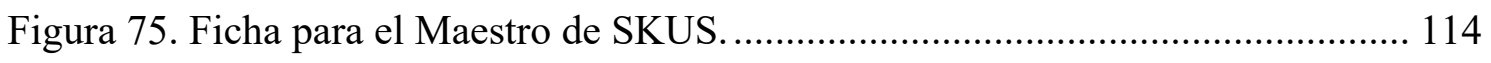

Figura 76. Ficha del Maestro de Unidad de Envío....................................................... 115

Figura 77. Ficha del maestro de política de Inventarios. .............................................. 115

Figura 78. Ficha de Maestro de Locaciones............................................................... 116

Figura 79. Ejemplo análisis de distribución de inventarios. ...................................... 119

Figura 80. Gantt de implementación en fase 1 ............................................................. 124

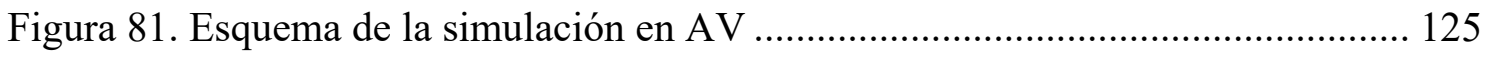

Figura 82. Resultado de la simulación en el sistema................................................. 126

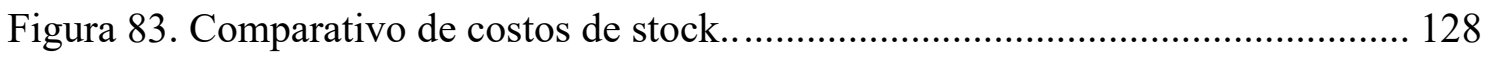

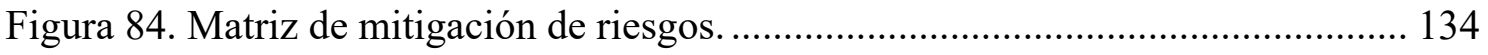




\section{Introducción}

En la actualidad, la industria del consumo masivo es uno de los rubros que controla gran parte del comercio mundial. Este sector está enfocado en la producción a gran escala con costos bajos y grandes volúmenes de venta. La creciente tendencia a la personalización de los productos ha ocasionado que cada vez más las empresas de consumo masivo diversifiquen sus productos. Se genera así una gran lista de SKUS (unidades de mantenimiento de alamcén) que deben ser gestionados con una gran precisión para evitar los excesos o desabastecimientos de productos y aumenten los costos de las compañías.

Existen diversos software o herramientas computacionales que actualemente se usan en las empresas para soportar el complejo proceso logístico. Sin embargo, los avances tecnológicos muchas veces no van de la mano con los procesos de planificación de las compañías, generando que no se usen al 100\% los recursos para cumplir los objetivos.

Esta tesis recoge el caso de una empresa que cuenta con una herramienta sofisticada para la gestión de la logística, no obstante, presenta graves problemas de vencimientos de inventario en gran parte de sus distribuidoras generando costos excesivos. Por ello, es necesario una revisión detallada a través de la gestión de procesos y metodologías logísticas actuales para determinar que metodologías aplicar a las herramientas actuales para reducir los excesos de inventarios y evitar el riesgo de vencimientos. 


\section{Capítulo I: Marco teórico y estado del arte}

El primer capítulo tiene por objetivo desarrollar el estado del arte y marco teórico sobre el que se basará la propuesta. Se describirán temas claves como la gestión de inventarios y la gestión por procesos. Se ahondará en la metodología de administración de almacenes y gestión de stock. Finalmente, se presentarán casos de éxito que apoyen la propuesta.

\subsection{Estado del arte}

El estado del arte es la recopilación de la información relacionada a la situación en la que se encuentra el sector de la empresa en estudio, en este caso el consumo masivo de bebidas. Se hizo un análisis de las dimensiones pertinentes, a nivel global y a nivel Perú que permitan dar un diagnóstico de los factores endógenos a la empresa que puedan afectar su desempeño corporativo, comercial y financiero.

\subsubsection{Industria Manufacturera}

La industria manufacturera es aquella actividad económica que se encarga de la transformación de bienes o materias primas en productos para el consumo. Dentro de las empresas de manufactura, se puede encontrar distintos rubros entre los cuales se encuentras: industria madera, alimentos y bebidos, producción textil y maquinaria y equipos. En el Perú, las empresas que son parte de la industria manufacturera hasta el año 2016 representan el 8.2\% del total, de acuerdo a la figura 1.

CUADRO No 1.4

PERÚ: EMPRESAS, SEGỦN ACTIVIDAD ECONÓMICA, 2015 - 16

\begin{tabular}{|c|c|c|c|c|}
\hline \multirow{2}{*}{ Actividad económica } & \multirow{2}{*}{2015} & \multicolumn{2}{|c|}{2016} & \multirow{2}{*}{$\begin{array}{c}\text { Var \% } \\
2016 / 15\end{array}$} \\
\hline & & Absoluto & Porcentaje & \\
\hline Total & 2042992 & 2124280 & 100,0 & 4,0 \\
\hline Agricultura, ganaderia, silvicultura y pesca & 36570 & 36973 & 1,7 & 1,1 \\
\hline Explotación de minas y canteras & 11894 & 11040 & 0,5 & $-7,2$ \\
\hline Industrias manufactureras & 167647 & 173427 & 8,2 & 3,4 \\
\hline Electricidad, gas y agua & 4253 & 4263 & 0,2 & 0,2 \\
\hline Construcción & 53364 & 55087 & 2,6 & 3,2 \\
\hline Commercio y reparacion de vehiculos automotores y motocidetas & 929231 & 962037 & 45,3 & 3,5 \\
\hline Transpotte y almacenamiento & 97795 & 108221 & 5,1 & 10,7 \\
\hline Actividades de alojamientio & 21380 & 22834 & 1,1 & 6,8 \\
\hline
\end{tabular}

Figura 1. Estructura empresarial del perú según actividad económica 2015-2016. INEI, 2016.

Figura 2. Estructura empresarial de la industria de manufactura. INEI, 2016Figura 3. Estructura empresarial del perú según actividad económica 2015-2016. INEI, 2016. 
Desde el año 2014, la industria manufacturera no primaria ha experimentado un decrecimiento en su aporte al PBI. Esto debido en parte a la desaceleración económica del país y la caída en los sectores eléctricos y de construcción. Esta información la podemos ver reflejada en la figura 2.

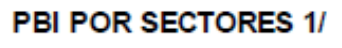

\begin{tabular}{|l|c|c|c|c|c|c|} 
& $\begin{array}{c}\text { Promedio } \\
2010-2012\end{array}$ & 2013 & 2014 & 2015 & 2016 & 2017 \\
\hline Agropecuario & 4,8 & 1,6 & 1,5 & 2,8 & 1,7 & 3,3 \\
Pesca & 0,4 & 24,1 & $-27,5$ & 15,9 & $-8,0$ & 18,0 \\
Minería metálica & $-0,8$ & 4,3 & $-2,1$ & 15,5 & 17,1 & 5,5 \\
Industria no primaria & 8,8 & 3,7 & $-1,0$ & $-2,6$ & $-1,7$ & 1,5 \\
Construcción & 12,4 & 8,9 & 1,7 & $-5,9$ & 0,3 & 2,5 \\
Comercio & 9,5 & 5,9 & 4,4 & 3,9 & 2,4 & 2,7 \\
Servicios & 7,5 & 6,4 & 5,9 & 5,1 & 4,5 & 4,7 \\
PBI & 7,0 & 5,8 & 2,4 & 3,3 & 3,7 & 4,0 \\
\hline
\end{tabular}

Figura 4. PBI por sectores del Perú. INEI, 2016.

En la figura 3, se presenta la estructura empresarial de la industria manufactura. Las microempresas representan el 93,2\% del total de empresas de manufactura, mientras que las grandes y medianas representan apenas el 1\% del total. Esta misma estructura se repite a nivel de otras industrias.

CUADRO N 5.1 LIMA METROPOLITANA: NÚMERO DE EMPRESAS, SEGŨN SEGMENTO EMPRESARIAL, 2015 - 16

\begin{tabular}{|c|c|c|c|c|}
\hline \multirow{2}{*}{ Segmento empresarial } & \multirow{2}{*}{2015} & \multicolumn{2}{|c|}{2016} & \multirow{2}{*}{$\begin{array}{r}\text { Var } \% \\
2016 / 15\end{array}$} \\
\hline & & Absoluto & Porcentaje & \\
\hline Total & 961240 & 993719 & 100,0 & 3,4 \\
\hline Microempresa & 896249 & 926775 & 93,2 & 3,4 \\
\hline Pequeña empresa & 54819 & 56325 & 5,7 & 2,7 \\
\hline Gran y mediana empresa & 9207 & 9621 & 1,0 & 4,5 \\
\hline Administración pública & 965 & 998 & 0,1 & 3,4 \\
\hline
\end{tabular}

Fuente: Instituto Nacional de Estadistica e Informática - Directorio Central de Empresas y Establecimientos.

Figura 5. Estructura empresarial de la industria de manufactura. INEI, 2016

\subsubsection{Industria Alimentos y bebidas}

Dentro de la industria manufacturera, el sector de Alimentos y bebidas era la actividad más importante en la industria de manufacturera, según información del Apoyo del año 
2012. Debido a que la naturaleza del sector, al incluir diversos procesos, tiene la capacidad de generar mayor empleo. En la figura 4, se puede observar el ingreso en millones de soles generado por empleo en la industria de alimentos y bebidas, la cual alcanza 215237 millones de nuevos soles al año.

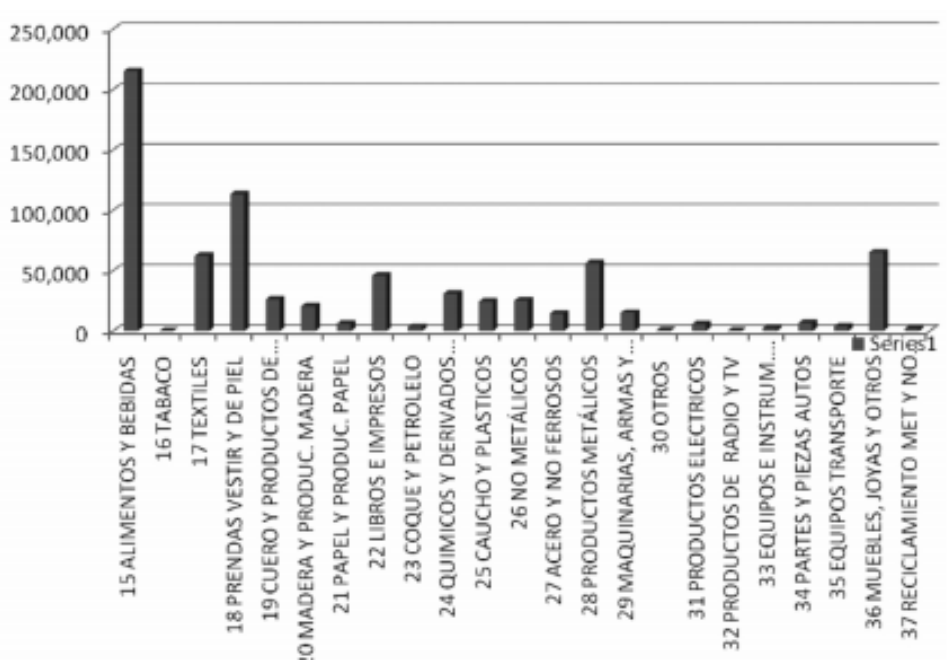

Figura 6. Ingreso por personal ocupado por empresas manufactureras. Apoyo Consultoría, 2012.

Si bien la industria de la manufactura ha experimentado un decrecimiento en los últimos años, el sector de bebidas no alcohólicas, no obstante, se ha visto menos afectado y ha tenido un crecimiento sostenible hasta el cierre del año 2016. En la figura 5, se observa una tendencia en crecimiento para la producción de bebidas no alcohólicas. Esto se debe también a que la demanda del sector está estrechamente relacionada a los cambios clima. 


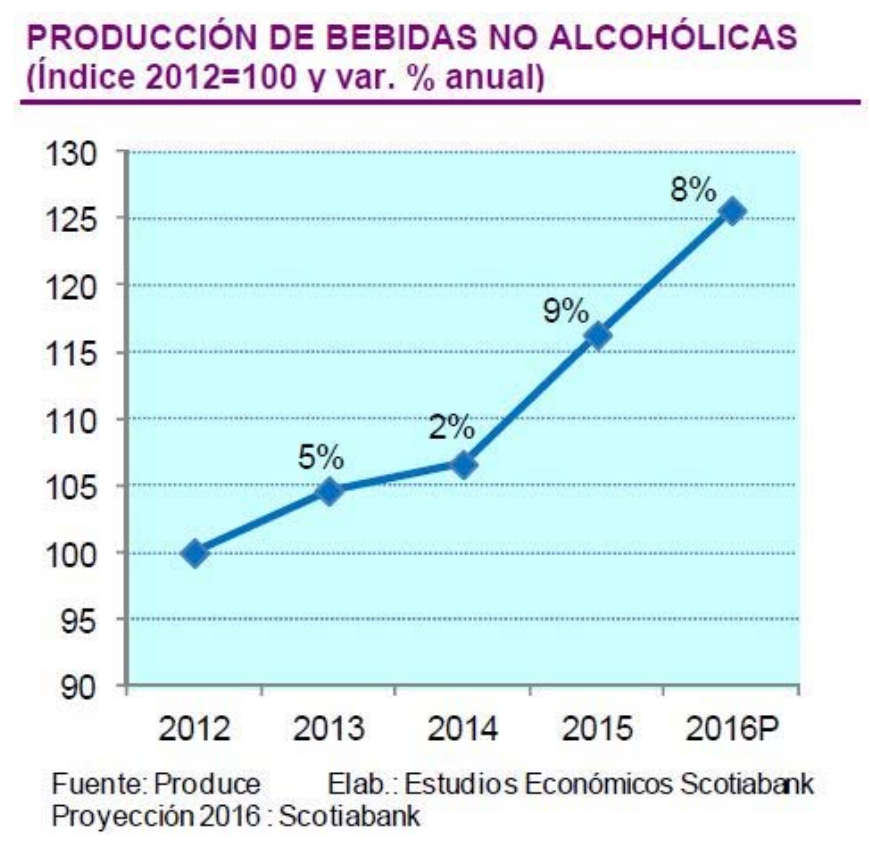

Figura 7. Producción de Bebidas NARTD. Estudios Económicos Scotiabank proyección 2016

De esta manera, en el año 2016 se logró un crecimiento de 6,0\% incluso por sobre el crecimiento del PBI, gracias al fenómeno de El niño. La industria de bebidas en el Perú ha contribuido con casi S/.5000 MM de soles tan solo en impuestos en la década del 2000 al 2011. Durante los últimos 6 años la industria de bebidas ha crecido sustancialmente, gracias a la tendencia de crecimiento en el consumo interno y mayor inversión en la canasta básica. Así como el impulso de las bebidas saludables, como el agua embotellada.

\subsubsection{Portafolio NARTD}

El mix de las bebidas no alcohólicas ha sufrido grandes cambios en los últimos años. La tendencia del consumidor a buscar opciones saludables y las leyes impuestas para cuidar el consumo de azúcar en la población, ha provocado un cambio de la participación. 


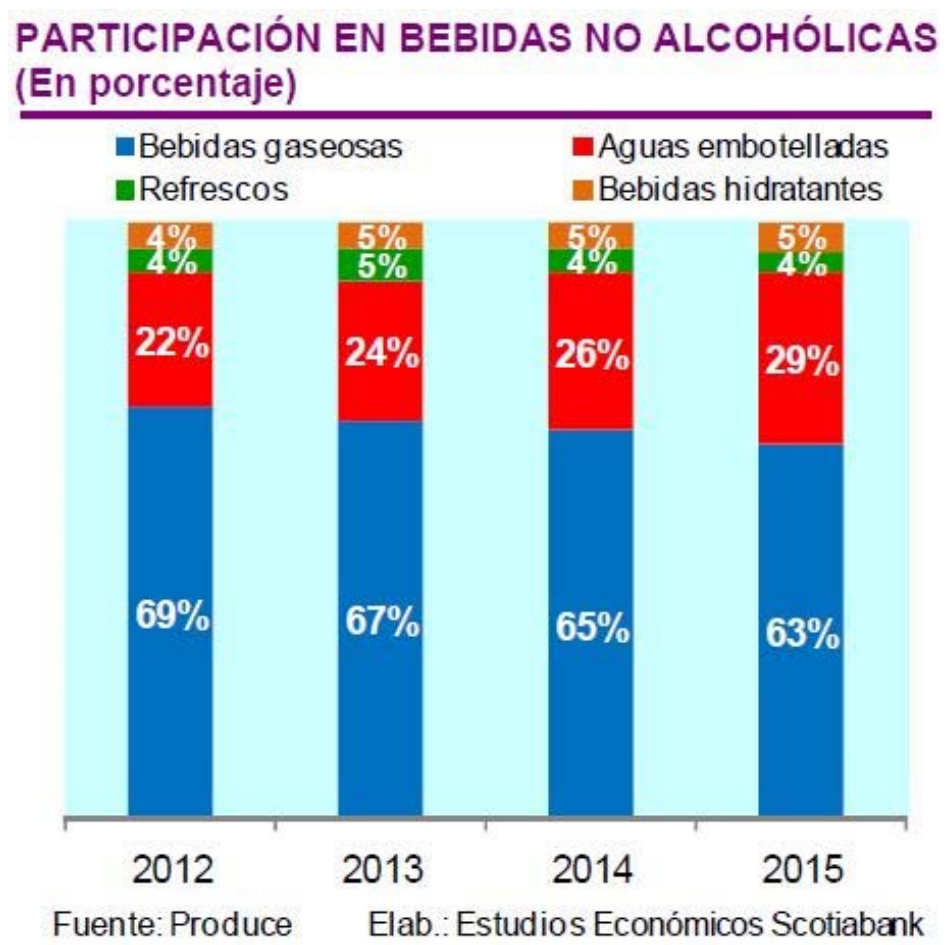

Figura 8. Evolución de Mix de NARTD. Estudios Económicos Scotiabank proyección 2016

En la figura 6 se puede observar que el mix de las categorías gaseosas ha ido disminuyendo cada año. Los productos de agua embotellada siguen ganando mayor participación en el mercado. Esto ha llevado a las empresas del rubro a cambiar la estrategia de sus productos para ofrecer cada vez más productos bajos en calorías. Los portafolios se diversifican y las categorías maduras como las gaseosas han sido reemplazadas por las bebidas no carbonatadas.

\subsubsection{Consumo masivo}

Los productos de consumo masivo son aquellos que perciben una demanda alta en todos los sectores de la sociedad. Para que un producto sea considerado de consumo masivo debe seguir las siguientes características:

- Consumo inmediato: son productos que están hechos para ser consumidos en el momento, ej: snacks. No suelen almacenarse por mucho tiempo.

- Compra cotidiana: productos de primera necesidad que son comprandos con una frecuencia regular.

- Fáciles de contrar: los productos de consumo masivo suelen siempre están disponibles en muchos puntos de venta. Manejan diversos canales para llegar al consumidor 
- Precio reducido: La alta demanda de los productos masivos permite que se maneje un precio asequible para aumentar la venta entre los consumidores

Por la naturaleza del rubro de gran demanda, las compañías de consumo masivo suelen ser grandes o medianas empresas debido a la capacidad de producción que necesitan para poder competir. Las grandes compañías de consumo masivo son trasanacionales, que venden sus marcas en diferentes partes del globo.

\section{Entorno del consumo masivo}

Las compañías de consumo masivo están evolucionando rápidamente con los cambios en la tecnología, demografía y la incertidumbre económica. Esta dinámica tiene el potencial de cambiar el panorama competitivo y volver obsoletos a los modelos tradicionales de negocio.

Globalmente, la industria ha reducido su margen de ganancia en los últimos 30 años. En tendencia se ha pasado de un 5.8\% de margen en 1980 a un $3.7 \%$ en el $2013^{1}$ De la misma manera, el nuevo entorno favorece más a las pequeñas empresas para que aumenten su participación de mercado sobre las tradicionales empresas líderes.

El nuevo panorama que enfrentan las empresas de consumo masivo para el año 2020 puede ser resumido en los siguientes puntos:

1. Poco crecimiento económico de los segmentos clave que obligarán a las empresas a desarrollar nuevas estrategias de canales y adecuar sus precios.

2. La salud y la responsabilidad social es la nueva base de las marcas. Por ello, las empresas deberán adecuar su estrategia de portafolio hacia una plataforma que promueva a salud y el crecimiento sostenible.

3. Digitalización de los canales de marketing abren paso a nuevos canales para alcanzar al consumidor

4. Proliferación de la personalización. El valor de las economías de escala masiva será reducido por los nuevos modelos de negocios enfocados en la personalización.

5. Reducción de recursos y precios volátiles de los commodities.

\footnotetext{
${ }^{1}$ Deloitte (2015)
} 
Estos potenciales retos para las empresas de consumo masivo no son mutuamente exclusivas y marcarán el camino para el crecimiento de las empresas en los próximos 3 años.

\subsection{Marco teórico}

El nuevo panorama de las empresas de consumo masivo, donde los recursos se hacen cada vez más escasos y se deben incursionar en nuevos canales con diversidad de productos manteniendo precios bajos, obliga a que las empresas apunten a mantener o mejorar sus márgenes, a través de la reducción de costos y preparándose para el manejo logístico de una gran variedad de productos. Por ello, la gestión de inventarios es uno de los puntos principales a enfocarse:

\subsubsection{Gestión de inventarios}

La gestión de inventarios es un proceso transversal a la cadena de suministro esencial para alcanzar el pleno potencial de la cadena ${ }^{2}$. En un mercado altamente competitivo es necesario que las empresas cuenten con un modelo de gestión de inventarios que les permita garantizar la satisfacción del cliente y alcanzar sus prioridades competitivas. Por ello, en esta sección se presentarán los conceptos básicos del manejo de inventarios y los modelos que actualmente se utilizan. «Las tareas de la gestión de un inventario, se relacionan con la determinación de los métodos de registro, los puntos de rotación, las formas de clasificación y los modelos de reinventario, determinados por los métodos de control (..)» (Viera, 2017)

Según Viera (2017), podemos definir a inventario como la acumulación de materiales que posteriormente serán usados para satisfacer una demanda futura. La gestión de inventarios está enfocada en la planificación y control de los materiales, es decir, busca determinar la periodicidad de revisión del estado de los materiales, las cantidades que se deben pedir y en qué tiempo se debe pedir. Gutiérrez (2008) también destaca la necesidad de mantener los costos y gastos asociados a la gestión de inventarios, Por otro lado, Castro (2014) ${ }^{3}$, resalta que el indicador fundamental de competitividad en cualquier sector industrial en gestión de inventario es alcanzar las metas tanto en niveles de servicio como costos. Es

\footnotetext{
${ }^{2}$ Gutierrez (2008)

${ }^{3}$ Castro (2014)
} 
por esto que se hace indispensable una eficiente administración de la cadena de suministro, y se busca la integración óptima de las actividades y actores que intervienen en los procesos logísticos de la empresa para alcanzar una ventaja competitiva sostenible. ${ }^{4}$

Los modelos de inventario tradicionales generalmente se desarrollaban desde el punto de vista de operaciones para una sola organización individual. Actualmente, se ha impuesto el concepto de "cadena de suministro". " « La Cadena de Abastecimiento (Supply Chain), incluye todas las actividades relacionadas con el flujo de materiales, productos, dinero, información necesaria para la transformación de materias primas en bienes y productos; en conclusión, la cadena de abastecimiento o suministro es el conjunto de actores o actividades que se encargan de la ejecución de la logística ». (Velez, 2015)

Una cadena de suministro involucra flujos de información, fondos y productos, con el objetivo de abastecer los materiales que se necesitan en el tiempo, cantidad y calidad que se requiere para satisfacer las necesidades del cliente. Por ello, es imprescindible el análisis de la logística como un sistema integrado en la cadena de suministro.

Según Viera, la toma de inventarios se puede clasificar de las siguientes formas: ${ }^{6}$

Clasificación de inventarios según su forma

1. Inventarios de Materias Primas: Inventario que no pasado por un proceso de transformación en la producción

2. Inventarios de Productos Terminados: Inventario transformado, que ha pasado por to el proceso de producción y está listo para ser almacenado y entregado.

3. Inventarios de Productos en proceso de fabricación: Inventario donde se realiza el conteo de las materias usadas en la elaboración de productos.

Clasificación de inventarios según su función

1. Stock de transito: Stock mínimo necesario para poder ejecutar las operaciones usuales del negocio

2. Stock de ciclo: stock creado por la naturaleza de las operaciones. Ejemplo, producción en lotes.

3. Stock de anticipación: stock de previsión en periodos de alta demanda para conseguir una tasa de producción estable

4. Stock de especulación: se mantiene en caso de incrementos de precios

\footnotetext{
${ }^{4}$ Veléz (2013)

${ }^{5}$ Díaz-Batista (2012)

${ }^{6}$ Viera (2017)
} 
5. Stock de seguridad: se usa para mantener un nivel de servicio satisfactorio ante la incertidumbre de suministros, demanda o en las operaciones.

Stock inútil: excedente que no tiene función. Suelen ser los productos obsoletos o vencidos.

La rotación de inventarios es un cálculo matemático - estadístico que representa las veces que un material o producto tiene que ser reabastecido, ya sea por compras o producción. Asimismo, representa el número de veces que se agotan los inventarios para fabricar un producto. La fórmula de cálculo es: ${ }^{7}$

$$
\text { Rotación del inventario: } \frac{\text { Costo de mercancía vendida }}{\text { Inventario }}
$$

Este cálculo es importante, ya que permite a las empresas determinar qué tan rápido recuperan, con alguna utilidad, su inversión.

Inventario de manufactura: Su función es estar disponible para ser convertida en producto terminado. Inventario regido por el plan de producción.

Inventario de distribución: Inventario disponible para cumplir la demanda del cliente. Limitado por la demanda del cliente

\subsubsection{Modelos de gestión de inventarios}

Entre los métodos para la clasificación de inventarios se tiene el análisis ABC. Con este método, se clasifican los artículos en tres clases (A, B o C), permitiendo dar un orden prioritario para la toma de decisiones a los distintos SKUS:

\section{Clasificación $\mathrm{ABC} 89$}

1. Artículos A: Son SKUS prioritarios: los materiales más usados, más vendidos o más urgentes. Su localización en la zona de almacenamiento debe ser cercana al área de salida, visibles en las estanterías o neveras de mantenimiento o congelación. Generalmente corresponden al 60\%-80\% del valor total del inventario.

2. Artículos B: Aquellos artículos de importancia secundaria. Su ubicación debe ser en las zonas intermedias del almacén. Representan el 20\%-30\% de todo el inventario, acumulando un valor total del 15\%-25\%

\footnotetext{
${ }^{7}$ Orozco (2013)

${ }^{8}$ Viera (2017)

${ }^{9}$ Assawawongmethee (2015)
} 
3. Artículos C: Los de importancia reducida. Muchas veces tenerlos en el almacén cuesta más dinero que el beneficio que aportan. Su ubicación en lugares de menor salida, ya que su rotación es más lenta y su uso también

La clasificación tradicional del $\mathrm{ABC}$ solo requiere de la definición de un criterio de clasificación, el cual suele ser las ventas anuales valorizadas al costo. Así también, en años posteriores se ha recurrido a la clasificación multicriterio, Para esta, deben definirse otros criterios para la clasificación y la importancia o peso de cada uno en la clasificación final, este criterio se denomina clasificación ABC Multicriterio, y pueden incluirse otros criterios, como: volumen por unidad, lead time, costos anules de inventario, etc. ${ }^{10}$

\subsubsection{Metodología Lean}

La metodología lean fue desarrollada en la compañía Toyota en Japón en el contexto después de la segunda guerra mundial cuando había escasez de recursos humanos y financieros.

El objetivo de la metodología lean era minimizar el consumo de recursos que no añadía valor al producto. La implementación de esta metodología en Toyota, los llevó a tener una gran ventaja competitiva sobre sus competidores en el mundo occidental. Así, en la década de los 90 la metodología se expandió rápidamente hacia Estados Unidos y otras partes del mundo ${ }^{11}$.

Los sistemas lean se enfocan reducir el desperdicio y maximizar el flujo y eficiencia de toda la cadena, con miras de aumentar la satisfacción del cliente y reducir el tiempo de respuesta

La filosofía lea tiene por objetivo principal la reducción del desperdicio también llamado "muda". Se identifica como "muda" a todo los que el cliente no está dispuesto a pagar. Originalmente en la filosofía de Taiichi para el sistema de producción de Toyota, clasificaba a la "muda" en 7 tipos: ${ }^{12}$

Tabla 1.

Tipos de desperdicio en manufactura

Tipos de desperdicio

Causas

\footnotetext{
${ }^{10}$ Castro (2014)

${ }^{11}$ Fernandez (2015)

${ }^{12}$ Saleeshya (2012)
} 
Sobreproducción

Inventario

Tiempo de Espera

Movimiento

Transporte

Defectos

Procesos
Producir más de lo que se necesita para el siguiente proceso o cliente. Este desperdicio es el desencadenante de los otros seis

Tener más del inventario mínimo necesario Operador inactivo por tiempo muerto en máquinas, falta de mantenimiento en máquinas, lead time proveedores

Movimiento de personal o máquinas que no añade valor

Movimiento de partes o productos que no añade valor directamente a la operación

Producción de partes defectivas, reprocesamientos e inspecciones

Cualquier proceso que no añade valor al producto

Para que se pueda aplicar la metodología lean se requiere que el diseño del proceso permita que el producto fluya ininterrumpidamente, así también este flujo debe estar apoyado en una cultura de mejora continua. Para esto se postulan los siguientes principios: ${ }^{13}$

\section{Principios de la metodología Lean}

4. Valor: El valor se define desde la perspectiva del cliente

5. Flujo de Valor (Value Stream): Se debe representar todas las actividades que añaden y no añaden valor de la empresa, para poder facilitar la identificación y eliminación del desperdicio y lograr un flujo.

\footnotetext{
${ }^{13}$ Saleeshya (2012)
} 
6. Flujo: Se busca el flujo continuo desde el desarrollo de un concepto/manufactura de un producto hasta el cliente, a través del análisis del proceso y la eliminación de desperdicios.

7. Sistema Pull: Solo se inicia la cadena cuando el cliente da la orden.

8. Perfección: Eliminar continuamente todos los desperdicios para mejorar la eficiencia, tiempo de clico, costos, calidad y alcanzar el flujo continuo.

Si bien las filosofías lean se originó dentro de la manufactura discreta poco a poco se ha ido implementando en todas las industrias de manufactura, así como en servicios y construcción. La extensión de esta filosofía ha llevado a muchos al desarrollo de varias herramientas y también a la confusión de lo que puede ser incluido o no dentro de la filosofía lean. Para esto, Lyons (2012) presenta un marco de referencia para la clasificación de herramientas y/o prácticas lean basándose en los siguientes lineamientos:

\section{Lineamientos de la filosofía lean}

9. Alineación con la producción y la demanda: Para poder reducir el desperdicio, es imperativo lograr los procesos estén diseñados para responder a los requerimientos del cliente. La alineación entre producción y demanda facilita el flujo del producto, sin interrupciones o retrasos.

10. Eliminación del desperdicio: Característica principal de la filosofía lean, la eficiencia en el uso de recursos.

11. Integración de proveedores: Pre-requisito para lograr alineación entre producción y demanda. Se maneja el concepto de proveedores como parte de una red cooperativa para reducir el tiempo de aprovisionamiento.

12. Involucramiento del personal en el proceso de mejora de las actividades: Alineado a la mejora continua. El involucramiento del personal en el proceso es esencial para crear la cultura lean. Por otro lado, si se cuentan con muchos procesos manuales, es el personal el que está encargado de mantener la calidad en el origen. 


\section{Metas Lean:}

Reducir costos, incrementar productividad y mejorar la calidad para aumentar el valor del cliente y los

márgenes de ganancia

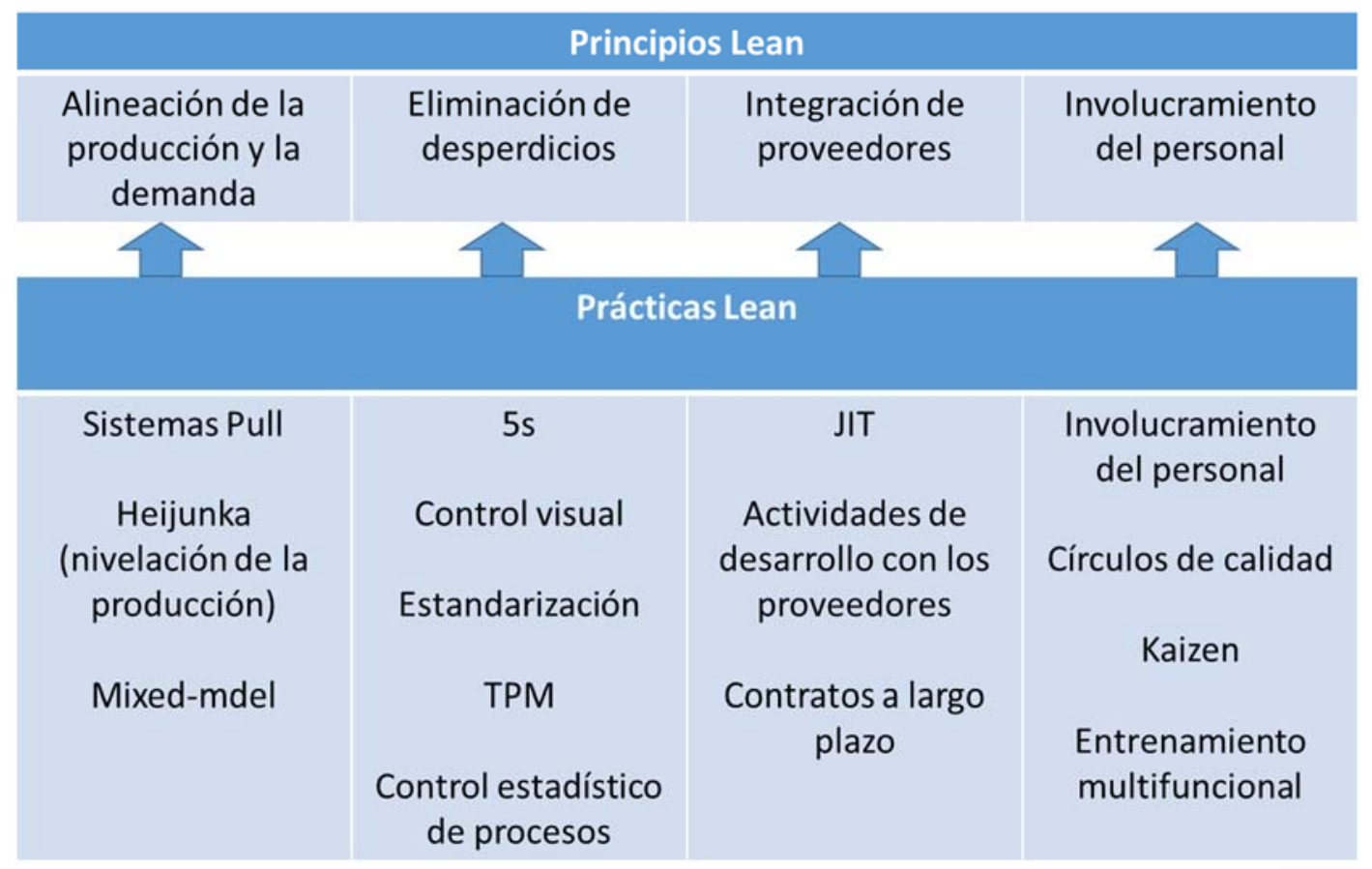

Figura 9. Clasificación de prácticas Lean. Lyons (2012)

VSM

En una cadena de abastecimiento compleja, el proceso de demanda se distorsiona por cada eslabón de la cadena, generando un mal manejo en el último eslabón. La metodología lean tiene por objetivo reducir esta amplificación de la demanda, estrechando la cadena de suministro, reduciendo el tamaño del lote y sincronizando el flujo de materiales e información ${ }^{14}$. Una de las herramientas que se puede usar para este propósito es el mapeo del flujo de valor (VSM)

El VSM puede ayudarnos a determinar los costos de almacenar inventarios, así como los costos de toda la cadena para analizar y tomar las decisiones adecuadas que permitan

${ }^{14}$ Fernandez (2015) 
reducir el costo total y las actividades de soporte que son necesarias para crear un producto.

VSM incluye todas las actividades: como aquellas que añaden valor, aquellas que no añaden valor y aquellas de soporte que son necesarias para crear un producto. Esto incluye el flujo de los procesos operacionales, de control y el flujo de información.

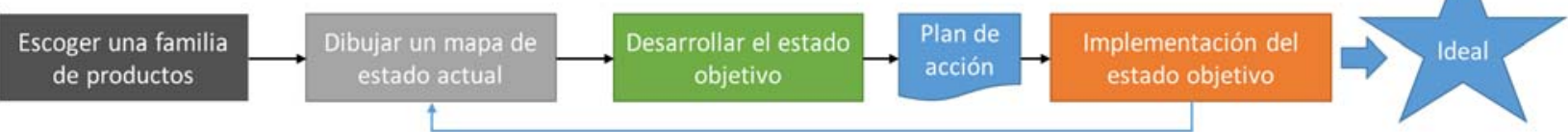

Figura 10. Pasos para el VSM. : Kuhlang (2014)

\subsubsection{Sistemas de control de Inventarios}

Uno de las decisiones importantes sobre la gestión de inventarios es establecer la cantidad y frecuencia del reabastecimiento. Para poder establecer la frecuencia de reposición existen dos sitemas de revisión: La revisión continua (Q) y la revisión periódica (P).

El sistema de revisión continua es la política donde el inventario es monitoreado en tiempo real y las ordenes de reposición son puestas cada vez que el inventario alcanza el punto de reorden. Por el contrario, la política de revisión periódica, es aquella en donde se expide el inventario en un intervalo determinado de tiempo y basado en la posición del inventario en ese momento se hace el pedido de reposición. ${ }^{15}$. Este tipo de política de revisión permite llevar un inventario exacto y manejar la cantidad exacta que se debe ordenar un pedido.

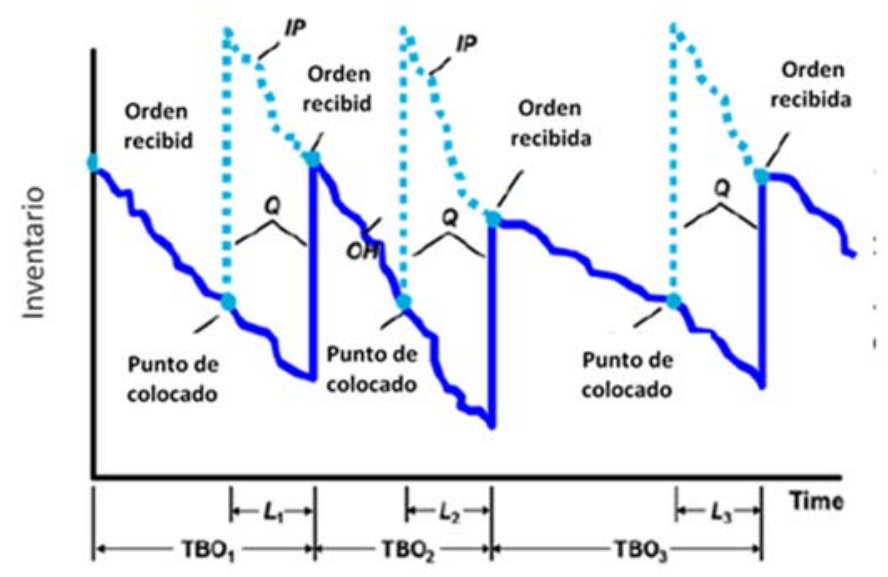

${ }^{15} \mathrm{Ma}(2013)$ 
Figura 11. Política de revisión continua. Ma, 2013

En la figura 9 se puede observar que la cantidad Q pedida es siempre igual. El punto de colocado de pedido siempre que el nivel de existencias llegue debajo del punto de reorden. Esta cantidad es fija, por lo que el tiempo entre órdenes (TBO) será siempre distinta, en función a la demanda. El tiempo L1, L2, L3 es el lead time entre la orden colocada y la orden recibida. En el modelo continuo las frecuencias de revisiones son constantes y el stock de seguridad es más pequeño que en las revisiones periódicas.

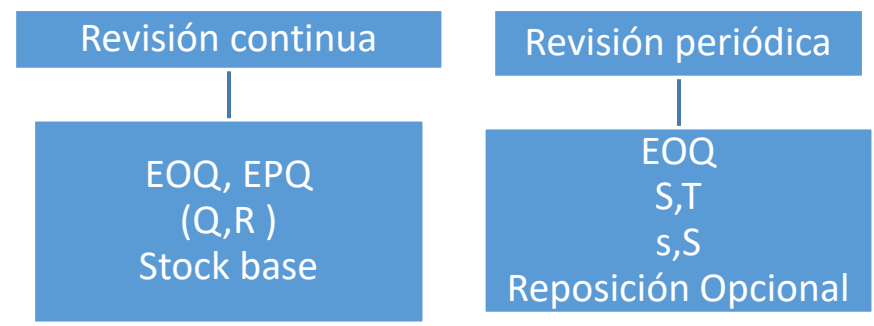

Figura 12. Modelos de control de inventarios, Ma (2013)

\subsubsection{EOQ}

La cantidad económica de pedido (Economic Order Quantity) es una herramienta analítica clásica que se encarga de minimizar el costo anual de colocar órdenes o almacenar inventario. De esta manera, permite reducir los costos sin ordenar en exceso (costo por mantenimiento de inventario) u ordenar muy poco (Costo por hacer pedido). ${ }^{16}$

La cantidad económica de pedido está dada por esta ecuación: ${ }^{17}$

Cantidad óptima de pedido: $Q=\sqrt{\frac{2 a d}{h}} \quad$ Duración de la orden: $T=\sqrt{\frac{2 a}{d h}}$

donde: a es el costo de ordenar o costo del tiempo de preparación por unidad

$$
\begin{aligned}
& d \text { es la demanda constante } \\
& h \text { es el costo de almacenaje }
\end{aligned}
$$

\footnotetext{
${ }^{16}$ Tanel, T. L. (2012)

${ }^{17} \mathrm{Ma}(2013)$
} 
EOQ suele usarse en compañías manufactureras donde el punto de reorden es constantes y repetitivo o cuando el proveedor de insumos tiene una política MTS ${ }^{18}$ Una variante del EOQ es el EPQ, cantidad óptima de compra, la cual es usada en situaciones donde el producto es producido porque el producto no estará disponible instantáneamente. En el $E P Q$, el costo de adquisición (ordenar) es reemplazado por el costo de set up (tiempo de preparación).

Según Tanel (2012) el EOQ es una fórmula que puede aplicarse en los procesos considerando las siguientes pautas:

1. La fórmula EOQ se aplica a productos que tienen un precio constante

2. Si se trabaja con demanda estacional, se debe ajustar el EOQ por temporada pues el EOQ considera una demanda fija

3. Se asume que no existe volatilidad de precios en los materiales

4. Si los productos tienen un ciclo de vida corto, la fórmula puede producir que la cantidad de un producto exceda su ciclo de vida basado en el ratio de ventas.

5. La fórmula considera la habilidad de mandar una sola orden por producto en cualquier momento. Si se quieren mandar muchos productos en una sola orden por temas de descuentos con el proveedor, en esos casos lo mejor sería hacer un análisis de costobeneficio para encontrar la cantidad mínima.

\subsubsection{Modelo DDMRP}

El demand driven MRP es un sistema de planificación basada en mejorar el flujo de materiales e información relevante para obtener mayores beneficios (retorno sobre el capital invertido). Para esto se basa en dos pilares fundamentales: la reducción del capital de trabajo (inventario) y los gastos relacionados a las órdenes de urgencia.

En la figura 11 se pueden observar los pilares fundamentales sobre los que se basa el DDMRP. MRP,DRP, lean, teoría de las restricciones, six sigma, innovación, El método de toma los métodos de planificaciones de materiales MRP y DRP y los combina con los principios lean. De esta manera, mitiga las variabilidades de la demanda y otorga flexibilidad a la cadena de abastecimiento a través de los ajustes dinámicos.

\footnotetext{
${ }^{18}$ Castro (2014)
} 


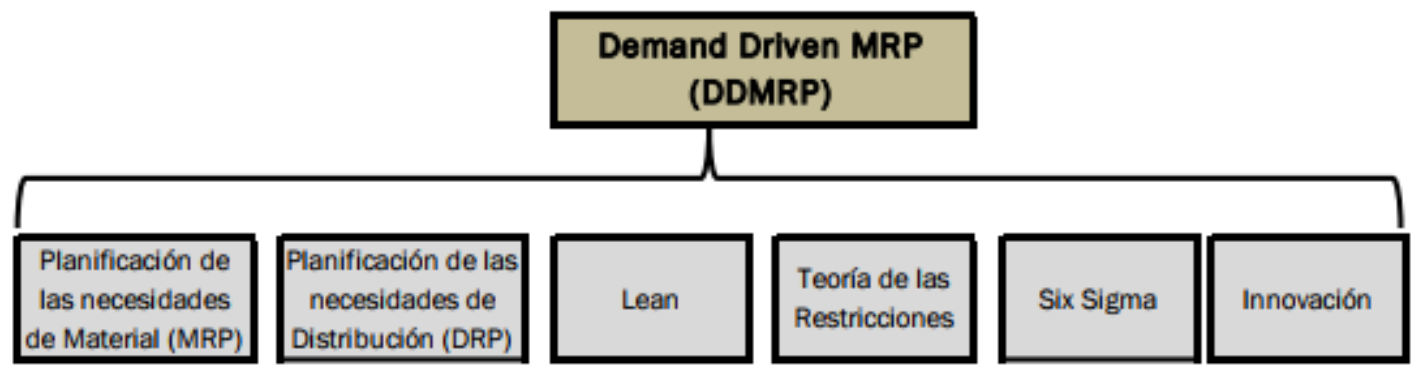

Figura 13. La pirámide del DDMRP. Román, 2017.

El DDMRP se basa en la mitigación del efecto látigo. Esto se obtiene a través de la implementación del desacoplamiento. Este método se refiere a la creación de independencia entre el suministro y el uso del material, de manera que una operación no limita la siguiente. Para esto el DDMRP propone una metodología de selección y ubicación estratégica de los puntos de desacoplamientos y la creación de amortiguación en esos puntos para poder de esta manera, mejorar el flujo de materiales.

Para esto se deben elegir estratégicamente puntos de desacoplamiento y el tamaño de la protección en cada punto. A esta protección en cada uno de los puntos, se le conoce como buffer. Existen diferentes tipos de buffer, según su posición: ${ }^{19}$

- Buffer de materias primas: posicionado con los proveedores

- Buffer de productos en proceso: posicionado en algunos de los procesos anteriores al producto terminado

- Buffer de producto terminado: posicionado antes de llegar a los centros de distribución

- Buffer de centros de distribución; posicionado en los centros de distribución para repartir a los clientes

Definición de los perfiles buffer

Para la definición de los perfiles de cada buffer, se utilizan zonas codificadas por colores. Esta segmentación intuitiva, permite priorizar la ejecución y planificación de cada ítem. En la figura 12 se puede apreciar cómo lo que tradicionalmente se conoce como las distintas posiciones del stock generan una prioridad de acuerdo a la zona en la que se

\footnotetext{
${ }^{19}$ Román (2017)
} 
encuentran. La zona verde representa el inventario que no requiere acción. La zona amarilla representa el inventario que ha entrado a la zona de reabastecimiento. El inventario rojo representa el stock que está en peligro y requiere de atención especial.

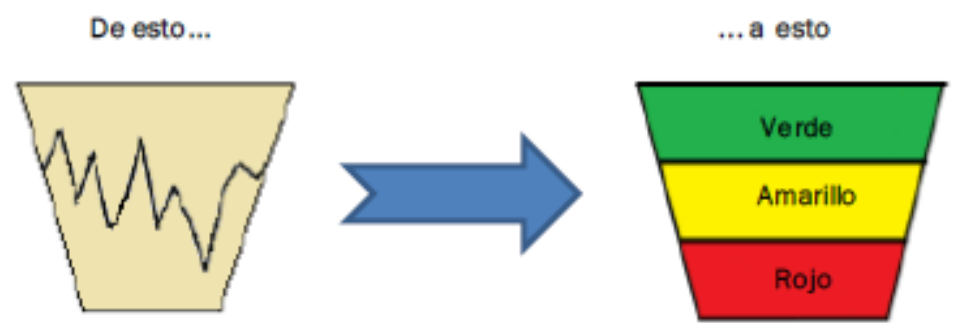

Figura 14. De estratificación zonal a buffer de stocks. Román, 2017.

Para calcular cada uno de estas zonas del buffer se deben definir en primer lugar, perfiles de buffer. Los perfiles son familias de productos que se comportan de manera similar. Existen 4 factores que se deben considerar para formar cada uno de estos grupos: ${ }^{20}$

1. Origen del producto: Se debe determinar si los productos son manufacturados, comprados o distribuidos. Cada uno de estos productos suele tener lead-times muy distintos y el control que se maneja sobre cada ítem no es similar.

2. Variabilidad: Se refiere a los picos potenciales de demanda que puede tener un SKU. Matemáticamente la variabilidad puede ser calculada por la desviación estándar, varianza, desviación promedia absoluta o errores del pronóstico. Otro punto importante a considerar dentro de la variabilidad, es la variabilidad de la operación. Esta se refiere al potencial y severidad que pueda sufrir un SKU por disrupciones en el proceso. La variabilidad puede ser segmentada en tres: alta, media y baja. Los rangos utilizados para poder calcular su impacto en el buffer están esquematizados en la figura 10.

\begin{tabular}{|c|c|}
\hline Rojo Seguridad & Impacto de la zona roja \\
\hline Variabilidad Alta & $60-100 \%$ Zona Rojo Base \\
\hline Variabilidad Media & $41-60 \%$ Zona Rojo Base \\
\hline Variabilidad Baja & $20-40 \%$ Zona Rojo Base \\
\hline
\end{tabular}

Figura 15. Rango de impacto de la variabilidad. Ramón, 2017

3. Lead time: Los productos manufacturados pueden tener distintos tipos de lead time calculados. En el DDMRP se recomienda utilizar el ASR lead time. Este lead time está basada en el camino crítico de los materiales, una vez que se han designado las posiciones estratégicas. El tiempo de abastecimiento puede ser clasificado en tres:

${ }^{20}$ Smith (2011) 
Corto, medio y largo. En la figura 14 se presenta el rango que se utiliza dentro del cálculo de las zona buffer

\begin{tabular}{|c|c|}
\hline Rojo Base & Rasgos del factor de Lead Time \\
\hline Lead time largo plazo & $20-40 \%$ del CPD a través de ASRLT \\
\hline Lead time Medio plazo & $41-60 \%$ del CPD a través de ASRLT \\
\hline Lead time Corto plazo & $61-100 \%$ del CPD a través de ASRLT \\
\hline
\end{tabular}

Figura 16. Rango del lead time para cálculo de las zonas buffer. Ramón , 2017.

4. Cantidad mínima de orden: Existen materiales que pueden requerir cantidades mínimas de orden, ya sea por lotes o política de compras. Estas cantidades mínimas terminan afectando las zonas del buffer.

Zonas de buffer

Cada una de las zonas de buffer está determinado por el CPD, consumo diario promedio sobre un porcentaje del lead time. La zona verde también puede tomar el valor de la cantidad mínima de orden. La zona amarilla es el total del consumo de la demanda en el tiempo de abastecimiento. La zona roja se divide en dos partes: La zona roja base y la zona roja segura. A continuación, se especifican cada una de las fórmulas utilizadas para el cálculo de las zonas:

Cálculo de la Zona Roja:

$$
\begin{gathered}
\text { Zona Roja }=\text { Zona roja base }+ \text { Zona roja segura } \\
\text { Zona roja base: } C P D \times L x f l \\
\text { Zona roja segura: zona roja base } x f v
\end{gathered}
$$

Donde

d: demanda promedio diaria (CPD)

L: lead time expresado en días

fl: factor de lead time, según figura 11

fv: factor de variabilidad de la demanda, según figura 10 
Cálculo de la zona amarilla:

$$
\text { Zona Amarilla }=\text { CPD } \times \text { L } \times 100 \%
$$

Donde:

d: demanda promedio diaria CPD

L: lead time expresado en días

Cálculo de la zona Verde:

La zona verde está determinada por el mayor de los siguientes cálculos. Si los SKUS no contaran con un ciclo de pedido o MOQ, se utilizará el cálculo de la zona roja base.

$$
\begin{aligned}
& \text { Zona verde }=C P D \times L \times f l \\
& \mathrm{O} \\
& \text { Zona verde }=M O Q \\
& \mathrm{O} \\
& \text { Zona verde }=\text { Ciclo de pedido }
\end{aligned}
$$

Donde:

d: demanda diaria promedio

fl: factor de lead time

MOQ: cantidad mínima de pedido

Ciclo de pedido: Establecida por una frecuencia de días a la que debe abastecerse un SKU

El resumen de estos cálculos es mostrado en la figura 15. 


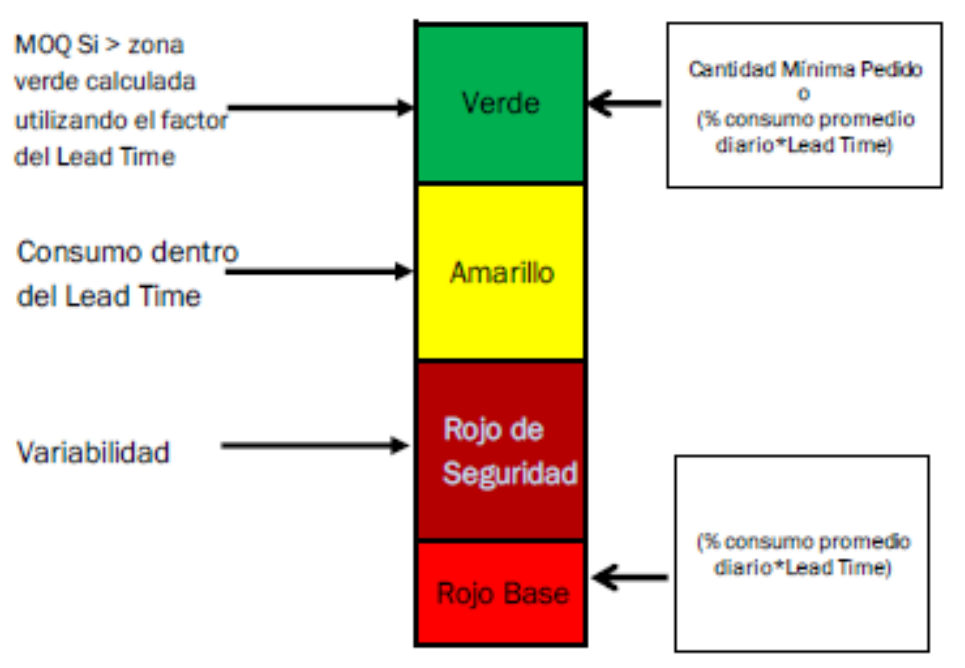

Figura 17. Resumen de cálculo de zonas buffer. Ramón, 2017

Una vez determinados las zonas buffers, dentro del procesa de planeamiento cada una de estas determina la necesidad real a la que debe llevarse un SKU (Zona verde). Para esto el reabastecimiento es calculado con el inventario disponible década buffer. Esto está determinado por la ecuación del flujo neto: ${ }^{21}$

$$
\begin{aligned}
& \text { Ecuación de flujo neto } \\
& \qquad \begin{aligned}
=\text { Inventario físico }+ \text { Inventario en tránsito } \\
- \text { Demanda calificada }
\end{aligned}
\end{aligned}
$$

Donde:

Inventario físico: Inventario almacenado disponible

Inventario en tránsito: Inventario que se ha solicitado, pero no se ha recibido

Demanda calificada: Son los pedidos de ventas vencidos (según el lead time) para entregar hoy o los futuros picos calificados.

La demanda calificada es una cantidad de demanda acumulada que puede generar desabastecimientos. Una orden pico se puede establecer como el 50\% de la zona roja.

\footnotetext{
${ }^{21}$ Demand Driven Institute (2016)
} 


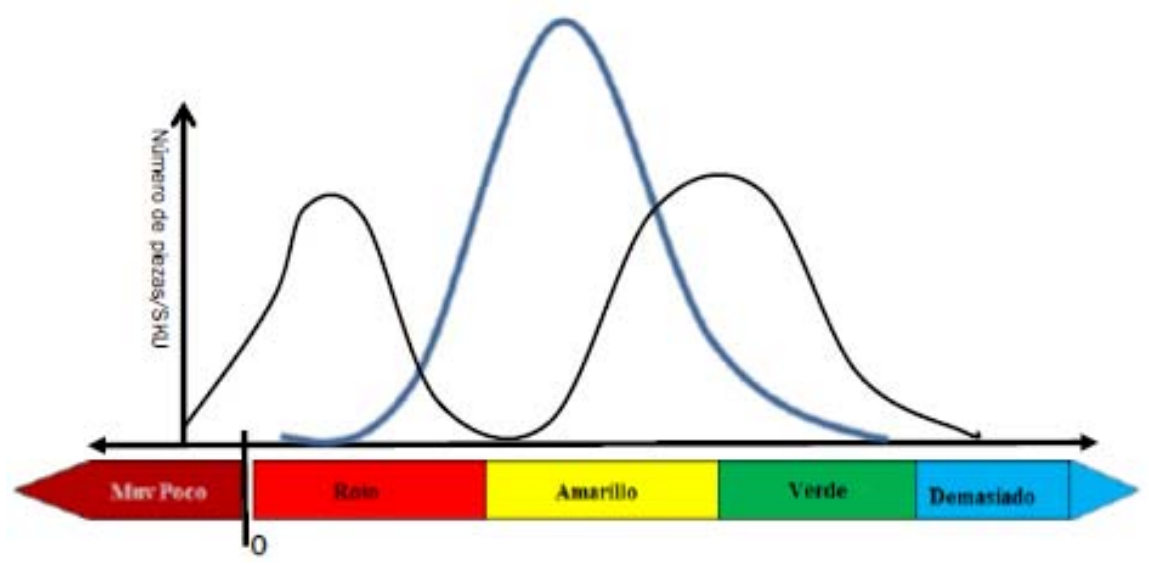

Figura 18. Realineación de las posiciones de inventario con la metodología DDMRP. Ramón, 2017.

Finalmente, con la aplicación de la metodología DDMRP se busca realinear las posiciones de inventario de manera que la mayoría de estos estén en un nivel aceptable. Con otras metodologías los inventarios sueles estar entre dos puntos en exceso y o en peligro de desabastecimiento, o cual es conocido como distribución bimodal. En la figura 16 se observa esta tendencia en color negro. La curva azul representa una distribución normal en donde se ha regularizado la posición de los inventarios con la aplicación del DDMRP.

\subsubsection{Gestión por procesos}

\subsubsection{Definición de Gestión por procesos}

La gestión por procesos implica un cambio en la visión jerárquica tradicional de las organizaciones, ofreciendo una imagen más precisa de lo que ocurre dentro de una empresa. Por ello, es necesario comprender los conceptos básicos para su aplicación.

Un sistema de gestión permite el cumplimiento de objetivos a través de la implementación y planificación de metodologías, herramientas, recursos, políticas y responsabilidades. "Los procesos se gestionan incorporando en el proceso las actividades de medición, análisis y mejora" (Pérez, 2010: 132). Gestionar es aplicar acciones previamente planificadas para conseguir un objetivo, no es posible efectuar una gestión por procesos 
sin haber primero realizado la identificación, medición y control de cada uno de estos. Estas actividades permiten la recolección de información para ejecutar el análisis, control y mejora, los pasos finales del ciclo de la gestión.

Para aplicar una gestión por procesos, primero se debe identificar todos los procesos que se realizan en la empresa, puesto que mediante ellos se conoce lo que se debe hacer y cómo se debe hacer. Para ello, se debe reconocer la naturaleza de un proceso. "[Un proceso es] cada una de las acciones que intervienen y se interrelacionan en el sistema, y que permiten la evolución del ciclo de vida de la información, donde las entradas a un proceso del sistema pueden constituir la salida de otro y a la inversa.” (Valdés, 2009)

Se puede concluir que los procesos son las diversas actividades que se realizan dentro de la organización cuyo fin principal es generar un valor agregado a los inputs y satisfacer las expectativas de un cliente interno o externo. De esta manera, este enfoque permite que las diversas operaciones de todas las áreas en el desarrollo de un proceso particular, integrando los objetivos individuales de cada departamento de la empresa.

La gestión por procesos rompe el esquema tradicional, dando paso a los procesos internacionales, que deja de limitar su enfoque a los departamentos de la empresa, y lo orientan hacia el cliente. Son estas interacciones entre los procesos las que permiten que la empresa se integre por completo para trabajar hacia un objetivo común, la estrategia corporativa. La gestión por procesos abarca todo el flujo de información, esto permite que cada proceso agregue un valor cada vez mayor al producto, beneficiando al cliente final.

Representado en la ilustración, se puede identificar que todo proceso está conformado por tres elementos ${ }^{22}$ : input (entrada principal), proporcionado por el proveedor, que son los recursos del ambiente externo, los cuales pueden ser salidas de otros procesos; el proceso de transformación (la secuencia de actividades), que son las operaciones que transforman

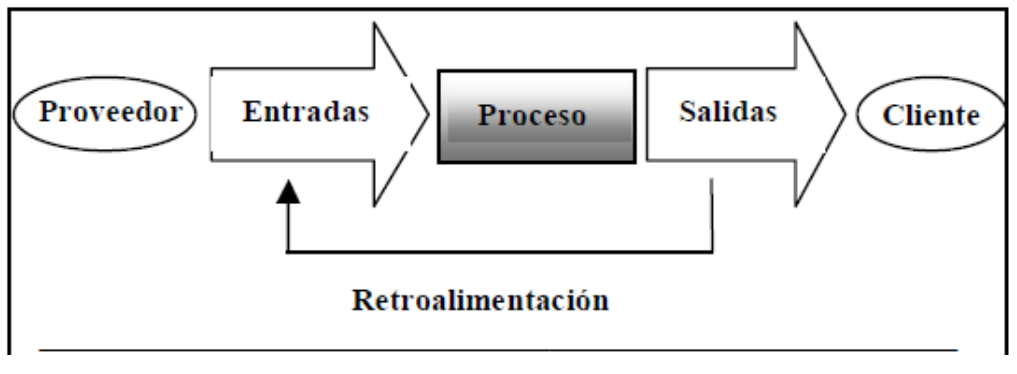

${ }^{22}$ Valdes (2009) 
los inputs agregando valor; y el output o salida destinado al cliente; que es el producto generado por el proceso.

Figura 19. Representación por proceso. Valdés, 2009.

La documentación de los procesos tiene por objetivo fomentar la estandarización, para facilitar el cumplimiento, seguimiento y evaluación del desempeño de las actividades que se realizan en una organización. Para ello, los procesos deben estar definidos a partir de su misión y visión, objetivos estratégicos y actividades involucradas. Este documento debe ser una guía para todos los actores involucrados y debe definir la razón de ser del equipo.

La documentación de procesos se recomienda cuando: ${ }^{23}$

- Se requiere precisión en las actividades.

- El resultado debe ser estándar y cumplir con un requisito de calidad definido.

- El proceso es rutinario.

- Son procesos críticos.

A continuación, se presentan las herramientas que se usarán para la documentación de procesos.

\section{Mapa de procesos}

Para facilitar la comprensión de las interacciones entre todos los procesos de una empresa, es necesaria la representación gráfica de estos en un mapa de procesos. Este permite una visión sistemática de la empresa a través de la identificación de las interrelaciones entre los procesos y la relación que tienen con los clientes.

\footnotetext{
${ }^{23}$ Luján (2009)
} 
La ruta para alcanzar las metas organizacionales, se base en entender cómo funciona una empresa mediante el análisis de sus procesos. Los mapas de procesos son herramientas necesarias, para poder entender cómo trabaja una organización para cumplir sus objetivos, y proponer mejoras. La elaboración de un mapa de procesos se hace mediante un esquema de agrupación de procesos que facilita la comprensión de las interacciones de estos en su conjunto. Así, dentro del mapa de procesos se pueden clasificar los siguientes grupos ${ }^{24}$ :

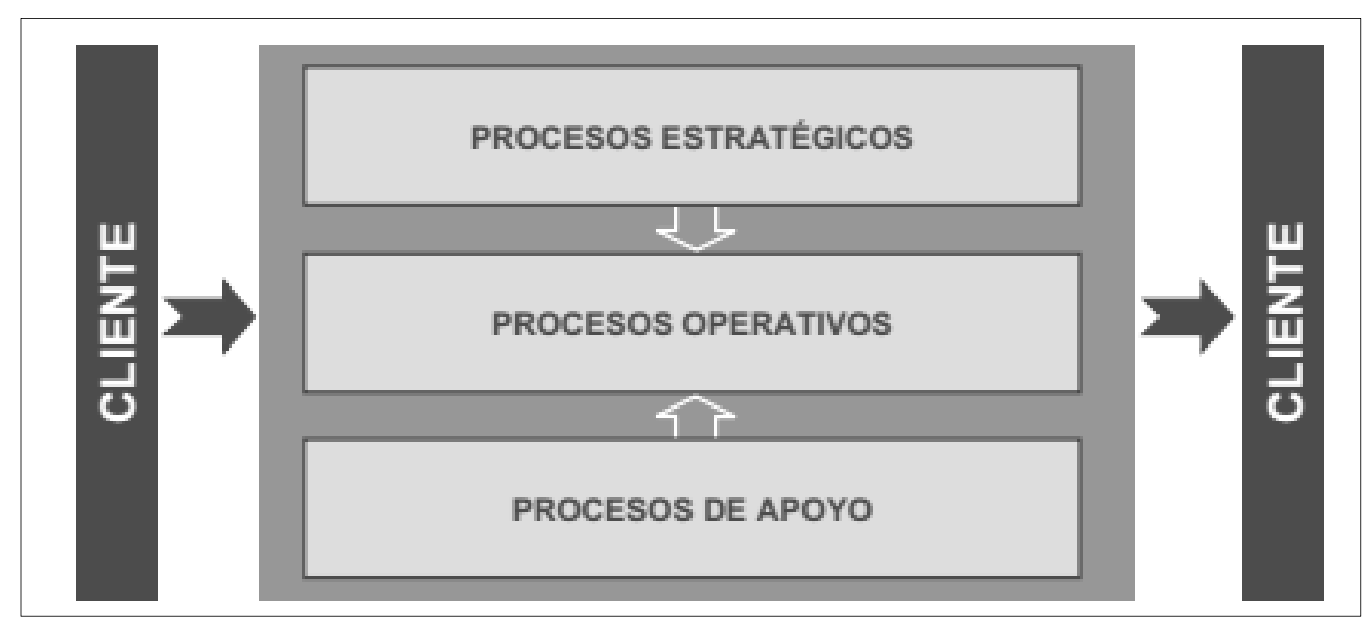

Figura 20. Modelo para la agrupación de procesos en el mapa de procesos. Luján, 2009.

a) Procesos estratégicos: Aquellos vinculados a la planificación, formulación y revisión de la estrategia. Brindan dirección a los demás procesos, indicando cómo deben desarrollarse.

b) Procesos clave: Directamente relacionados con entregar valor al cliente externo a través de la realización del producto.

c) Procesos de apoyo: Son los que brindan soporte a los procesos operativos y estratégicos. Referidos a la gestión recursos, control y mediciones.

\subsection{Casos de éxito}

El propósito de la presente tesis es presentar un modelo de gestión de inventarios que ayude a reducir los desmedros de la empresa y generar menores costos. Para esto se

\footnotetext{
${ }^{24}$ Luján (2009)
} 
fundamenta la propuesta sobre casos de éxito e investigaciones publicadas en los últimos 5 años. A continuación, se presenta casos de éxito para el modelo de inventarios y metodología elegida:

\subsubsection{Marco de Referencia para el desarrollo de un sistema de apoyo para la toma de decisiones para la gestión de inventarios}

En Colombia, diversos estudios demuestran que los costos logísticos representan cerca del 20\% de las ventas. En el caso de las PyMes, la baja competitividad se debe a que no se pueden costear herramientas de política de inventarios. En el caso de las grandes empresas esto se debe al enfoque que se tiene principalmente en el control de inventario.

Las herramientas informáticas como SAP, Oracle, QAD o Dynamics están enfocadas en el control de inventarios y las operaciones transaccionales. Cuando los sistemas ERP incluyen modelos de gestión de inventarios, los usuarios tienen la responsabilidad de determinar, en muchos casos empíricamente, los parámetros que se usarán para procesar esta información. Los sistemas no tienen incorporado una herramienta que soporte la toma de decisiones sobre los inventarios.

En un proceso de gestión de inventarios se deben definir políticas, modelos y parámetros sobre una gran cantidad de SKUS. Un DSS (Sistema de soporte para la toma de decisiones) es puede ayudar a los gerentes a evaluar cómo afectan estas políticas, modelos y parámetros a los niveles de inventario y su estrategia. En la figura 19, se muestra el layout del modelo propuesto. 


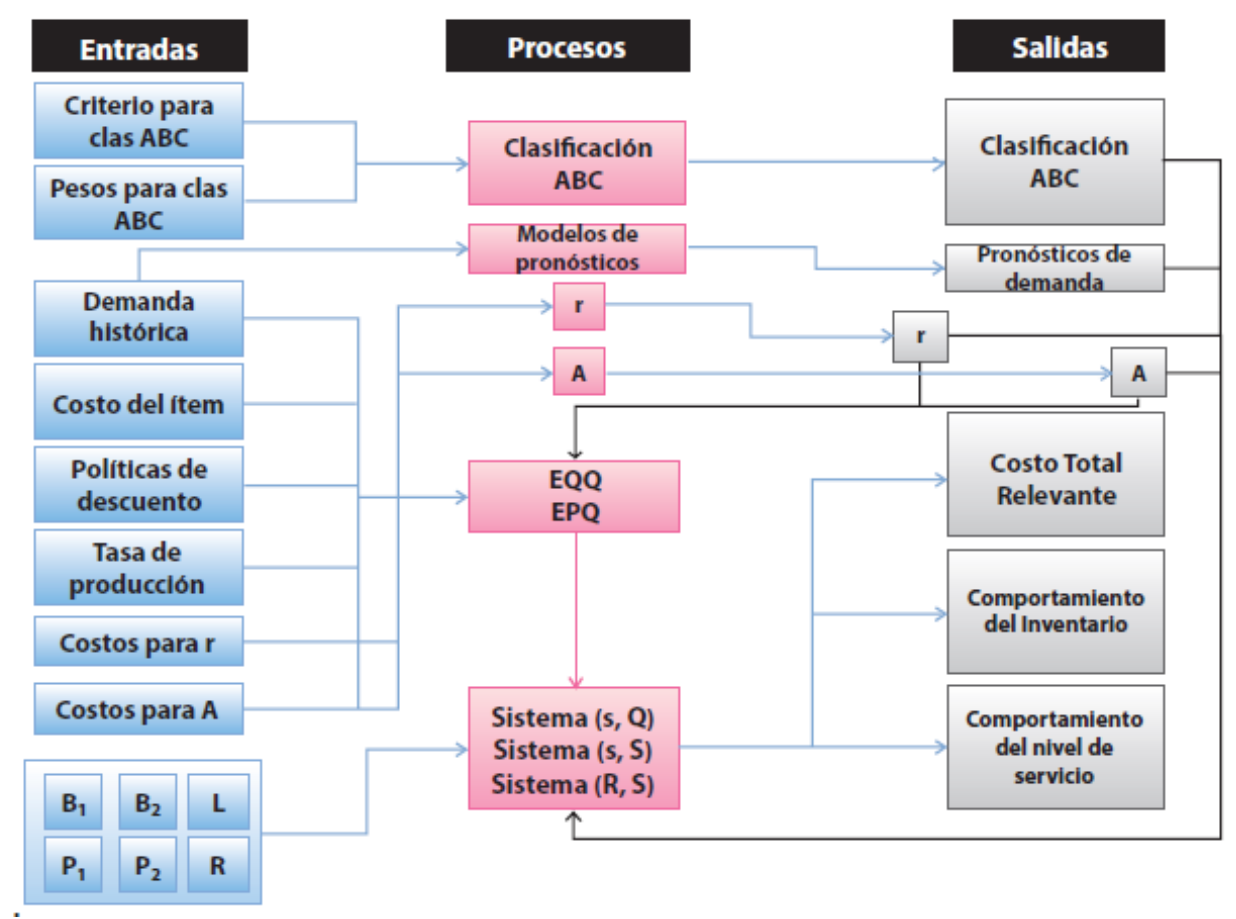

Figura 21. Layout de modelo DSS para stocks. Castro (2014)

El modelo DSS basa las decisiones de inventario sobre los outputs finales de comportamiento del inventario, nivel de servicio y costo relevante. Para esto se base en los siguientes inputs:

- Clasificación ABC multicriterio

- Proyección de la demanda: Usando Modelos de serie de tiempo y medidas de error

- EOQ: Define el punto de reabastecimiento

- Sistema de control de inventario: Para evaluar el momento en cuando se coloca un orden de reabastecimiento y su comportamiento. Para esto se decide entre $(\mathrm{s}, \mathrm{Q})(\mathrm{s}, \mathrm{S})$ $\mathrm{y}(\mathrm{R}, \mathrm{S})$

Se implementó el modelo en una de las empresas colombianas, con datos de simulación en el sistema DSS. Con los resultados se pudieron comprobar que método alineado al EOQ generaba menores costos que los modelos empíricos. 
COMPORTAMIENTO DEL INVENTARIO

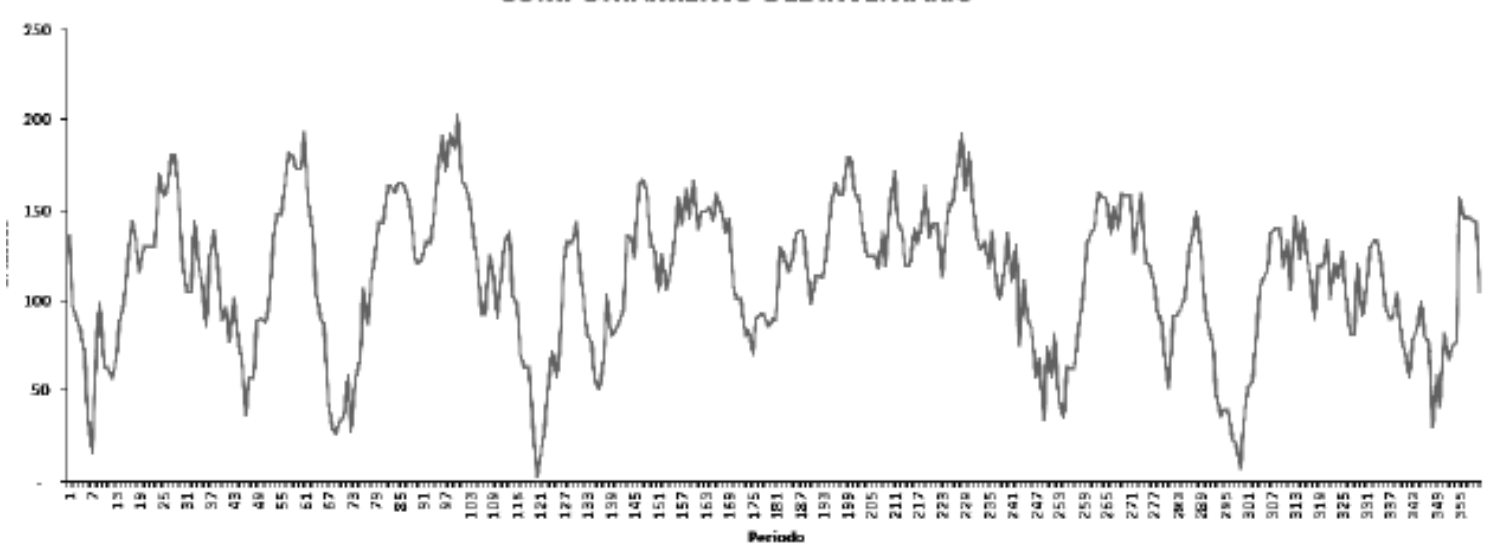

Figura 22. Comportamiento del inventario en simulación final. Castro, 2014.

\subsubsection{Comparación de MRPII y DDMRP}

Para manejar inventarios físicos y flujo económico el MRPII es uno de los métodos más difundidos. Otra metodología reciente que evoluciona este concepto es el Demand Driven material requirements Planning DDMRP. Desde los años 200s muchas compañías de los Estados unidos han adoptado esta metodología obteniendo buenos resultados. Sin embargo; hasta el momento de la publicación del artículo no existía una prueba científica que demuestre que el DDMRP permite mejores resultados que otras metodologías como el MRPII.

Por ello, los autores se enfocan en analizar un mismo escenario como caso de estudio aplicando las dos metodologías MRPII y DDMRP para comparar si realmente se obtienen mejores resultados. El caso de estudio se trata de una compañía que produce reductores de motores compuestos de tres partes: una corona, un contenedor de aceite y una tuerca. Se tienen la lista de materiales para cada subcomponente. Así como la demanda del producto para las siguientes 6 semanas.

Se presentan 6 tipos de escenarios con distintos parámetros sobre la demanda. Para cada escenario se hace una simulación de 6 semanas por 8 ciclos. En la figura 21 se presentan los resultados de la simulación para el escenario 7, con demanda estacional. Las ordenes de reabastecimientos parecen ser mucho más pequeñas para el DDMRP que para el 
MRPII. Además, existe gran variabilidad entre las órdenes en el MRPII, mientras el DDMRP, muestro una pequeña variabilidad para los productos terminados. Se puede concluir que los buffers están regularizando la variabilidad de la gestión.

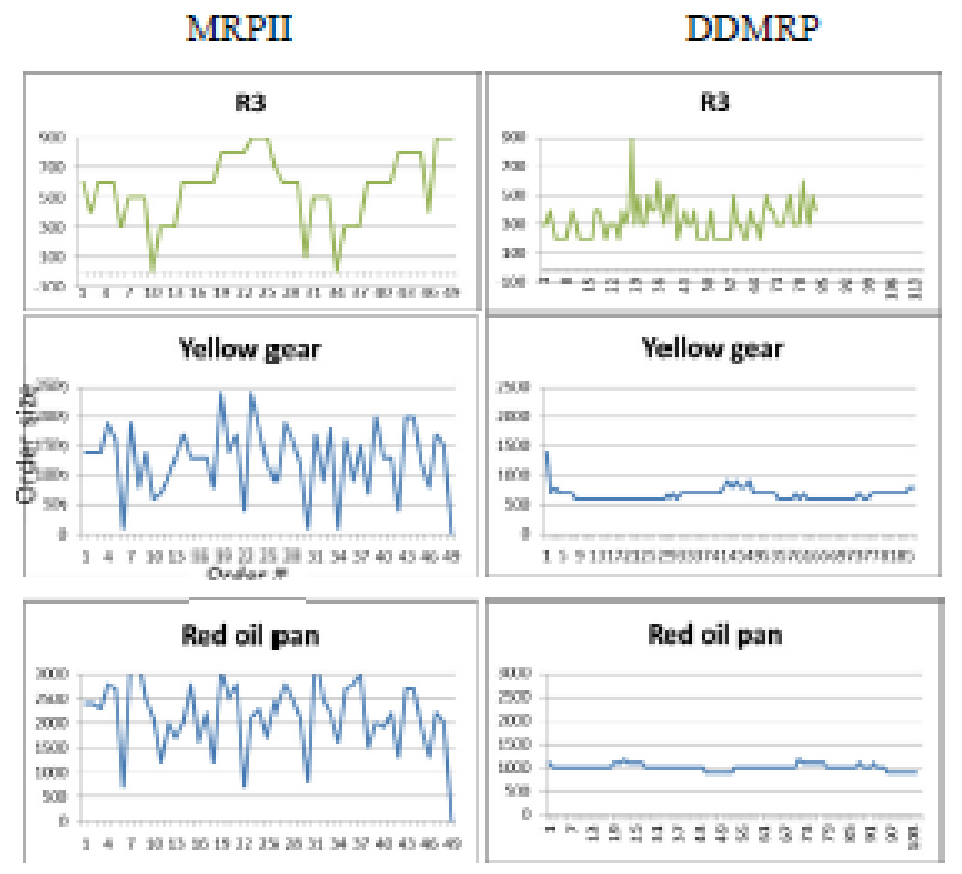

Figura 23. Tamaño del reabastecimiento para las órdenes del escenario 7.

Miclo, 2016

En la figura 22 se aprecia los niveles de stock de los componentes y del producto final. La distribución del MRPII es plana, lo cual indica una alta probabilidad de obtener excesos o desabastecimientos en algún momento. Sin embargo, la distribución no es bimodal. Por el contrario, la distribución del DDMRP es mucho más centrada, lo que significa que el stock raramente entrará en las zonas de peligro. Por lo tanto, se concluye que el DDMRP es un método efectivo para equilibrar el stock reduciendo riesgos de exceso y desabastecimiento. 


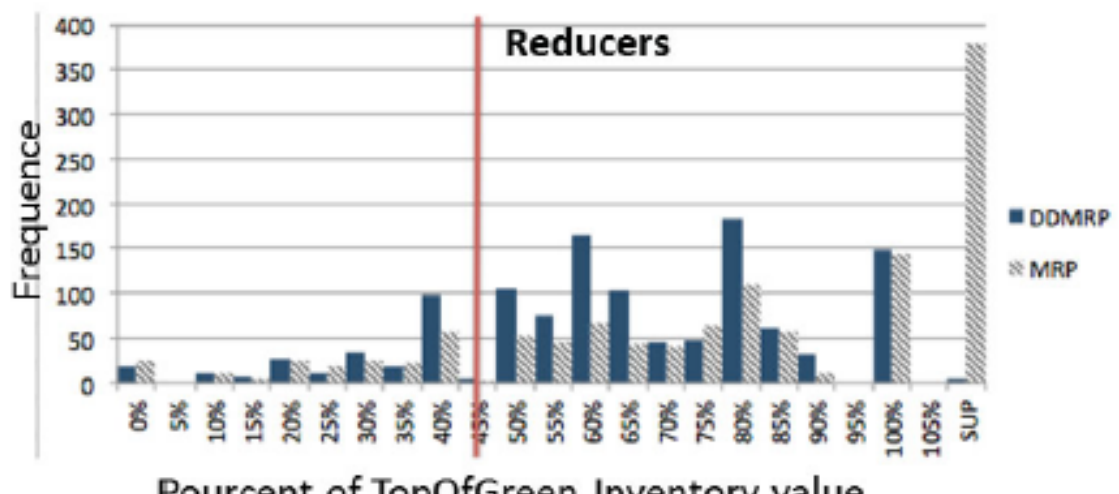

Pourcent of TopOfGreen Inventory value

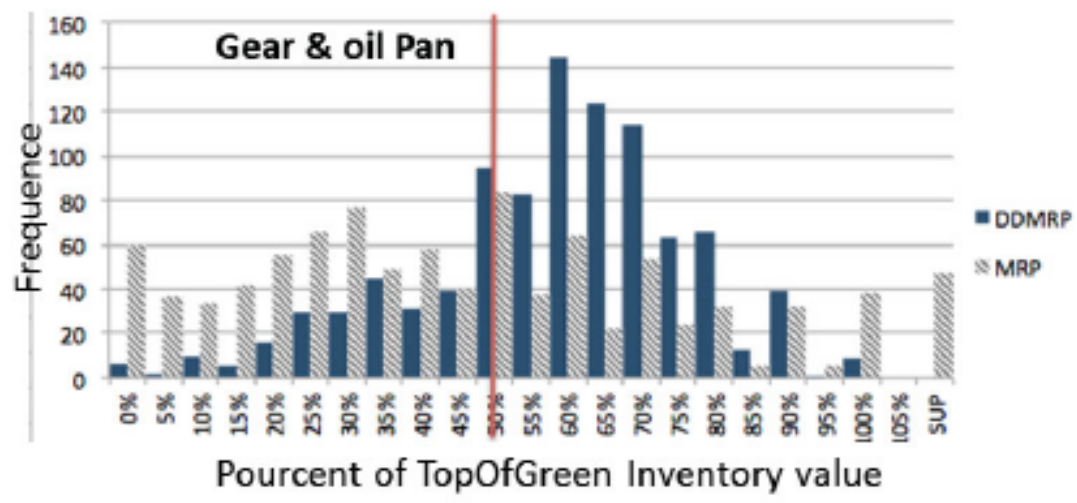

Figura 24. Distribución del inventario con MRPII y DDMRP. Miclo, 2016 


\section{Capítulo II: Diagnóstico de la empresa}

En el segundo capítulo se desarrollará el diagnóstico detallado de la empresa considerando las variables internas. Para ello, se presentarán herramientas para identificar la causa raíz y su impacto económico, sobre la cual se presentarán las metodologías a desarrollarse.

\subsection{Presentación de la empresa}

La empresa "Botellas" se dedica a la producción y comercialización de bebidas no alcohólicas y pulpas, bajo un sistema internacional de embotelladores que comercializan reconocidas marcas en el mundo, lo cual que le permite ser uno de los líderes a nivel nacional en su rubro.

La empresa fue fundada en el año 1910 bajo un esquema de empresa familiar. En 1935 crean una bebida gaseosa de sabor único y se comercializa por todo el país, logrando posicionar a la empresa como líder del sector de gaseosas. El crecimiento sostenido que presenta durante los siguientes años le permite formar alianzas con otras embotelladoras y aumentar su participación en el mercado. En el año 1999 se une al sistema internacional de embotelladores que comercializan marcas de renombre mundial, lo cual le permite entrar en otros mercados y comenzar la exportación de bebidas. En el año 2016, la empresa es adquirida por una corporación extranjera, lo cual la impulsa a ordenar, estandarizar y mejorar sus operaciones para poder hacer la transición de empresa a familiar a corporación internacional.

Actualmente, la empresa cuenta con más de 336000 clientes a nivel nacional, tiene más 3500 colaboradores, 2500 vendedores en todo el Perú y 8 plantas de producción.

\subsubsection{Descripción de la organización}

Para describir a la organización se presentarán tres factores medio ambiente organizacional, relaciones organizacionales y procesos principales. 


\subsubsection{Medio ambiente organizacional}

En esta sección se presentarán la misión, visión, definición de la oferta y portafolio de productos, estructura organizacional y el modelo ventas que sigue la empresa.

\subsection{Misión, Visión y Valores}

La estrategia de la empresa "Botellas" se basa en tres principales lineamientos:

- Misión: Operar con excelencia para ser la opción preferida de clientes y consumidores, logrando un crecimiento rentable y sostenible, y generando valor al público de interés.

- Visión: Ser la empresa peruana de clase mundial líder en bebidas no alcohólicas.

- Modelo de liderazgo: Competencias para consolidar el liderazgo del negocio.

- Foco al cliente y consumidor

- Orientación a resultados

- Gestión de la excelencia

\subsection{Portafolio de productos}

El portafolio de la empresa está compuesto por dos grandes grupos:

- Bebidas carbonatadas; Son aquellas bebidas saborizadas, efervescentes y sin alcohol. Dentro de las bebidas carbonatadas se encuentran las siguientes agrupaciones de productos:

- Gaseosas: En la agrupación gaseosas se manejan 12 marcas.

- Agua Gasificada: Solo existe una marca de agua envasada.

- Bebidas no carbonatadas: Son aquellas bebidas saborizadas, sin alcohol y sin efervescencia. Dentro de las cuales se encuentran:

- Agua Purificada: Solo existe una marca de agua purificada.

- Bebidas energéticas: Se maneja una sola marca de bebida energética, la cual es importada. 
- Isotónicos: Se tienen 2 marcas de isotónicos

- Jugos: Se tienen 4 marcas de jugos de diferentes concentraciones.

El portafolio de la empresa maneja en total 20 marcas a nivel nacional, de la cuales 19 son producidas en sus diferentes plantas y una es importada y distribuida.

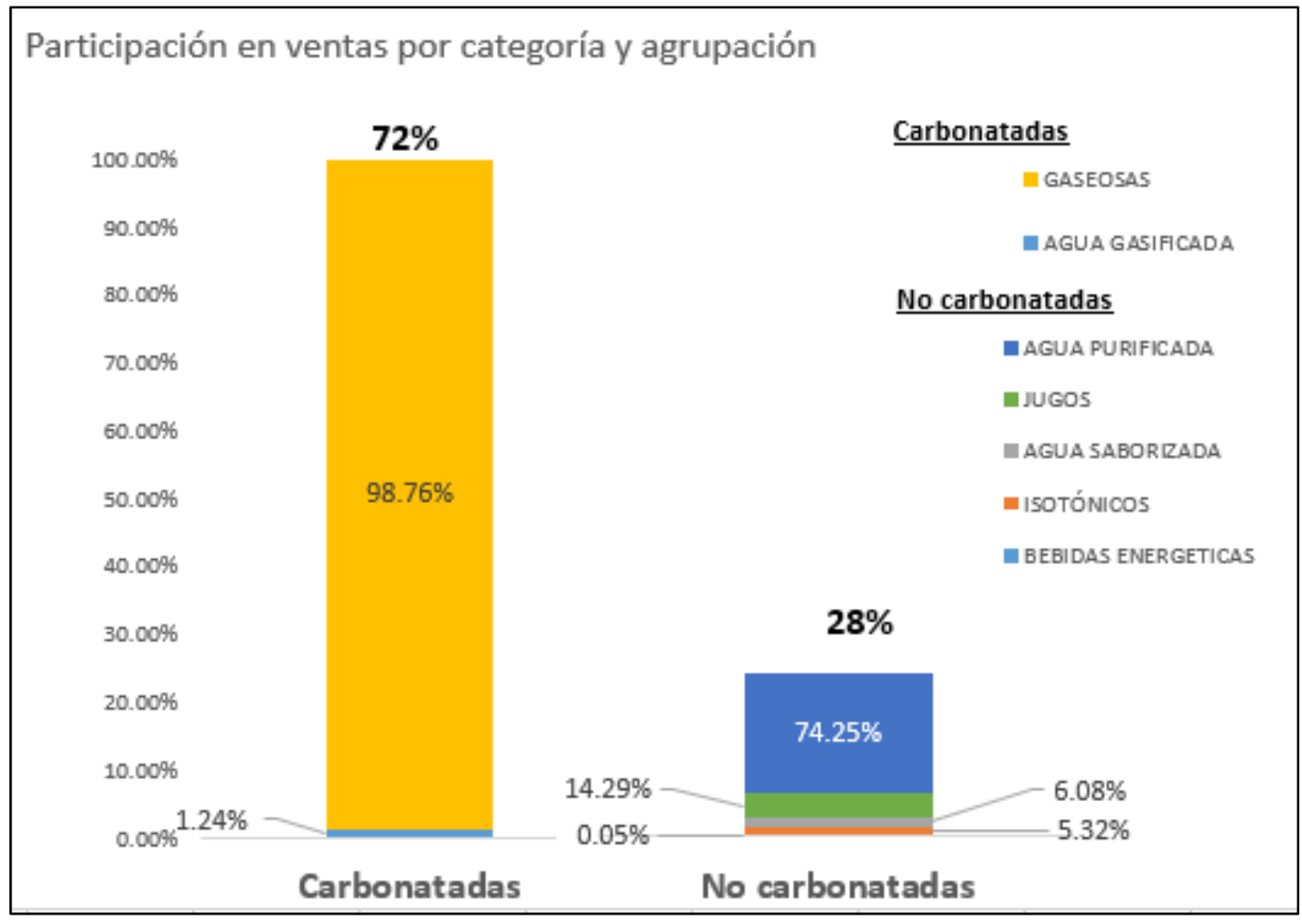

Figura 25. Participación en ventas por categoría y agrupación del 2016. Derechos reservados Vilela, 2017

En la figura 23, se puede observar que el core de negocio son las bebidas carbonatadas, pues representan el $72 \%$ del volumen de ventas. Dentro de esta categoría, son las gaseosas las que tienen casi toda la participación con $98 \%$.

La medida oficial para poder estandarizar el volumen de ventas de diferentes empaques y presentaciones son las cajas unitarias. Una caja unitaria $(\mathrm{CU})$ representa un valor de 5.678 litros por cada CU. 


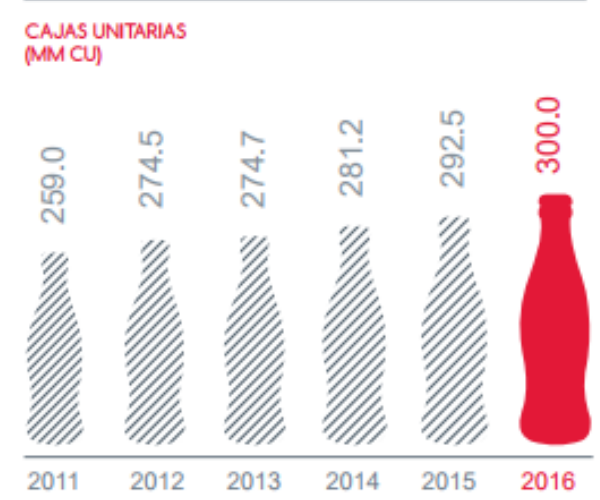

Figura 26. Evolución de ventas de los últimos 5 años. Tomado de 'Memoria Anual 2016”, por la empresa Botellas, 2016

La empresa ha tenido una evolución sostenida de volumen de ventas en los últimos 5 años. El año 2016 llegó a crecer 2.5\% respecto al año anterior, lo que representa 300 mil millones de CU en un año. Esto debido a una buena performance en indicadores operativos y grandes inversiones en los canales de venta.

\subsubsection{Relaciones organizacionales}

En la siguiente sección se describirán as relaciones organizacionales de la empresa. Se presentará a estructura organizacional, los cliente, proveedores, socios y partes interesadas.

\subsubsection{Estructura organizacional}

En la siguiente ilustración se muestra el organigrama de la empresa en Perú. A nivel macro la empresa con 6 direcciones que lideran los principales procesos de la empresa y dos gerencias adjuntas bajo reporte directo de la gerencia general. 


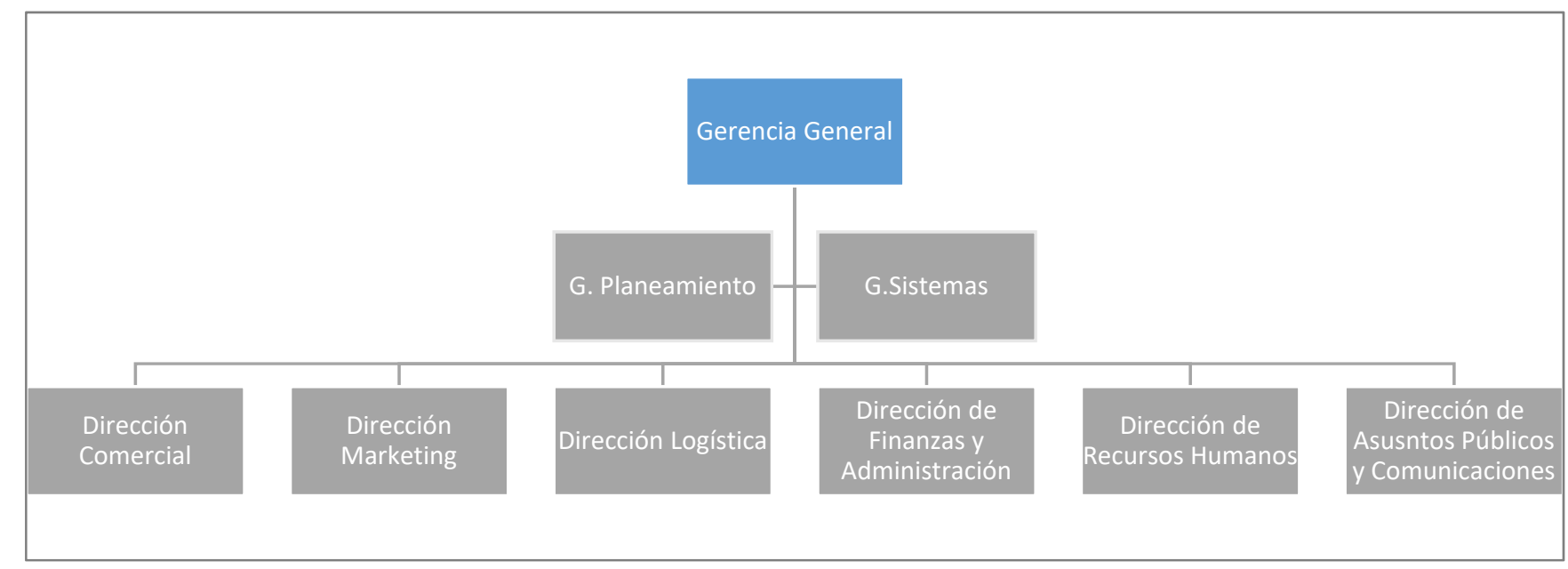

Figura 27. Organigrama de la empresa. Derechos reservados Vilela, 2017

- Gerencia de planeamiento: Es la gerencia encargada de alinear las estrategias de la empresa con las direcciones. Analiza las oportunidades de la empresa y propone las metas de venta y proyecciones de demanda alineadas a los objetivos organizacionales de la empresa y su filial extranjera. Así también, analiza las oportunidades de business intelligence con la gerencia de sistemas.

- Gerencia de sistemas: Es la encargada de dar soporte y desarrollar los proyectos de sistemas de información en la empresa. Lidera los proyectos de mejora de infraestructura informática.

- Dirección Comercial: Se encarga del proceso de comercialización de los productos en cada una de las regiones donde opera la empresa. Analiza, segmenta y negocia acciones para la cartera de clientes de cada canal de ventas. Define el volumen esperado por ventas de acuerdo a los planes comerciales.

- Dirección de Marketing: Se encarga de desarrollar las categorías de cada producto con diferentes planes para incrementar la participación y volumen de ventas en el mercado. Define los planes de lanzamiento de nuevos productos y la presentación que se debe tener en cada punto de venta.

- Dirección logística: Se encarga de la cadena de suministro de la empresa. El área de logística se separa en tres grandes gerencias: La gerencia industrial, que 
gestiona el funcionamiento y productividad de cada planta, así como los estándares de calidad de la empresa; la gerencia de supply chain, que se gestiona los procesos de la cadena de abastecimiento desde la compra de materia prima hasta la distribución a los centros autorizados; y la gerencia de distribución, que gestiona la distribución de los centros autorizados a los clientes finales y la administración de los almacenes.

- Dirección de Finanzas y administración: Se encarga de la gestión financiera y contable de la empresa. Está conformada por las gerencias de contabilidad tributaria, finanzas, tesorería, compras.

- Dirección de Recursos Humanos: Se encarga de gestionar el talento humano de la empresa y los procesos de selección, desarrollo y planillas.

- Dirección de Asuntos públicos y comunicaciones: Maneja las comunicaciones a los medios, y vela por el cumplimiento con las entidades gubernamentales y filiales extranjeras.

\subsubsection{Clientes, Socios y Proveedores.}

\section{$\underline{\text { Clientes }}$}

Los casi 336000 clientes de la empresa "Botellas" se encuentran en todo el Perú. La distribución de sus clientes de acuerdo al volumen de ventas es la siguiente.

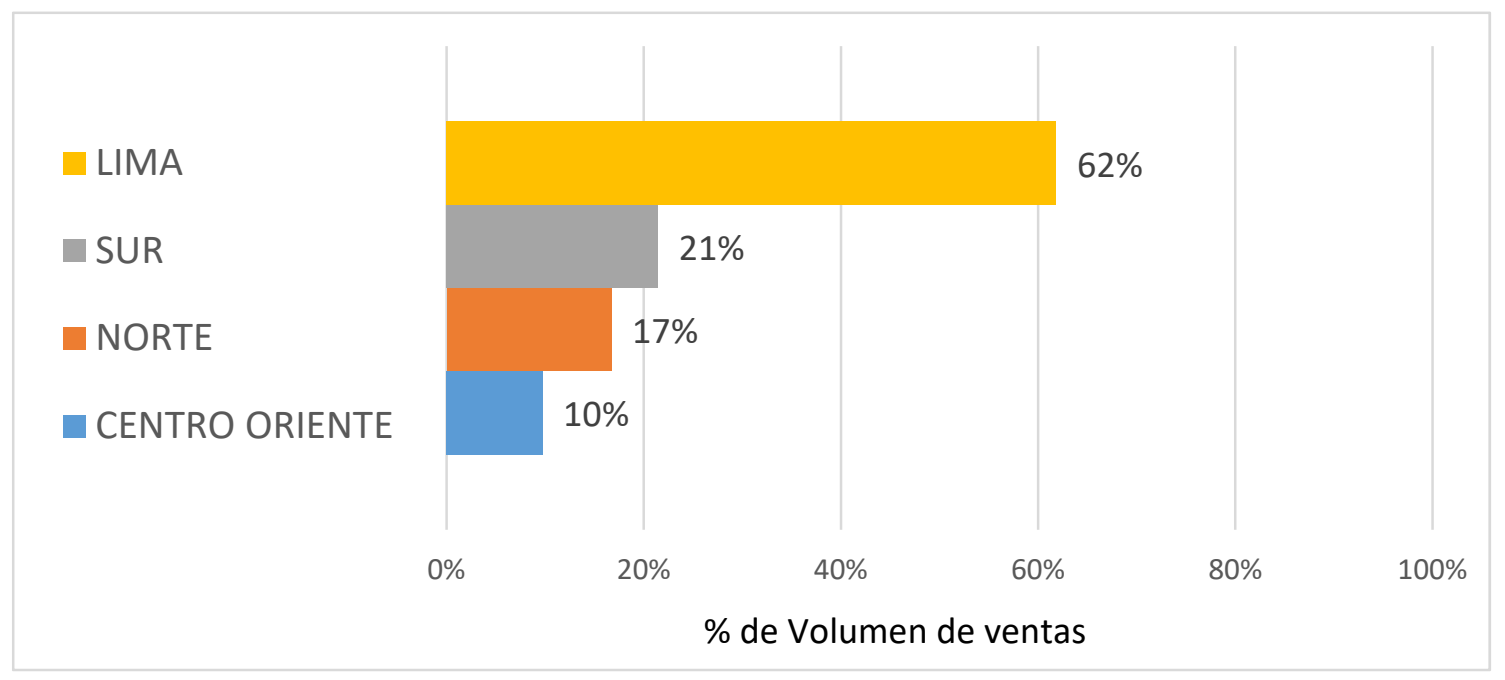

Figura 28. Participación de regiones en el volumen de ventas acumulado del 2016. Derechos Reservados Vilela ,2017 
El 62\% de las ventas se encuentran concentradas en la región Lima, la cual comprende el departamento de Lima, Huaraz e Ica. Esto se da por el mayor desarrollo de la región Lima, en ingresos familiares, empleabilidad y mayor diversidad de canales de venta en la capital.

Los canales de venta de la empresa en cuatro grandes categorías Exportaciones, Canal Horizontal, canal moderno y canal vertical.

\subsubsection{Entorno competitivo}

Al ser una empresa de consumo masivo, existen pocas empresas que tienen la capacidad industrial de competir con la empresa "Botellas" a nivel nacional. En la tabla 2, podemos ver que "Botellas" tiene la mayor participación en el mercado de bebidas no alcohólicas respecto a sus 3 competidores principales.

Tabla 2

Participación de mercado de la empresa botellas en el rubro de bebidas del año 2017

\begin{tabular}{lc}
\hline \multicolumn{1}{c}{ Compañía } & Share $2017 \%$ \\
\hline BOTELLAS & $51.80 \%$ \\
COMPETIDOR 1 & $26.90 \%$ \\
COMPETIDOR 2 & $7.30 \%$ \\
COMPETIDOR 3 & $6.00 \%$ \\
OTROS & $8.00 \%$ \\
\hline
\end{tabular}

Nota: Derechos reservados Vilela, 2017

\subsubsection{Procesos de la empresa}

En esta sección se pasarán a detallar los principales procesos de la empresa. Los resúmenes de estos se presentan en la siguiente figura. 


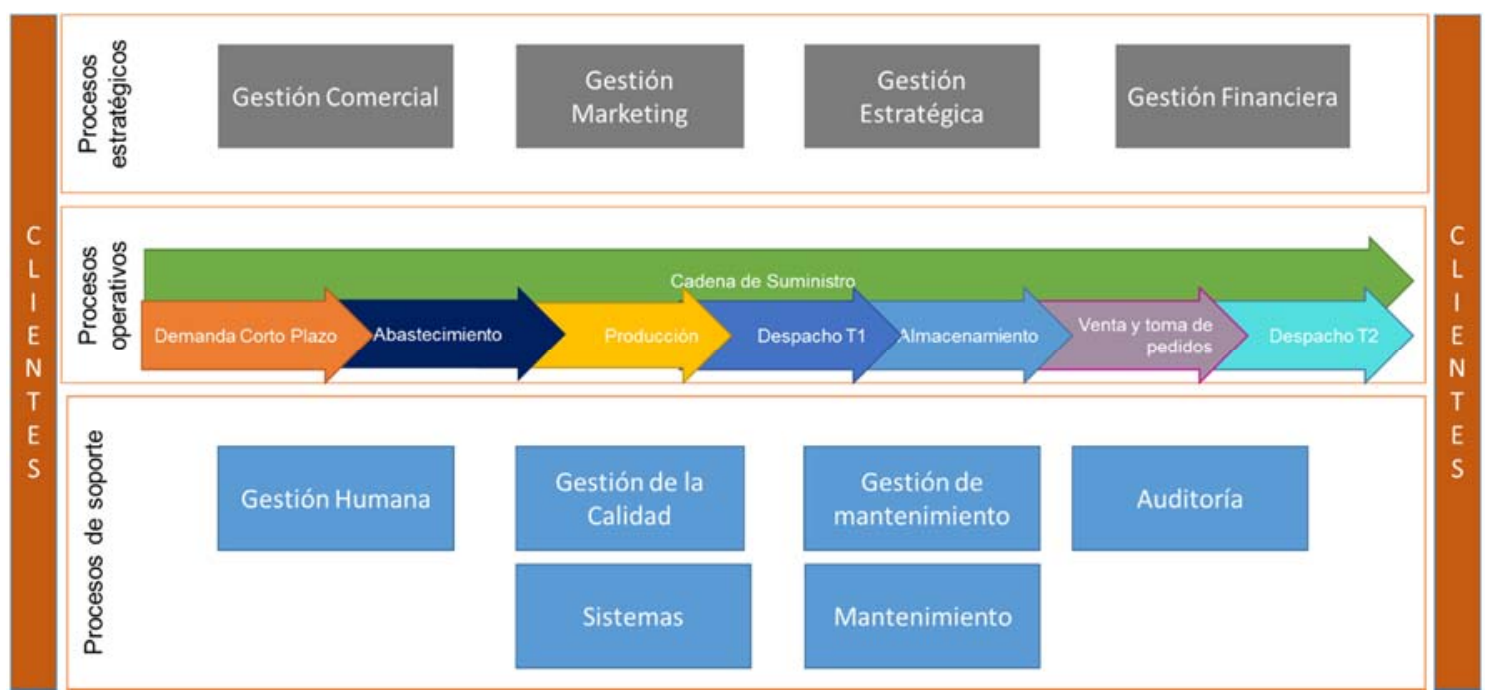

Figura 29. Mapa de procesos de "Botellas". Derechos reservados Vilela, 2017.

Procesos estratégicos:

- Gestión Estratégica: Planifica el volumen de venta anual de la empresa, de acuerdo a los lineamientos dados por la corporación extranjera, y en colaboración con los volúmenes incrementales de la gestión comercial y marketing.

- Gestión Comercial: Es un proceso estratégico que se encarga de proponer y planificar los planes comerciales y acciones para aumentar las ventas. Este input genera un building block para establecer la meta de cuota de ventas del año o mes y así también la demanda proyectada.

- Gestión de Marketing: Tiene como objetivo lograr un mejor posicionamiento de los productos en el punto de venta. Entrega los planes para aumentar la cobertura de clientes e impulsar la venta de productos nuevos. Planifica incrementales de venta de acuerdo a los planes de marketing.

- Gestión de Finanzas: El proceso se relaciona al presupuesto y costos de la empresa. Los grandes proyectos y planes comerciales y marketing son limitados por los presupuestos asignados.

Procesos operativos:

- Demanda corto plazo: El proceso de demanda de corto plazo se realiza semanalmente para 2 semanas de proyección. Para esto se utiliza un software que realiza la 
proyección estadística de la demanda, y luego con el input de planes comerciales y de marketing, se ajusta la demanda para entregarla a Abastecimiento.

- Abastecimiento: El área de abastecimiento se encarga de establecer las cantidades óptimas que deben distribuirse a cada centro de distribución (política de stock) y los objetivos de cobertura del plan semanal de producción.

- Producción: El área de producción, lleva el control de todas las plantas y planes diarios de producción realizados en conjunto con Abastecimiento. Se hace seguimiento a las eficiencias y los stocks de cada planta para llegar al objetivo de cobertura.

- Despacho T1: Siguiendo la política de stocks y objetivos del área de abastecimiento, se realizan los planes de transporte de las plantas hacia los centros de distribución autorizados. Se controla la flota y los horarios de despacho diarios.

- Almacenamiento: En los centros de distribución autorizado se realiza la descarga de los trailers enviados por el transporte primario en los centros de distribución. Los operarios se encargan de la colocación de los pallets enviadas en los sitios designados y los procesos de inventario.

- Venta y toma de pedidos: El área de ventas de los centros de distribución, realiza las visitas a los clientes, de acuerdo al plan de cuota dada por el área de demanda LP. En las visitas recogen los pedidos de los clientes de cada una de las rutas de los centros.

- Despacho T2: El área de despacho T2 se encarga de armar las cargas de los camiones de los centros para enviar los pedidos a cada uno de los clientes y cerrar la venta.

Procesos de soporte:

- Gestión Humano: Brinda el soporte en la administración de personal y cubrimiento de plazas para poder llevar a cabo la operación.

- Gestión de la Calidad: Se encarga del aseguramiento de la calidad durante todo el proceso.

- Gestión de Mantenimiento: Esta área se encarga de planificar y ejecutar los mantenimientos en todas las plantas para asegurar la operatividad de las máquinas.

- Auditoría: Se encarga de reglamentar todos los procesos para el reporte a las entidades gubernamentales y las filiales corporativas 
- Sistemas: Se encarga de brindar soporte a las herramientas informáticas que se usan durante todo el proceso desde la demanda hasta la liquidación.

\section{Gestión de inventarios}

La empresa gestiona sus inventarios con el modelo otorgado por la empresa Arete para sus sistemas AV y PV. Este modelo se basa en la gestión de stocks por días de venta, debido a la alta variabilidad de demanda en las industrias de bebidas.

El inventario es calculado en días de venta de la siguiente manera:

$$
\begin{gathered}
\text { Stock en almacé } n=500 \text { cajas } \\
\text { Demanda diaria }=200 \text { cajas } \\
\text { Días de venta en almacé } n=\frac{500}{200}=2.5 \mathrm{DV}
\end{gathered}
$$

El stock expresado en días de venta se refiere a cuántos días se puede abastecer con stock a la demanda hasta que se agote. En el ejemplo anterior, las 500 cajas solo abastecerán a 2.5 días de venta.

El cálculo operativamente en el sistema es más sofisticado, pues las ventas diarias no suelen ser las mismas para cada día. Entonces el sistema realiza el cálculo de los días de inventario que pueden abastecerse con el stock de acuerdo a lo pronóstico de demanda proyectado.

El sistema de inventarios ha ordenado los niveles de inventarios de manera que se puede identificar con alertas cada uno de ellos sobre los siguientes puntos:

1. Crítico: Punto mínimo que debería existir en una locación para poder cubrir la demanda de un ciclo de planificación. Se suele poner los leads days hacia una locación.

2. Seguro: Nivel de inventario donde se cumple el nivel de servicio deseado. Si el inventario actual está por debajo de este nivel, se debe activar una orden de reposición. Para conocer este punto se utiliza el software de planificación.

3. Parar: Nivel máximo al que debe abastecerse un producto.

4. Extra: Nivel que solo se usa cuando existe producto extra en las plantas y se distribuye el exceso en las locaciones.

Existen dos tipos de planeamiento: 
a) Planeamiento de productos críticos: Aquellas cargas que se programan en la mañana para enviarse antes de las $6 \mathrm{pm}$ y satisfacer la demanda

b) Planeamiento regular: Aquellas cargas que programan en la tarde para que lleguen a las locaciones para la venta del siguiente día.

\subsection{Identificación del Problema}

\subsubsection{Definición del desmedro}

Como empresa dentro del rubro de consumo masivo uno de los enfoques principales es mantener los gastos bajos. Por la tanto, existen diversos indicadores que ayudan a controlar que los gastos no excedan los presupuestos planificados.

Uno de los gastos en los que incurre la empresa es el ocasionado por los desmedros. Se define como desmedro a todo producto terminado o implícitos, apto para la venta, que a través de su paso por los procesos de almacenaje, transporte y comercialización se deteriora efectivamente y no llega al consumidor final, generando pérdidas.

El desmedro puede originarse por distintos tipos tanto el mercado como en el almacén. Estos tipos se pueden separar en tres grandes grupos de motivos:

1. Proceso: Ocurre por mala manipulación en los procesos de almacén y transporte, generando deterioro en el producto.

2. Rotura: Su origen es la naturaleza del producto gasificado que cuando es embotellado en envases de vidrio puede generar una rotura espontánea. Sucede cuando no se han pasado controles de calidad.

3. Vencimiento: Se refiere a los productos que pasan su fecha de vencimiento. Este tipo de vencimiento suele ser el de mayor incidencia.

Así también, el desmedro puede analizarse en dos tipos por su origen:

- Mercado: Todo lo que viene reportado por el cliente cuando ya se ha realizado la transacción en el punto de venta.

- Almacenes de la Empresa: Todo producto que se convierte en desmedro durante los procesos de producción, transportes y almacenaje. 
En la figura siguiente se presenta en qué lugar de la cadena se reportan cada uno de los tipos de desmedro según su origen.

En el caso del vencimiento, este puede ocurrir tanto en los almacenes de la empresa (Planta, distribución o almacenes del CEDI) como en el punto de venta (Cliente). Si bien los vencimientos en el punto de venta, son responsabilidad entera del cliente, la empresa tiene por política hacer cambios de productos vencidos a sus clientes. Esto es controlado con objetivos establecidos a cada CEDI sobre los vencimientos que pueden registrarse del mercado. El mayor porcentaje de desmedro se da por vencimiento.
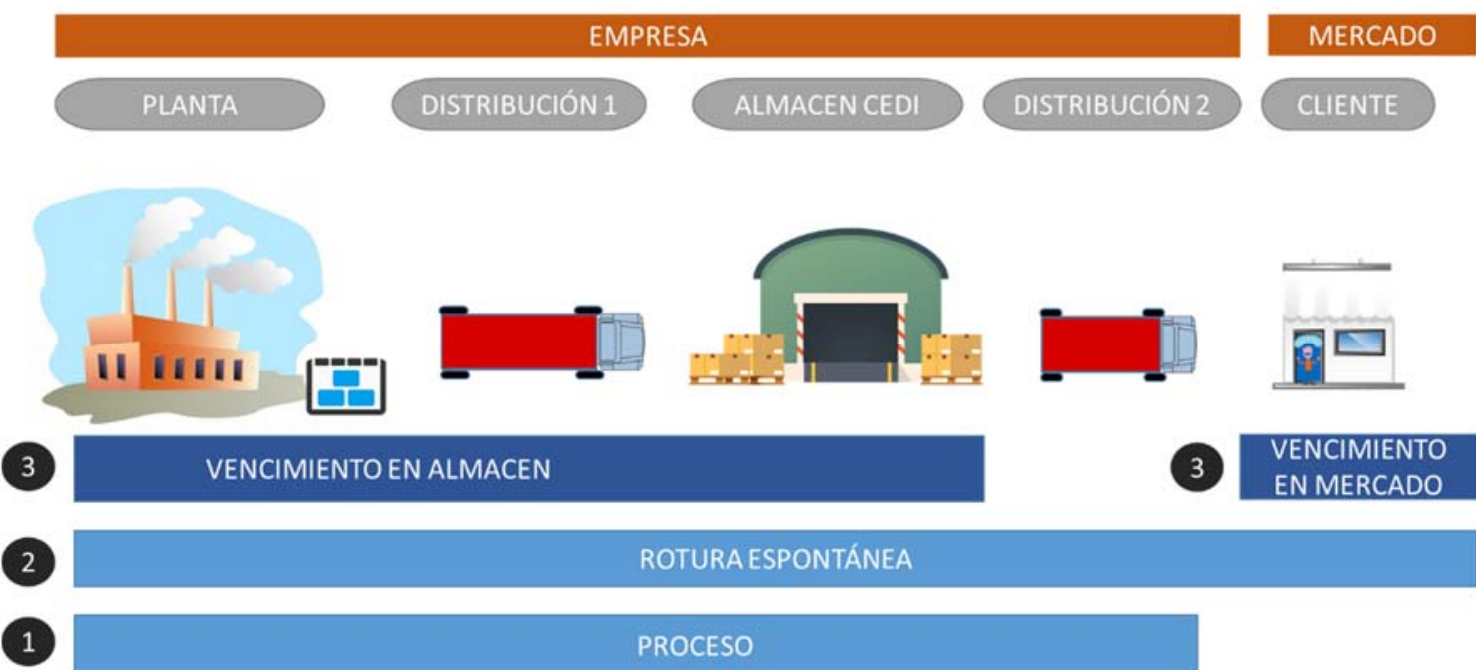

Figura 30. Eslabones del desmedro. Derechos reservados Vilela,2017

El tipo de rotura espontánea puede ocurrir en cualquier parte de la cadena, esto sucede cuando no se han pasado los controles de calidad y la botella se rompe al no resistir tensión sobre su superficie. Cuando esto sucede en el mercado, el cliente puede solicitar el cambio de su producto por uno nuevo. 


\subsubsection{Análisis del problema}

Para hacer el seguimiento mensual al desmedro se llevan dos indicadores:

- Desmedro contable: Desmedro que pasa por todos los procesos hasta su baja física contable y en el sistema en SAP. El desmedro contable considera los costos de venta y producción.

- Desmedro operativo: Desmedro que se genera en el mes el curso. Su registro se hace día a día en los almacenes.

El área de operaciones mide el desmedro operativo, lo cual les permite llevar tracking en tiempo real de lo que se clasifica como desmedro y tomar acciones en el corto plazo para reducir su incidencia. En la figura siguiente, se presenta que el desmedro operativo no ha llegado a su meta en lo que va del año 2017. La meta establecida para el desmedro operativo no es estacional y se basa en el promedio de desmedro reportado el año anterior.

Los indicadores de la empresa se miden en CU, cajas unitarias. Unidad de medida estándar en litros para las embotelladoras del sistema de marcas internacionales que maneja la empresa. Una caja unitaria equivale a la venta de 5.678 litros de bebida.

\begin{tabular}{|c|c|c|c|c|c|c|c|}
\hline & Ene-17 & Feb-17 & Mar-17 & Abr-17 & May-17 & Jun-17 & Jul-17 \\
\hline Desmedro en CU & 187,610 & 203,369 & 198,261 & 181,390 & 201,050 & 153,976 & 175,782 \\
\hline Meta & 154,547 & 154,547 & 154,547 & 154,547 & 154,547 & 154,547 & 154,547 \\
\hline$\% \operatorname{Var}$ & $-17.6 \%$ & $-24.0 \%$ & $-22.0 \%$ & $-14.8 \%$ & $-23.1 \%$ & $0.4 \%$ & $-12.1 \%$ \\
\hline
\end{tabular}

Figura 31. Indicador de Desmedro operativo 2017. Derechos reservados, 2017

Un vencimiento en almacén, puede llevar a reducir el nivel de servicio de los clientes, pues no solo se pierde el producto para una posible venta, si no también se desperdicia la capacidad de los recursos para producir y distribuir eficientemente lo que está pidiendo el cliente.

Al ser la demanda estacional, los indicadores se comportan de acuerdo al índice de ventas. Así, cuando la demanda es mayor se espera que el desabastecimiento sea menor. En la figura siguiente podemos observar que el indicador de desabastecimiento tampoco ha llegado a su meta en el primer semestre del 2017, así también el indicador de desmedro también tuvo una baja performance. 
Cuando aumentó el desmedro, afectó al desabastecimiento de los pedidos, ocasionando una baja del nivel de servicio. En la figura siguiente, se comparan ambos indicadores en volumen de CU para el primer semestre del 2017. Los meses en donde no se llegó a la meta en desabastecimiento coinciden casi con los meses en donde se reportó un mayor desmedro.

\begin{tabular}{|c|c|c|c|c|c|c|c|}
\hline & Ene-17 & Feb-17 & Mar-17 & Abr-17 & May-17 & Jun-17 & Jul-17 \\
\hline Desmedro en CU & 187,610 & 203,369 & 198,261 & 181,390 & 201,050 & 153,976 & 175,782 \\
\hline Desabastecimiento en $\mathrm{CU}$ & 278,009 & 354,387 & 340,957 & 310,485 & 301,846 & 285,084 & 298,932 \\
\hline
\end{tabular}

Figura 32. Desmedro vs Desabastecimiento 2017. Derechos reservados Vilela, 2017

La temporada de demanda alta coincide con la estación de verano y primavera (octubre a Abril) y la temporada de baja demanda se da entre los meses de mayo a septiembre. En la figura siguiente podemos observar como en el año 2016, a medida que los valles de desmedro corresponden con la temporada alta y los picos en la temporada baja. Por el contrario, en el año 2017 la tendencia del desmedro ha sido casi constante e incluso más alto de lo que se va reportando en la temporada baja.

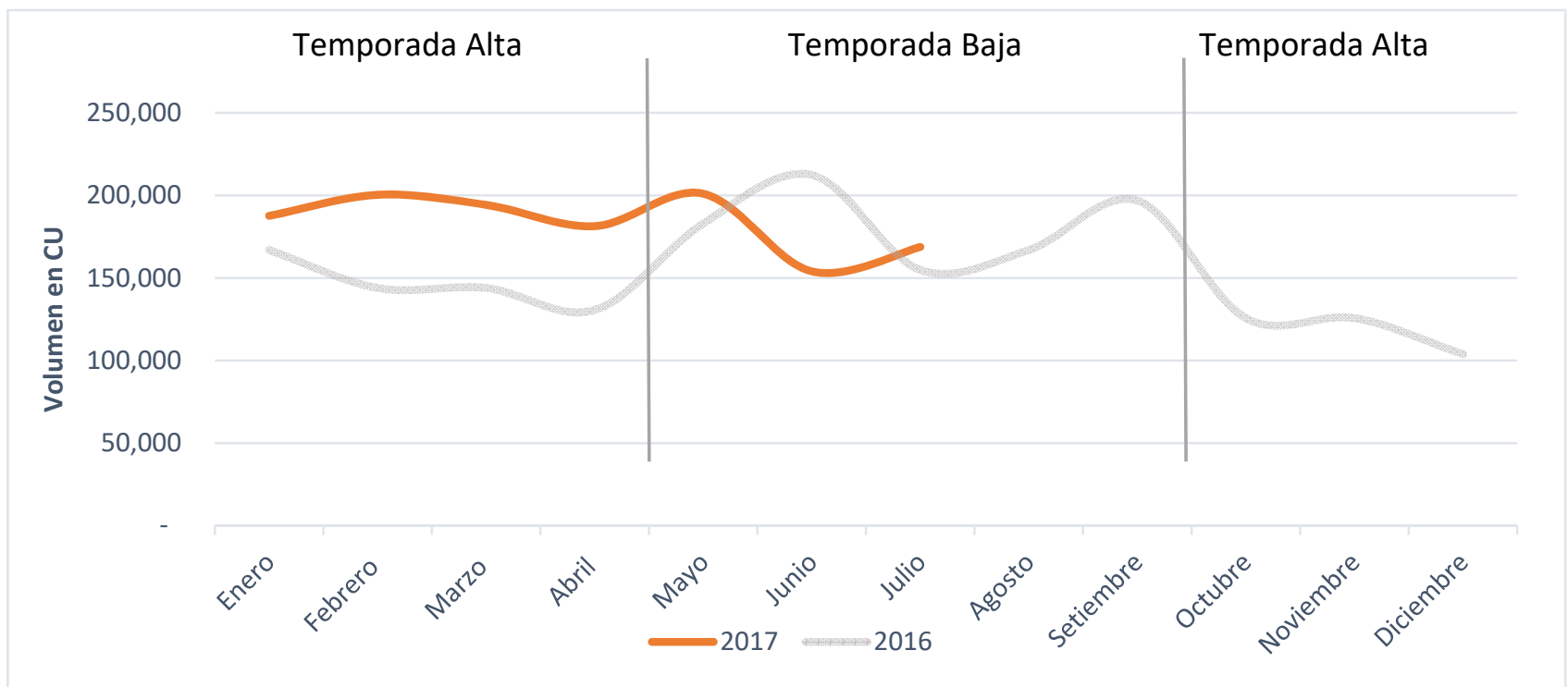

Figura 33.Tendencia del desmedro 2016 vs 2017. Derechos reservados Vilela, 2017.

En la figura siguiente se observa que la venta del 2017 vs 2016 ha aumentado, lo cual debería reflejarse en la disminución del desmedro. Sin embargo; el desmedro se ha incrementado evidenciando así problemas en la gestión de inventarios. 


\begin{tabular}{|c|c|c|c|c|c|c|c|}
\hline & \multicolumn{2}{|c}{ Enero } & \multicolumn{1}{c}{ Febrero } & Marzo & Abril & \multicolumn{2}{c|}{ Mayo } \\
\hline $\begin{array}{c}\text { Variación de venta en CU } \\
\text { vs Año pasado }\end{array}$ & $2.0 \%$ & $0.5 \%$ & $6.2 \%$ & $-0.8 \%$ & $1.0 \%$ & $0.5 \%$ & $-0.8 \%$ \\
\hline
\end{tabular}

Figura 34. Comparación de crecimiento de volumen de venta mes año 2017 vs 2016. Derechos reservados Vilela, 2017.

Por otro lado, el desmedro reportado durante el 2017 ha sido mayor que en el 2016. En el Mes de Junio podemos ver una baja drástica en lo reportado, debido a que se implementó la política de restricciones a los cambios de mercado. Cada uno de los CEDIS tiene un objetivo de cambios de mercado por vencimiento, lo cual ha permitido la reducción de los vencimientos sin necesidad de gestionar los problemas en los almacenes.

Tabla 3

Comparación de volumen de desmedro 2017 vs 2016 al mismo periodo

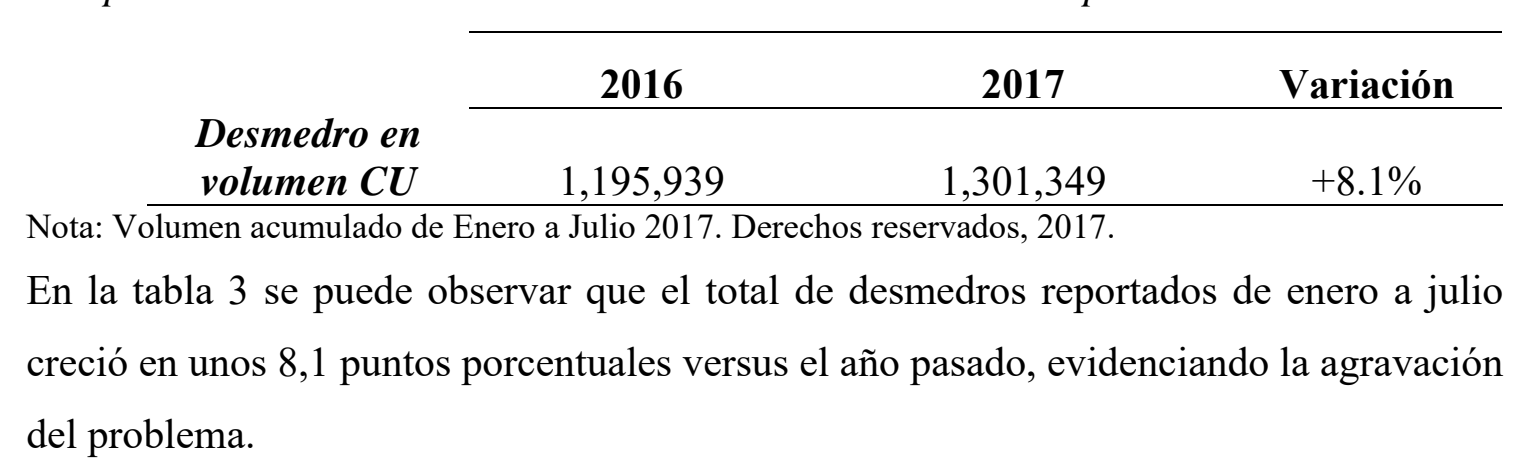

Para controlar los gastos de la empresa, el área de contabilidad mide el desmedro contable para comparar mensualmente si los gastos superan el presupuesto. Este desmedro reportado incluye tanto desmedro por producto terminado como materia prima. Cuando se trata de desmedro por producto terminado, existe un desfase de tiempo con el desmedro operativo, pues necesita cumplir todos los procesos para su baja en los sistemas.

En la tabla 2 se visualiza que, en el año 2016, el indicador por gastos de desmedro contable superó la meta asignada a por 9.3\%. En lo que va del año 2017, el desmedro ha superado la meta cada mes, incluso en temporada baja. El costo acumulado al año va sobre el $15,7 \%$ de lo presupuestado. Por lo tanto, si se quiere llegar a la meta de este año, se deberán solucionar el problema raíz. 
Tabla 4

Indicador de gastos de desmedros en miles de $\mathrm{S} /$.

\begin{tabular}{c|ccccccccc}
\cline { 2 - 7 } & $\begin{array}{c}\text { Año } \\
\text { 2016 }\end{array}$ & Ene-17 & Feb-17 & Mar-17 & Abr-17 & May-17 & Jun-17 & Jul-17 & $\begin{array}{c}\text { Año } \\
\mathbf{2 0 1 7}\end{array}$ \\
\hline Resultados & 29,390 & 1,531 & 2,284 & 2,187 & 2,084 & 2,460 & 2,580 & 2,340 & 15,466 \\
Meta & 26,900 & 1,862 & 1,862 & 1,862 & 1,862 & 1,862 & 1,862 & 1,862 & 13,034 \\
Desvío (\%) & $-9.3 \%$ & $17.8 \%$ & $-22.7 \%$ & $-17.5 \%$ & $-11.9 \%$ & $-32.1 \%$ & $-38.6 \%$ & $-25.7 \%$ & $-15.7 \%$ \\
\hline
\end{tabular}

Nota: Derechos reservado Vilela, 2017.

\subsubsection{Análisis de causas}

Para el análisis de las causas raíz y definir el alcance de la propuesta se utilizará el diagrama de árbol de causas raíces. La empresa cuenta con casi 80 almacenes a nivel nacional y 7 plantas. Por tal motivo, el análisis y propuesta de solución al problema de desmedro se realizará sobre un almacén representativo de la región Lima. En la tabla 4, se muestran los resultados del Pareto del año 2017. El Almacén MEPA, lleva casi el 30\% de todo el desmedro total, siendo el almacén que ha reportado más desmedro en el año 2017 a la fecha. Por lo tanto, para el análisis del problema, se considerará el estudio del almacén MEPA. Este almacén terciarizado, es uno de los principales de almacenes de la empresa pues se encarga de la distribución del producto a 5 canales de venta principales de la empresa.

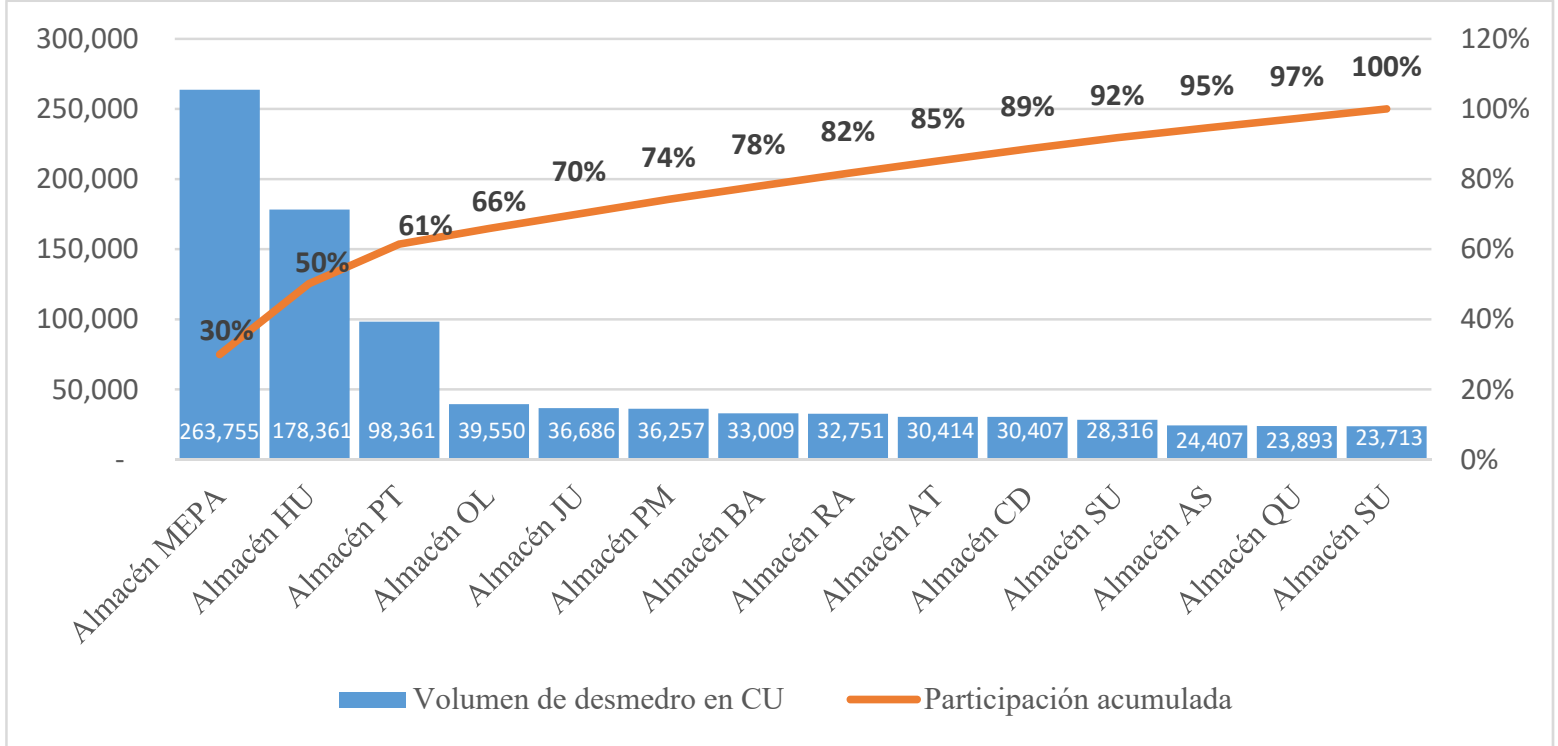

Figura 35. Pareto de participación en volumen de desmedro por almacenes en Lima del año 2017. Derechos reservados Vilela, 2017. 
Para el análisis del desmedro se ha divido el estudio del almacén MEPA en tres fases para definir el alcance del problema, finalmente se realiza un estudio de la causa raíz.

\subsubsection{Análisis del alcance del problema}

1. Primera fase de análisis: Tipo de Desmedros

En primer lugar, se analizará la causa reportada de los desmedros en los últimos 12 meses. En la tabla 4, se puede observar que la mayor incidencia de desmedro se debe al vencimiento del producto. Representa más del $80 \%$ de todo el desmedro reportado. Si bien el desmedro por proceso, ocupa un 16\% del total, tiene un menor impacto económico, pues no todo el desmedro por proceso es asumido por la empresa. En varios casos cuando se trata de una mala operación, el supervisor de patio tiene la obligación de asignar responsabilidades para que se asuman los costos de venta de las cajas de producto terminado perdidas.

Tabla 5 .

\% Participación por tipo de desmedro en los últimos 12 meses en Almacén MEPA

\begin{tabular}{lll}
\hline Tipo Desmedro & $\begin{array}{l}\text { Volumen de Desmedro } \\
\text { en CU }\end{array}$ & $\begin{array}{l}\% \text { Participación del Desmedro } \\
\text { total }\end{array}$ \\
\hline Roturas & 8,262 & $3 \%$ \\
Por Proceso & 41,591 & $16 \%$ \\
Vencimiento & 213,902 & $81 \%$ \\
\hline Total & 263,755 & $100 \%$ \\
\hline
\end{tabular}

Nota: Derechos reservados Vilela, 2017.

De acuerdo a lo presentado en la tabla 5 se observa que el desmedro por origen de vencimiento representa el $81 \%$ total del desmedro acumulado en los últimos 12 meses. En la figura 34, se puede observar que, históricamente, el desmedro ocasionado por vencimiento es siempre mayor a los otros dos orígenes en todas las temporadas para los otros almacenes 


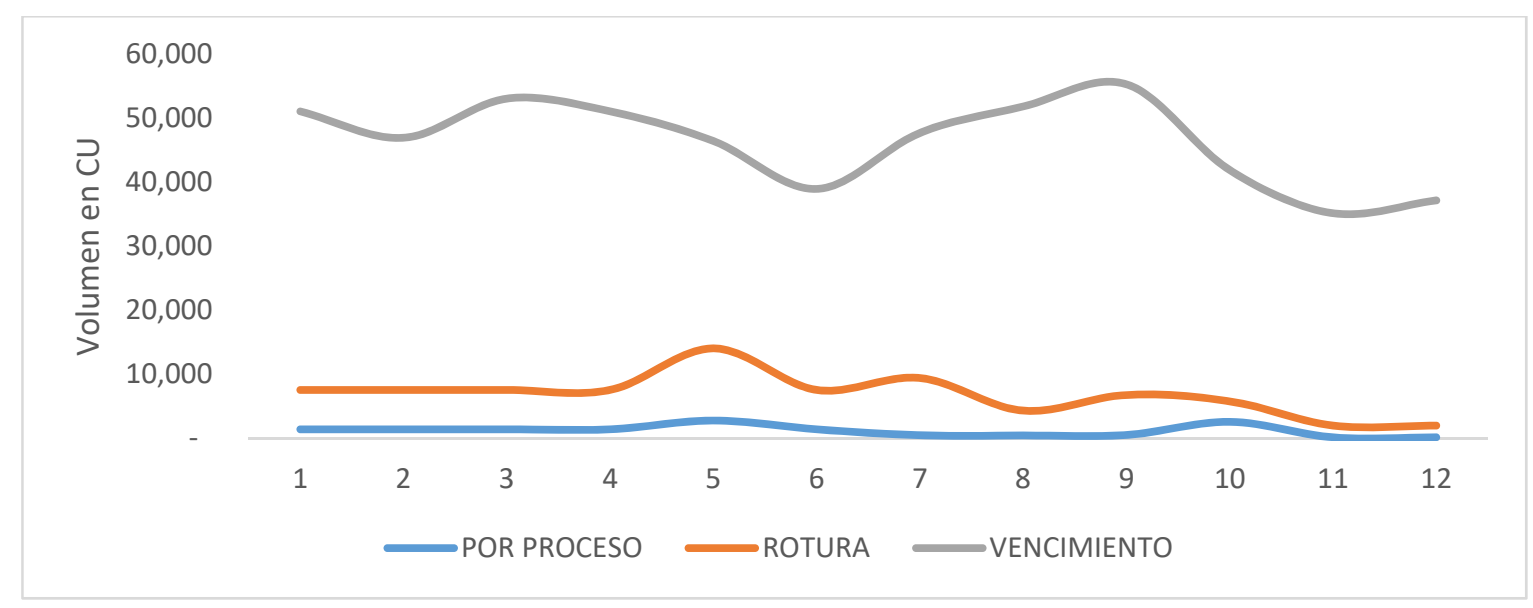

Figura 36. Evolución del desmedro por tipo en los último 12 meses (Julio 2016 - Julio 2017). Derechos reservados Vilela,2017

Por lo tanto, el siguiente nivel de análisis se concentrará en examinar el origen del desmedro por vencimiento.

2. Segunda Fase de análisis: Origen del Vencimiento

En la tabla 6 se presenta que el mayor impacto es generado por los vencimientos en la empresa. Si bien los vencimientos por origen de mercado representan en total un $33 \%$ sobre el total de los vencimientos, ya se han tomado medidas correctivas para disminuir lo total reportado por los puntos de ventas.

Tabla 6.

\% Participación por origen del volumen total de vencimientos del Almacén MEPA en los últimos 12 meses

\begin{tabular}{ccc}
\hline Origen del Vencimiento & $\begin{array}{c}\text { Volumen de desmedro } \\
\text { en CU }\end{array}$ & $\begin{array}{c}\text { \% Participación sobre } \\
\text { vencimientos }\end{array}$ \\
\hline Almacén & 142,779 & $67 \%$ \\
Mercado & 71,122 & $33 \%$ \\
\hline Total general & 213,902 & $100 \%$ \\
\hline
\end{tabular}

Nota: Derechos reservados Vilela, 2017. 


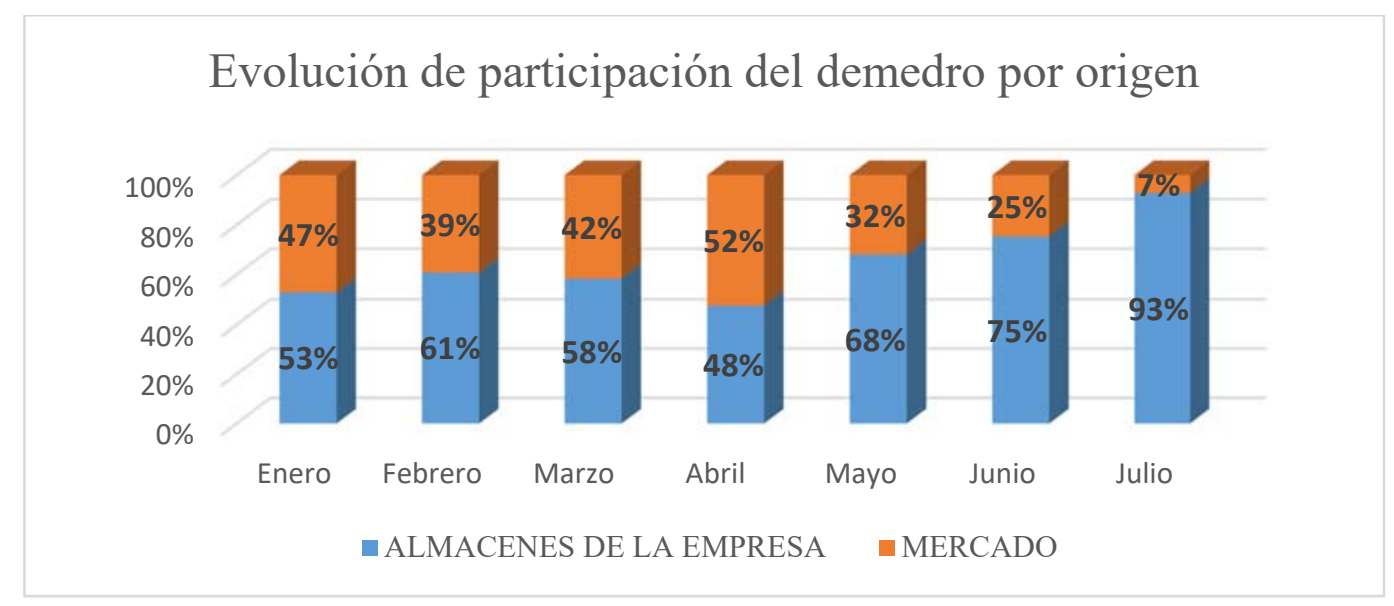

Figura 37. Evolución de la participación en el desmedro por origen en el año 2017 del Almacén MEPA. Derechos reservados Vilela, 2017.

Hasta inicios del 2017, la empresa tenía como política el cambio de productos vencidos reportados por los clientes en sus puntos de ventas a través de sus centros de distribución. Esta devolución no tenía un límite específico para cada centro de distribución. A raíz del aumento de los vencimientos por mercado, se establecieron objetivos de devoluciones para centro. En la figura anterior, se puede observar que a partir de junio 2017 el porcentaje de participación de desmedro de mercado se redujo en 18 punto porcentuales. Con la nueva política de cambios del mercado, se espera reducir el desmedro de mercado a casi 0 en el siguiente año.

Actualmente, el vencimiento que se reporta corresponde casi en su totalidad a los almacenes de la empresa (como se observa en Junio y Julio de la figura 35), por ello, la investigación se centrará en identificar qué soluciones se deben aplicar para cada eslabón de la cadena.

En general, como política de la empresa, se tiene que los inventarios de productos terminado solo deben permanecer como máximo 15 días en las plantas. Esto debido al reducido espacio que existe. Solo el inventario que necesita cuarentena, puede pasar más de 15 días hasta cumplir su cuarentena. En la figura 29, se muestra un mapa de calor con los días de almacenamiento en plantas para el primer semestre del año 2017. Se puede observar, que solo el 1\% de los productos sin cuarentena no cumple la orden de almacenamiento máximo de 15 días en planta. 


\begin{tabular}{|l|c|c|c|}
\hline \multicolumn{1}{|c|}{} & $0-7$ días & $8-15$ días & $15-20$ días \\
\hline Productos sin cuarentena & $86 \%$ & $13 \%$ & $1 \%$ \\
\hline Productos con cuarentena & $3 \%$ & $59 \%$ & $38 \%$ \\
\hline
\end{tabular}

Figura 38. Mapa de calor de días de almacenamiento en plantas de

Lima según tipo de producto para Enero - Julio 2017

De esta manera, podemos identificar que el lugar donde se producen los vencimientos son los almacenes externos y no las plantas. En las plantas de la empresa los productos tienen un alto flujo.

3. Tercera fase de análisis: Identificación del eslabón responsable

Anteriormente, se identificó que los almacenes son el lugar donde se producen los vencimientos. Estos almacenes son encargados de procesos operativos como almacenamiento, comercialización y distribución a los clientes finales, de los productos que la empresa envía a cada uno de estos.

Debido a que los desmedros reportados se originan en el almacén externo, que solo lleva a cabo las actividades de operativas de almacenamiento y distribución, existen dos causas posibles de acuerdo a lo investigado: Mal manejo del inventario en el almacén, es decir deficiencias en las operaciones de almacén o exceso de producto en el almacén, es decir, deficiencias en la planificación del inventario.

\section{Análisis de deficiencias de operaciones en almacén}

Para poder comprobar que existen deficiencias en las operaciones de almacén, se procede a analizar los lotes de todos los skus reportados como vencidos entre los meses de mayo - agosto 2017. El criterio que se utiliza es verificar el lote vencido con su número juliano y revisar si en el mismo mes que fue reportado vencido hubo una venta de un lote con número juliano más reciente, esto bajo la consigna del método FEFO. El lote que expira primero debe ser el primero que salga a la venta. 
Comprobamos esta afirmación con el historial de salidas del SKU 254733. En la figura 37, se presentan la salida de dos cargas con su id de lote. Los primeros caracteres son la identificación de la planta y los siguientes 6 números es la fecha de producción. Se puede observar que un lote del día 19.07.17 salió a carga antes que un lote del mes anterior. Esto representa una evidencia de que no se ha manejado correctamente las salidas de los productos más frescos.

\subsubsection{C11907171 \\ $31.07 .2017 \quad C 12406171$}

Figura 39. Salida de lotes del sku 254733

Adicionalmente, para comprobar esta clasificación se utilizó el siguiente criterio basado en la rotación de un producto:

Rotación de SKU sin vencimiento x marca $<$ Rotación de SKU vencido

En primer lugar, se agruparon los SKUS a nivel de marca. Luego se calcula el índice de rotación de inventarios de los productos que no fueron reportados como vencimiento de esa marca. Si todos los productos de la marca fueron reportados como vencidos en ese mes, se usa un producto similar. De la misma forma, se calcula el índice de rotación de inventarios del producto vencido. Si la rotación de inventario del producto vencido es mayor a la del producto sin vencer de la misma marca, se considera que la causa fue la operación de patio. La fórmula utilizada para calcular la rotación es la siguiente:

\section{Rotación de Inventario x marca$$
=\frac{\text { costo de cajas unitarias vendidas } x \text { mes }}{\text { cajas unitarias almacenadas promedio } x \text { mes }}
$$

Para explicar el método se toma como ejemplo el SKU 254733 de marca SL. En primer lugar se calcula la rotación de todos los skus de la marca SL durante un periodo de 4 meses:

$$
\text { Rotación SKU } 254733=\frac{836666}{29408}=7.20
$$


Luego se calcula la rotación del SKU 254733 en el mismo periodo

$$
\text { Rotación SKU } 254733=\frac{99802}{23460}=4.25
$$

En este caso la rotación del SKU 254733 es menor a la rotación de la marca; por lo tanto, se puede clasificar como un sku de alta rotación. De acuerdo a la definición de rotación de inventarios, a menor rotación el SKU permanece menor tiempo en el almacén. Si el sku tiende a salir del almacén con frecuencia y aun así genera vencimiento, se debe a un mal manejo de los lotes en el almacén y por lo tanto es clasificado como "vencimiento por operación de patio".

En la tabla 7 se presentan los resultados del análisis por número julianos

Tabla 7.

Criterios de clasificación de vencimiento en almacén

\begin{tabular}{|c|c|c|}
\hline Criterios & Indicador & $\begin{array}{l}\text { \%SKUS que } \\
\text { cumplen con } \\
\text { indicador }\end{array}$ \\
\hline FEFO correcto & $\begin{array}{l}\text { Juliano del lote vencido es } \\
\text { mayor a los julianos de lotes } \\
\text { despechados. }\end{array}$ & $93 \%$ \\
\hline $\begin{array}{l}\text { Mal manejo del } \\
\text { inventario }\end{array}$ & $\begin{array}{l}\text { Juliano del lote vencido es } \\
\text { menor a los julianos de lotes } \\
\text { despachados }\end{array}$ & $7 \%$ \\
\hline
\end{tabular}

Nota: Derechos reservados Vilela, 2017.

Del total de SKUS analizados solo el 7\% presentó mal manejo en el inventario. Esto significa que los SKUS restante se deberían a deficiencias en la planificación del inventario.

$\underline{\text { Análisis de deficiencias en la planificación de inventarios }}$

En la planificación de las cantidades enviadas al almacén es un proceso que involucra diferentes actividades. Dentro de esta planificación, intervienen tres áreas o procesos (Demanda, Producción y Abastecimiento). Cada una de ellas depende de la información 
que obtiene del eslabón anterior para poder entregar su planificación. Este proceso se ha esquematizado en la figura 38.

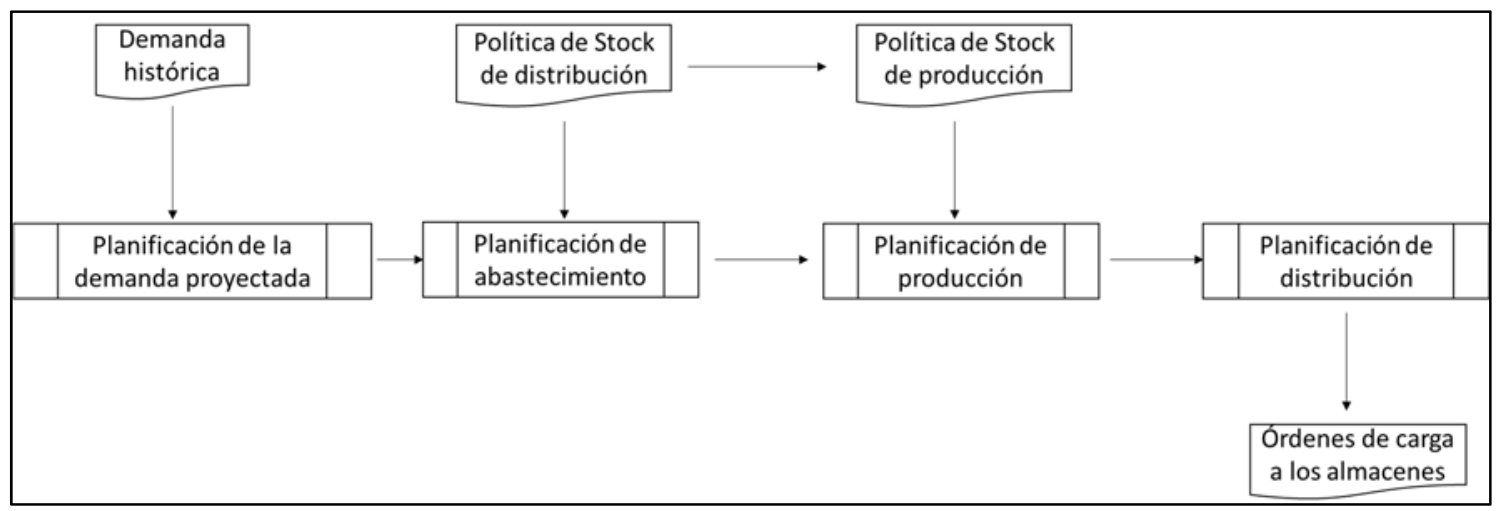

Figura 40. Secuencia de procesos de la planificación de la cadena de abastecimiento. Derechos reservados Vilela, 2017.

Se puede observar que el proceso inicia con la proyección de demanda, la cual sirve de input para calcular el abastecimiento de acuerdo a la política de distribución, es decir la cantidad que se debería enviar al almacén para cumplir con la demanda incluyendo stocks de seguridad etc. Esta cantidad que se debe enviar a cada almacén se suma a nivel de planta, de manera que se realice la planificación de la producción utilizando esta cantidad como base.

Tanto para la planificación de producción como para la planificación de abastecimiento se utiliza una política para definir el número, es decir no solo se toma la demanda proyectada, sino que se le agrega un adicional de acuerdo a lo que haya decidido cada área. Por ello, se segmentarán el análisis para dos procesos:

\section{$\underline{\text { Análisis del proceso de la demanda }}$}

El primer proceso que inicia toda la cadena de planificación es el de la proyección de la demanda. Si este proceso no da como resultado una demanda acertada, entonces los demás procesos planificarán un número muy lejano a lo que se necesita ya sea por exceso o defecto. Para poder medir si este proceso está dando los resultados adecuados, se utilizará el indicador de asertividad de demanda.

La fórmula utilizada para medir asertividad es la siguiente: 


$$
\begin{gathered}
\text { Asertividad }=100 \%-\text { Error } \% \\
\text { Error } \%=\frac{\mid \text { Proyección de demanda }- \text { Demanda Real } \mid}{\text { Demanda real }} \times 100
\end{gathered}
$$

Análisis del proceso de planeamiento de abastecimiento y producción

Si el análisis anterior da como resultado un asertividad menor al objetivo, se procede a analizar los otros dos procesos de abastecimiento y producción a nivel sistema, es decir, se consideran los 14 almacenes que abastece la planta de lima por cada SKU.

Para esto se compara la necesidad de Envío según la política abastecimiento vs lo producido mensualmente y lo enviado. Esto con el fin de detectar cuál de los tres eslabones es responsable por el exceso de inventario. El análisis se hace por el método de descarte.

En la figura 39 se puede observar que el abastecimiento para el SKU presentado tanto la producción estuvo alineada a la necesidad de abastecimiento. Esto quiere decir que se cumplió la política de abastecimiento y aun así se generaron desmedros.

\begin{tabular}{|c|c|c|c|}
\cline { 2 - 4 } & Abastecimiento & Distribución & Producción \\
\hline Semanas & Necesidad CF & Cargas CF & $\begin{array}{c}\text { Producción } \\
\text { CF }\end{array}$ \\
\hline 1 & 0 & 0 & 600 \\
\hline 2 & 160 & 600 & \\
\hline 3 & 400 & 600 & 800 \\
\hline 4 & 1800 & 800 & 800 \\
\hline Total & 2360 & 2000 & 2200 \\
\hline
\end{tabular}

Figura 41. Comparación de planeamiento entre abastecimiento, producción y distribución para el SKU 250068 para el sistema

Si lo producido fueses mucho mayor a la necesidad de abastecimiento y generara un envío de más de 40\%, se concluye en el área de producción es la que está generando excesos en la cadena de planificación. 
Finalmente, se presentan un resumen de los criterios usados para el análisis de la planificación de inventarios :

Tabla 8

Criterios de clasificación por tipo de causa

\begin{tabular}{ccc}
\hline Tipo de Causa & $\begin{array}{c}\text { Criterio de } \\
\text { planificación de stock }\end{array}$ & Indicador \\
\hline Producción en exceso & $\begin{array}{c}\text { Producción total superó el } \\
\text { abastecimiento en } 40 \% \\
\text { Lanificación de inventarios }\end{array}$ & $\begin{array}{c}\text { Stocks de reorden muy } \\
\text { alto } \\
\text { estuvieron alineadas dentro del } \\
40 \%\end{array}$ \\
& $\begin{array}{c}\text { Baja asertividad de la } \\
\text { demanda }\end{array}$ & $\begin{array}{c}\text { SKU vencido no llegó al objetivo } \\
\text { de asertividad de la demanda }\end{array}$ \\
\hline
\end{tabular}

Nota: Derechos reservados Vilela, 2017

Con estos criterios se realizó la clasificación de cada uno de los SKUS vencidos, El resultado se muestra en la tabla 9.

Tabla 9.

Clasificación de causa raíz de planificación deficiente

\begin{tabular}{ccccc}
\hline \multicolumn{5}{c}{ Criterio de clasificación } \\
\hline $\begin{array}{c}\text { Causas de planificación de } \\
\text { stock deficiente }\end{array}$ & $\begin{array}{c}\text { Baja asertividad } \\
\text { de la demanda }\end{array}$ & $\begin{array}{c}\text { Producción } \\
\text { en exceso }\end{array}$ & $\begin{array}{c}\text { Stock de reorden } \\
\text { alto }\end{array}$ & $\begin{array}{c}\% \text { de } \\
\text { incidencia }\end{array}$ \\
\hline $\begin{array}{c}\text { Deficiencias en política de } \\
\text { Stocks }\end{array}$ & $\mathrm{x}$ & $\mathrm{x}$ & $95 \%$ \\
\hline $\begin{array}{c}\text { Baja asertividad de } \\
\text { planificación de la demanda }\end{array}$ & $\mathrm{x}$ & $\mathrm{x}$ & $\mathrm{x}$ & $5 \%$ \\
\hline
\end{tabular}

Nota: Derecho reservados Vilela, 2017.

Finalmente, de acuerdo a lo presentado, la incidencia de vencimientos en el almacén es dada en el 94\% de los casos por deficiencias en la política de stocks. Por ello, el desarrollo de la propuesta se enfocará en la política de stocks. 
Sobre el total de skus enviados al almacén durante 4 meses, se contrastaron las ventas reales de la locación con cada causa de acuerdo a los criterios establecidos en la tabla 10 . A continuación, se procederá a explicar cada uno de los criterios presentados en la figura 40, ilustrando cada uno con el ejemplo de SKU 251393 CCZ x 06

1. Análisis de la planificación

\begin{tabular}{|c|c|c|c|}
\cline { 2 - 4 } & Abastecimiento & Distribución & Producción \\
\hline Meses & Necesidad CF & Cargas CF & $\begin{array}{c}\text { Producción } \\
\text { CF }\end{array}$ \\
\hline Mayo & 6094 & 7000 & 12500 \\
\hline Junio & 6000 & 6500 & \\
\hline Julio & 9502 & 12000 & 10000 \\
\hline Agosto & 10456 & 10000 & 15000 \\
\hline Total & 32052 & 35500 & 37500 \\
\hline
\end{tabular}

Figura 42. Comparación de abastecimiento, distribución y producción para 251393 en Lima

En la figura 40 se muestra el historial de producción, necesidad de abastecimiento (política) y cargas enviadas a todos los almacenes de la región de abastecimiento Lima. Se puede comprobar que tanto la distribución como abastecimiento y producción estaban alineadas en menos 40\%. Por lo tanto, este SKU queda clasificado como stock de reorden muy alto., pues se cumplieron todas las condiciones para entregar la necesidad según la política y esto generó desmedro.

2. Análisis de la demanda

Para medir el asertividad de la demanda se consideró el pronóstico semanal acumulado al mes del sku 251393. El error fue medido a nivel semanalocación- SKU - canal.

En los meses donde se reportó el vencimiento, el SKU cumplió con el objetivo impuesto. 
Tabla 10.

Asertividad del pronóstico del SKU 251393

\begin{tabular}{ccc}
\hline Mes & $\begin{array}{c}\text { Acumulado Asertividad del } \\
\text { pronóstico semanal }\end{array}$ & Meta \\
\hline Mayo & 82 & $75 \%$ \\
& $\%$ & $75 \%$ \\
Junio & $76 \%$ & $75 \%$ \\
\hline
\end{tabular}

Nota: Derechos reservados Vilela, 2017.

Finalmente, para el ejemplo presentado el sku 251393 quedaría clasificado en las siguientes causas:

Tabla 11.

Clasificación del SKU 251393

\begin{tabular}{cccc}
\hline SKU & $\begin{array}{c}\text { Baja asertividad } \\
\text { de la demanda }\end{array}$ & $\begin{array}{c}\text { Producción de } \\
\text { stock alto }\end{array}$ & $\begin{array}{c}\text { Puntos de reorden } \\
\text { muy altos }\end{array}$ \\
\hline $251393-$ CC Z x 06 & & $x$ \\
\hline
\end{tabular}

Nota: Derechos reservados Vilela, 2017.

Finalmente, en la tabla 12 se muestran las incidencias por causas de deficiencia en la planificación de la cadena. Se puede observar que el stock de reorden alto es la principal causa que se envíen excesos de inventario a los almacenes, pues representa el $87 \%$ de las causas para los SKUS analizados

Tabla 12.

Clasificación final de skus vencidos en MEPA por tipo de causa

\begin{tabular}{clc}
\hline Tipo de Causa & Criterio de planificación de stock & $\begin{array}{c}\% \text { de SKUS que } \\
\text { cumplen con el } \\
\text { indicador }\end{array}$ \\
\hline \multirow{2}{*}{$\begin{array}{c}\text { Deficiencias en la } \\
\text { planificación de la cadena }\end{array}$} & Producción en exceso & $8 \%$ \\
& Stocks de reorden alto & $87 \%$ \\
& Baja asertividad de la demanda & $5 \%$ \\
\hline
\end{tabular}

Nota: Derechos reservados Vilela, 2017. 
Como conclusión, se presenta una tabla con las causas de vencimiento analizadas. El principal vencimiento en almacén con $80 \%$ de los skus se deben a las deficiencias en la política de stocks, luego está la producción exceso con 7\%, luego las deficiencias en operaciones con $7 \%$ y finalmente la asertividad de la demanda con 5\%.

Tabla 13

Causas de vencimiento de los almacenes de la empresa

\begin{tabular}{cc}
\hline Causas de Vencimiento & $\%$ Participación \\
\hline $\begin{array}{c}\text { Deficiencias en política de } \\
\text { stocks }\end{array}$ & $81 \%$ \\
Deficiencias en operaciones & $7 \%$ \\
de almacén & \\
Asertividad de la demanda & $5 \%$ \\
Producción en exceso & $7 \%$ \\
\hline
\end{tabular}

Nota: Derechos reservados Vilela, 2017.

Por lo tanto, la mayor oportunidad de mejora está en la política de stocks. Por ello a continuación se analizan las causas raíces que generan deficiencias en la política.

\subsubsection{Análisis de las causas raíces}

$\underline{\text { Análisis situacional de la política de stocks }}$

Actualmente, en el área de supply chain se manejan tres tipos de procesos: estratégicos, operativos y de soporte. Dentro de los procesos estratégicos, se puede observar en la figura 41, existen tres: Producción, Materiales y distribución. Las planificaciones estratégicas (a largo plazo) de estas actividades sirven para planificar las capacidades y compras de materiales y recursos (negociones con proveedores), presupuestos y costos en periodos mensuales, trimestrales y anuales. Actualmente no existe ningún proceso que se dedique a la planificación de stock 


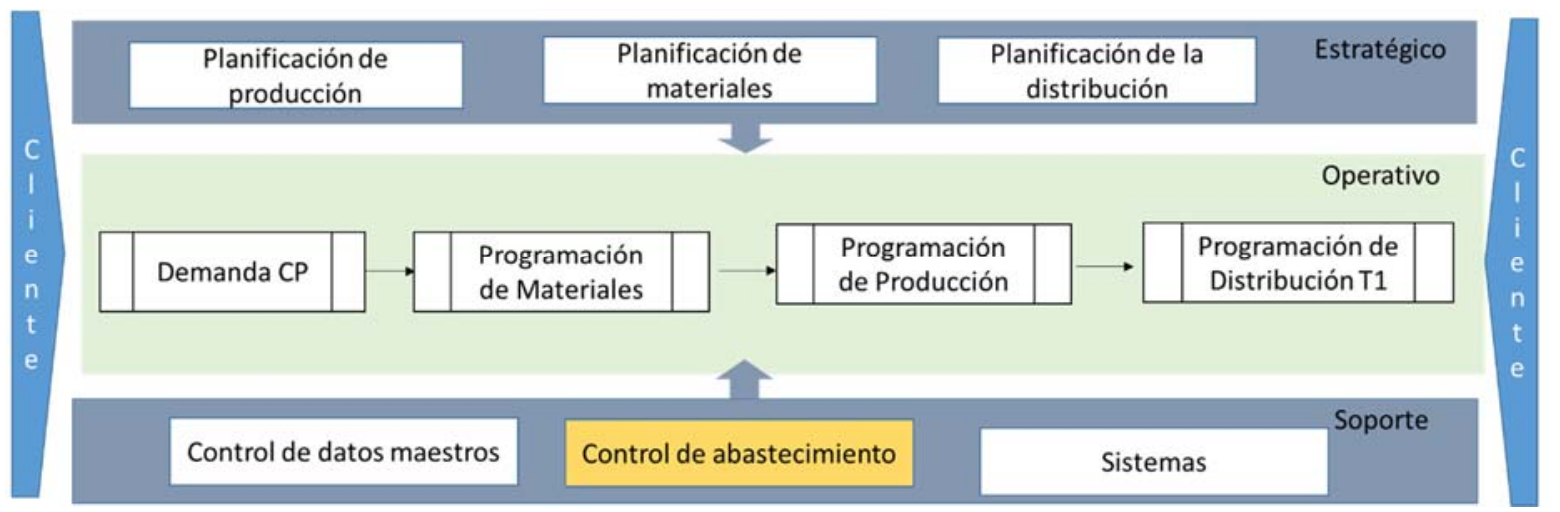

Figura 43. Mapa de procesos principales actual del área de Supply Chain

Dos años atrás, el proceso de definición de la política de inventarios era una tarea que pertenecía a los programadores de la distribución de cargas de cada locación. Cada uno de los programadores establecía el nivel de existencias mínimo que debía tener cada locación por SKU. No existía una centralización de la tarea y por lo tanto el proceso de definición estaba sujeto al criterio de cada uno de los programadores.

El año pasado la empresa creó el área de abastecimiento, la cual centralizaría todo el seguimiento de los inventarios para evitar desabastos en las locaciones. Una de las tareas impuestas fue la definición de política de inventarios. Por diversos motivos, el área aún no ha asumido esta tarea, y solo reparte algunos lineamientos para las otras áreas. En la figura 42, se presenta el flujo actual de los procesos entre las áreas de supply para la operación diaria. 


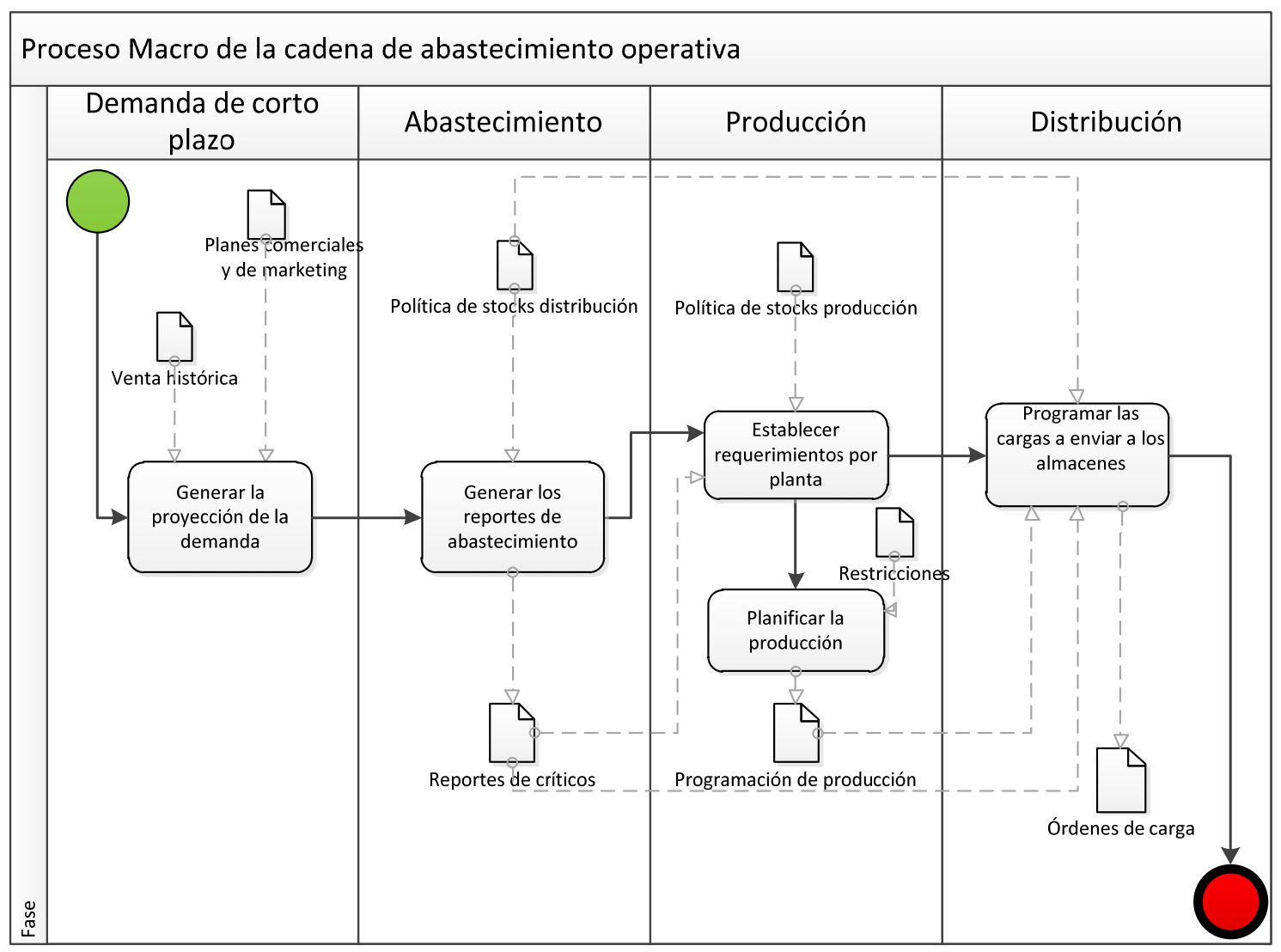

Figura 44. Macro proceso actual del planeamiento operativo de la cadena de suministro

A continuación, se explica cada uno de los procesos:

1. Generar proyección de la demanda: El área de demanda de corto plazo (DCP) proyecta la demanda semanal en el sistema de pronósticos, con el input de venta histórica y los planes comerciales y de marketing. Esta demanda proyectada es subida al sistema AV de abastecimiento.

2. Generar reportes de abastecimiento: El área de abastecimiento ingresa al sistema AV, donde está registrada la política de stocks de distribución y la demanda subida por DCP. Ahí genera un reporte de coberturas a nivel nacional con corte de 7am. El reporte de coberturas indica por cada combinación Locación-SKU en qué estado de alerta se encuentra el SKU (crítico, seguro, parar) de acuerdo al inventario de las 7am, las cargas programadas y la política de stocks de distribución por locación sku ingresada en el sistema para cada combinación. Luego se actualiza la información de las coberturas en Microsoft Excel con el inventario y cargas efectuadas de las 9am y se reparte el informe final "Reporte de Crítico". En este se establece la necesidad de cada locación-sku restando la demanda proyectada diaria para las siguientes dos semanas y los inventarios actualizados.

3. Establecer requerimientos por planta: El área de producción recibe el reporte de críticos y lo traslada a un Ms Excel donde se sumarizan las demandas y stocks de cada locación-sku según la planta que las abastece. Luego se resta la demanda del stock 
total obtenido y se obtiene la necesidad de cada planta. A esta necesidad se le agrega la política de stock de producción por planta-sku y se obtiene el requerimiento de producción de cada planta.

4. Planificar la producción. El requerimiento de producción por cada planta es subido a una macro en Ms Excel donde se le agregan las restricciones de cada planta por línea (lotes mínimos, horarios, batches, velocidades de línea, etc.). Se realiza la programación de la producción para la siguiente semana y se ajusta el plan de producción de la semana de acuerdo a los resultados y se comparte a distribución.

5. Programar las cargas a enviar a los almacenes: El área distribución recibe el plan semanal de producción y el reporte de críticos y programa sus cargas diarias y planificación semanal de acuerdo a los stocks disponibles y las necesidades de cada locación.

En el anterior proceso se puede observar que no existe una unión entre la política que usa producción como la de distribución. Cada área trabaja la política separadamente y no existe una integración como cadena. Según las entrevistas con el área, este problema se da también porque no existe una herramienta adecuada que facilite esta integración. Este es uno de los principales problemas que impacta en las deficiencias de política de stock. Para entender detalladamente cada uno de los problemas, se realizó una entrevista al área de abastecimiento y se realizó un diagrama de Ishikawa con los principales problemas que generan deficiencias en la política de stocks presentado en la figura 43 .

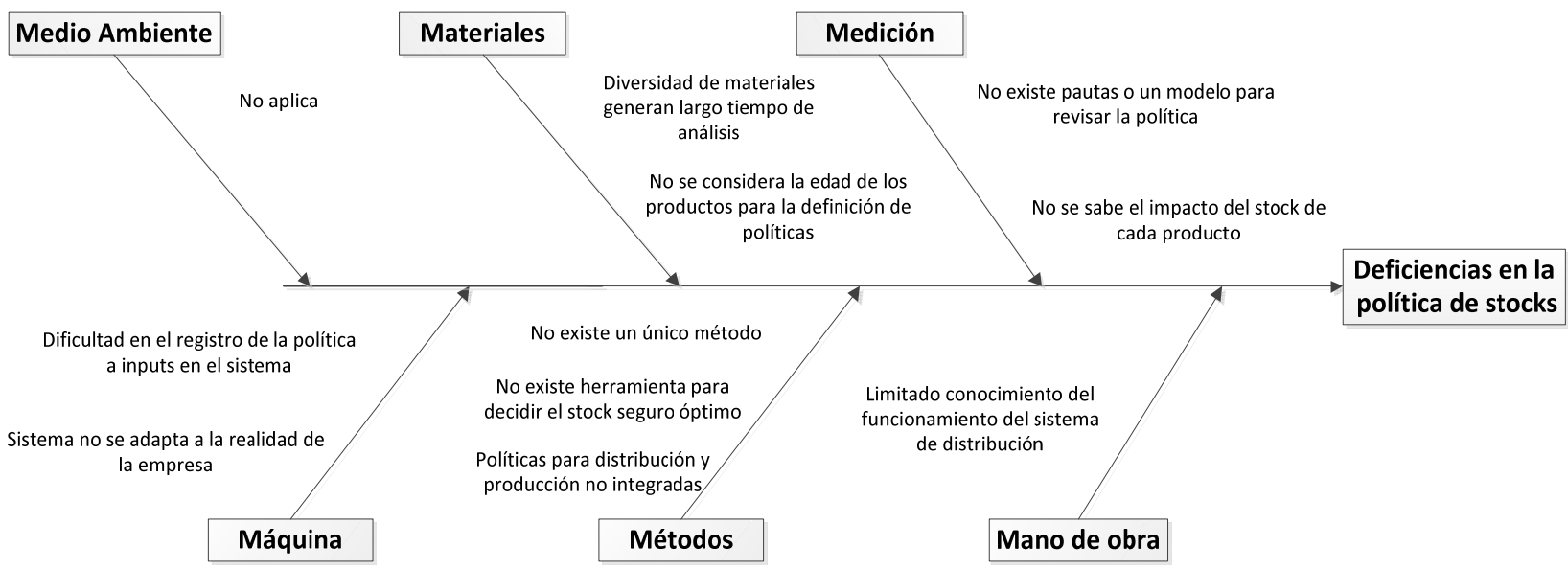

Figura 45. Diagrama de Ishikawa de política de stocks

Los focos principales del problema se explican a continuación: 
- Mano de obra:

- Limitado conocimiento del funcionamiento del sistema distribución: El sistema "AV", que se utiliza para la planificación del abastecimiento y producción, tiene muchas funcionalidades en inglés que no son del todo comprendidas por los analistas. Esto es una limitante para poder explotar la herramienta en la definición de la política de inventarios

- Métodos:

- No existe un único método para la definición de la política: La política de inventarios fue hecha inicialmente junto con los consultores del sistema "AV" como parte de la instalación del programa. Luego, de la configuración inicial cada programador de distribución movía la política de acuerdo al criterio propia de cada uno. En la tabla 12, se puede observar un ejemplo de dos criterios muy distintos utilizados por dos programadores que comparten un SKU para un solo CDA.

Tabla 14.

Diferencias en stock seguro para un SKU de un CDA

Nota:

\begin{tabular}{cccc}
\hline SKU & Origen & Destino & Stock Seguro \\
\hline 252670 & PLPUC & CDA 1 & 4.0 días
\end{tabular}

$\mathrm{Se}$

$\begin{array}{llll}252670 & \text { PLCLL } & \text { CDA } 1 & \text { días }\end{array}$

muestran las diferencias entre stock seguro de dos plantas en Lima del año 2017 para un solo SKU. Derechos reservados Vilela 2017.

- No existe una herramienta que soporte la decisión del stock seguro óptimo: Actualmente el software usado da un resultado de impacto del stock seguro definido a un nivel muy detallado que no permite ver el impacto en la locación como sistema total. Por lo tanto, decidir la cantidad exacta de stock seguro para cada SKU se basa más en el historial de stocks definidos anteriormente sin un sustento metodológico. 
- Política de distribución y producción no integradas: Cada área maneja su propia política y no existe una validación entre ambas para consensuar la verdadera necesidad del almacén.

- Máquina

- Dificultad en el registro de la política a inputs del sistema: El sistema está separado en tres puntos de reorden: Crítico, Seguro, Parar, Exceso. Este es un método único de este sistema que no se adapta a las enseñanzas tradicionales sobre un único punto de reorden, lo que hace difícil la definición de cada punto.

- Sistema no se adapta a la realidad de la empresa: El sistema no puede manejar una matriz de abastecimiento multi punto, donde se pueda abastecer a una región con distintas plantas, lo que no permite que se pueda usar el módulo de producción y distribución completamente y dificulta el seguimiento de los niveles de inventario en cada locación

- Medición:

- No se tiene pautas para la revisión de la política: La política no se revisa. No existe pautas que establezca la frecuencia de revisión o el método de revisión. Así también, no existe un criterio claro de aprobación de la política. Cada programador asume responsabilidad por el inventario que maneja.

- No se sabe el impacto del stock de cada producto: No se tiene claro en cuánto y en qué impacta cada unidad adicional de stock que se añada al punto de reorden.

- Material

- No se considera la edad de los productos en la definición de la política: Como input para modificar la política de inventarios nunca se ha considerado la edad de los productos. 
- Tiempo excesivo de análisis por diversidad de materiales con distintas edades y demandas: la empresa cuenta con 160 skus activos vigentes que tienen diferentes edades y distribuciones de proyección de demanda. Solo en la región LIMA, se cuenta con 20 locaciones, lo que hace un total de 320 combinaciones que deben revisarse. Por lo que es imperativo, tener un sistema de clasificación en la revisión de la política

La política de stocks presenta diferentes aristas que deben ser consideradas para el planteamiento de la solución. En la tabla 13, se priorizan los puntos que serán solucionados considerando dos aristas:

- Impacto: Se refiere a al potencial de beneficio que puede otorgar la resolución de ese punto. Cuánto influye este punto en el problema total.

- Urgencia: Referido a la velocidad con la que se debería resolver el problema. Si el problema permite el funcionamiento adecuado con soluciones alternas o temporales es de prioridad baja.

A estos campos se les coloca un valor en escala donde 1 significa Crítico y 4 significa Bajo. Luego de tener ambos valores, se asigna una prioridad de acuerdo a la figura 44.

\begin{tabular}{|c|c|c|c|}
\hline Type & Impacto & Urgencia & Prioridad interna \\
\hline SR & 1 - Crítico & 1 - Crítico & 1 - Urgente \\
\hline SR & 1 - Crítico & 2 - Alto & 1 - Urgente \\
\hline SR & 1 - Crítico & 3 - Medio & 2 - Alto \\
\hline SR & 1 - Crítico & 4 - Bajo & 3 - Medio \\
\hline SR & 1 - Crítico & 5 - En planificación & 3 - Medio \\
\hline SR & 2 - Alto & 1 - Crítico & 1 - Crítico \\
\hline SR & 2 - Alto & 2 - Alto & 2 - Alto \\
\hline SR & 2 - Alto & 3 - Medio & 2 - Alto \\
\hline
\end{tabular}

Figura 46. Matriz de prioridades de IBM.

Se realizó una entrevista con los analistas del área de abastecimiento para colocar priorizar los problemas. Los resultados se muestran en la tabla 15. 
Tabla 15.

Matriz de prioridades para la deficiencia de política de stocks

\begin{tabular}{cccc}
\hline Problemas & Impacto & Urgencia & Prioridad \\
\hline No existe un único método & 2 & 2 & Alto \\
No existe pautas para la revisión & 2 & 1 & Crítico \\
No se sabe el impacto del stock de cada producto & 1 & 1 & Urgente \\
Largo tiempo de análisis por diversidad de materiales & 2 & 3 & Alto \\
No se considera la edad de los productos & 2 & 3 & Alto \\
Políticas no integradas con producción y distribución & 3 & 2 & Alto \\
El sistema no se adapta a la realidad de la empresa & 1 & 4 & Medio \\
Limitado conocimiento del sistema & 3 & 4 & Bajo \\
Dificultad en el registro de política en el sistema & 4 & 4 & Bajo \\
No existe herramienta para decidir el stock óptimo & 2 & 4 & Medio \\
\hline
\end{tabular}

Nota: Derechos reservados Vilela, 2017

Los problemas categorizados como Alto, Crítico y Urgente son seleccionados y reagrupados en dos metodologías de solución presentados en la tabla 16.

Tabla 16.

Metodologías de solución para política de stocks

\begin{tabular}{cc}
\hline Causas Raíz & Metodología \\
\hline No existe un único método & Mejora de \\
No existe pautas para la revisión & Procesos \\
margo tiempo de análisis por diversidad de & \\
No se considera la edad de los productos & Modelo para la \\
política de stock
\end{tabular}

Nota: Derechos reservados Vilela, 2017 


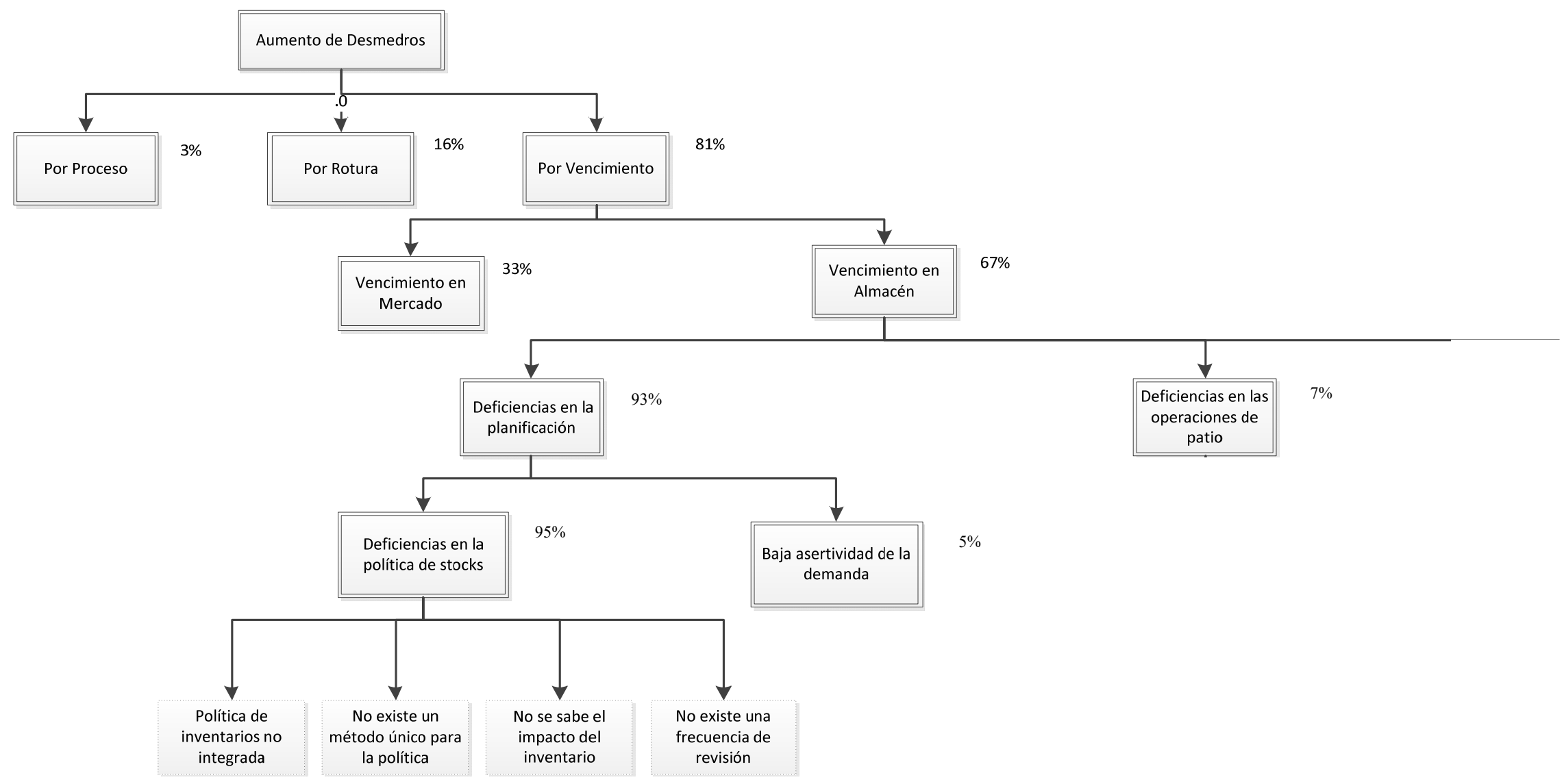

Figura 47. Diagrama de árbol de causa raíz. Derechos reservados Vilela,2017 
Resumiendo, las causas raíces se presentan en la figura 33 con sus respectivos modelos.

\subsubsection{Formulación de la hipótesis}

Finalmente, se presentan las causas raíces encontradas en la formulación de variables de la propuesta en la tabla 17:

Tabla 17.

Variables de la propuesta

\begin{tabular}{cc}
\hline Variable Dependiente & Variables independiente \\
\hline $\begin{array}{c}\text { Aumento de desmedros en } \\
\text { una empresa de consumo } \\
\text { masivo }\end{array}$ & Niveles de inventario \\
\hline
\end{tabular}

Nota: Derechos reservados Vilela, 2017.

De acuerdo a lo presentado en el punto anterior, se formula la siguiente hipótesis: "Mediante la mejora en el proceso de definición de la política de inventarios se lograrán reducir los desmedros ocasionados por vencimiento en una empresa de consumo de masivo, generando reducción de costos y aumento en el nivel de servicio". 


\section{Capítulo III: Elaboración de la propuesta}

En este capítulo se desarrollará la propuesta de solución según el alcance definido en el capítulo anterior. Se ejemplificará la propuesta con los datos del almacén MEPA para luego replicarlo a nivel nacional.

\subsection{Objetivos de la propuesta de solución}

La propuesta de mejora del proyecto es la variable independiente para solucionar el problema principal identificado, aumento de desmedros por vencimiento. Este problema está asociado a las causas raíces de Redefinición del proceso de política de stocks. Por ello, se aborda el problema desde el frente estratégico/planeamiento y operativo para asegurar la reducción de vencimientos.

De acuerdo a lo visto en el capítulo 2, la causa principal para vencimientos son las deficiencias en el método, medición y estandarización de la política de stocks. Por ello, la propuesta tiene como objetivo específico mejorar el proceso de definición. Para esto, se planteará un modelo de inventarios y proceso que soporte este modelo.

Tabla 18.

Objetivos de la propuesta

\begin{tabular}{|c|c|c|c|}
\hline Objetivo Principal & Objetivos Generales & Objetivos específicos & Herramienta \\
\hline \multirow{2}{*}{$\begin{array}{c}\text { Mejorar la gestión } \\
\text { de inventarios para } \\
\text { evitar vencimientos }\end{array}$} & $\begin{array}{c}\text { Eliminar } \\
\text { deficiencias política } \\
\text { de stocks }\end{array}$ & $\begin{array}{c}\text { Mejorar proceso para de la } \\
\text { política de stocks }\end{array}$ & Gestión por procesos \\
\cline { 2 - 4 } & $\begin{array}{c}\text { Establecer un método para la } \\
\text { política de stocks }\end{array}$ & $\begin{array}{c}\text { Modelo de política de } \\
\text { stocks }\end{array}$ \\
\hline
\end{tabular}

Nota: Derechos reservados Vilela, 2017. 


\subsection{Desarrollo de la propuesta de solución}

En esta sección se desarrollará la propuesta de mejora para la definición de política de stock y la mejora en los controles de los procesos en el almacén MEPA

\subsubsection{Propuesta para mejora del proceso definición de política de stocks}

Una de las causas raíces para el aumento de vencimiento son las deficiencias en la política de stocks. Los puntos de reorden establecidos para los SKUS son demasiado altos generando vencimientos en el almacén.

Para esta causa la propuesta se basará en el mejorar el proceso de definición de la política de stocks considerando las deficiencias encontradas y estableciendo un sistema para la toma de decisiones basado en los casos de éxitos investigados.

La descripción de la propuesta se presentará en tres partes:

- Diseño

- Desarrollo del modelo

- Plan de implementación

\subsubsection{Diseño}

Desde el año pasado, se ha visto un incremento en los costos de desmedros, sobrepasando a más del $9 \%$ de lo asignado en el presupuesto. Se presentó en detalle que a nivel compañía el $88 \%$ de estos desmedros son del tipo de vencimiento. En el caso de la locación elegida, se analizó que el origen de estos vencimientos proviene de los almacenes y son causados en un $70 \%$ por deficiencias en la política de stocks.

En cada uno de las causas raíces presentadas en el diagrama de Ishikawa del capítulo 2, se evidencia la falta de integridad entre las distintas áreas para determinar y hacer uso de una política de stock. No existe un único método para determinar el nivel de inventarios en la cadena de abastecimiento, por ello existe una gran variabilidad en los vencimientos y desabastecimientos incluso de un mismo SKU en locaciones de una misma región. Esta problemática resalta que cada uno de los procesos que conforman la cadena de planeación actúan como islas y no como una cadena para la planificación de los productos. No existe 
una política de stocks normalizada, medible y desplegada en toda la cadena que de dirección a las actividades realizadas por todas las áreas.

En la empresa, la política de stocks es llevada como un número estático que se registra en el sistema y dispara la distribución o la producción, según quién la haya establecido. No existe un enfoque de procesos sobre la política. Por lo tanto, se carece de actividades de seguimiento, una definición estándar de cómo establecerla y un claro entendimiento de cómo afecta el número a otros eslabones en la cadena. La propuesta de desarrollo está centrada en cambiar este enfoque y crear un proceso para la definición de la política de stock y definir como debe interactuar en el proceso de planificación de la cadena de abastecimiento.

La gestión por procesos permite la integración de los objetivos individuales en una estrategia común orientada a las metas de la empresa. Se eligió este enfoque porque aporta una visión de cadena de valor y de sus relaciones internas La gestión por procesos requiere de una serie de pasos para la caracterización del proceso. Para asegurar la mejora continua de ese proceso, la metodología empleada será el círculo de Deming, en su reciente versión, el P (Plan) D (Do) S (Study) A (Act).

Para esto se estructura la propuesta de acuerdo a lo presentado en la tabla 19. En Primer lugar, se iniciará por la actividad de Planear. En esta sección, se caracterizará el proceso estableciendo lineamientos del proceso con sus objetivos, la descripción de la voz del cliente y su traducción al SIPOC. Así también, se diagramará el impacto del nuevo proceso en el planeamiento de la cadena de abastecimiento. Por otro lado, se presentará el modelo de inventarios que se implementará y se explicará cada uno de los pasos. En la sección de Hacer, se desarrollará cada uno de los pasos del modelo ajustados a la situación de la locación MEPA. Se realizará la segmentación de los productos y se presentará la matriz de costos. En tercer lugar, en la sección de Estudiar, se describirán las actividades de seguimiento y medición que se deben realizar para analizar los resultados de los indicadores. Finalmente, en Actuar se presenta los pasos a seguir para una implementación de mejoras. 
Tabla 19. Cronograma de la propuesta de definición del proceso de política de stocks

\begin{tabular}{l}
\hline Cronograma de la propuesta \\
\hline 1. Planear \\
\hline 1.1. Definición de lineamientos \\
1.2. Estandarización del proceso \\
1.3.1. Caracterización del proceso \\
1.3.2. Análisis del modelo propuesto \\
1.4 Estandarización de procesos \\
\hline 2. Hacer \\
\hline 2.1. Lineamientos de la política \\
2.2. Estandarización del proceso \\
2.2.1. Mapa de procesos de Supply \\
2.2.2. SIPOC de la definición de niveles de stocks \\
2.2.2.1. Presentación del modelo de inventarios \\
2.2.3. Rediseño del flujo de planeamiento \\
3. Estudiar \\
3.1. Indicadores \\
\hline 4. Actuar \\
\hline 4.1 Plan de implementación de mejoras
\end{tabular}

Nota: Derechos Reservados Vilela, 2017.

\subsubsection{Desarrollo del modelo}

\subsection{Planear}

\section{Definición de lineamientos}

El proceso de política de stocks debe estar orientado en términos de valor hacia la empresa y el cliente. Sobre estos puntos se caracterizará la naturaleza, alcance y responsabilidades. Los objetivos definidos deberán estar orientados a las metas de la empresa del año o temporada, considerándose estrategias de marketing, comercial y supply.

Los lineamientos sobre naturaleza y política deberán ser inmovibles y servir como guía en casa se necesiten realizar modificaciones al proceso u modelo.

Para realizar esta definición se trabajará con el equipo de abastecimiento en una sesión de brainstorming. Los lineamientos establecidos luego deberán ser presentados a la gerencia de Supply para su aprobación y despliegue con las otras gerencias de la empresa. 


\section{Estandarización del proceso}

La política de stocks debe estar soportado sobre un proceso de planificación estandarizado y que se despliegue al área de abastecimiento y a la gerencia de Supply. El proceso debe incluir la documentación necesaria sobre la nueva planificación de stocks, así como las instrucciones detalladas para poder usar el nuevo modelo de inventarios.

Esto asegurará que se tenga un método único y ordenado para establecer los inventarios en toda la cadena. Así también, para poder tomar decisiones sobre cambios urgentes en la política de stocks se tendrá un modelo que valide con objetividad el impacto del cambio.

El proceso de planeamiento de la cadena de abastecimiento toma como input principal a la política de stocks para las proyecciones de producción, materiales y distribución. Para esto se deberá rediseñar también el flujo de información que se da entre las áreas con el nuevo proceso de planificación stocks; así también, y de acuerdo a las causas raíces, se deberá tener una actividad o herramienta que sea vínculo e integre la política de stocks de abastecimiento a producción para la planificación estratégica. Por ello, también se tendrá una herramienta que soporte esta actividad y un instructivo. Finalmente, para poder validar el impacto de cambio se debe

\section{Caracterización del proceso}

- Mapa de procesos de Supply

- $\quad$ SIPOC del proceso de planificación de stocks

- Instructivo para uso herramienta planificación de stocks

- Flujograma de la planificación de la cadena abastecimiento (operativo y estratégico)

- Diagrama de bloques de actividad requerimientos por planta

- Instructivo para actividad establecer requerimientos por planta

- Ficha de indicadores

\section{Modelo de inventarios}

Como se vio en el capítulo 2, se necesita de un modelo objetivo que permita establecer el nivel de inventarios ideal en cada locación de manera que se reduzca el inventario sin caer en desabastecimientos o sobrecostos. 
Así, la política de stocks estará soportada en un sistema de toma decisiones (DSS) para la gestión de inventarios basada sobre el modelo de inventarios adaptado del caso de éxito de Castro y Otros (2014). El modelo propuesto luego deberá ser programado en la aplicación Visual basic de Microsoft Excel para simplificar los cálculos. Esta herramienta servirá como soporte a las definiciones sobre niveles de inventario que sirven como parámetros en los sistemas transaccionales ERP (SAP, Oracle, etc.). Para el caso de tesis, el sistema es el AV.

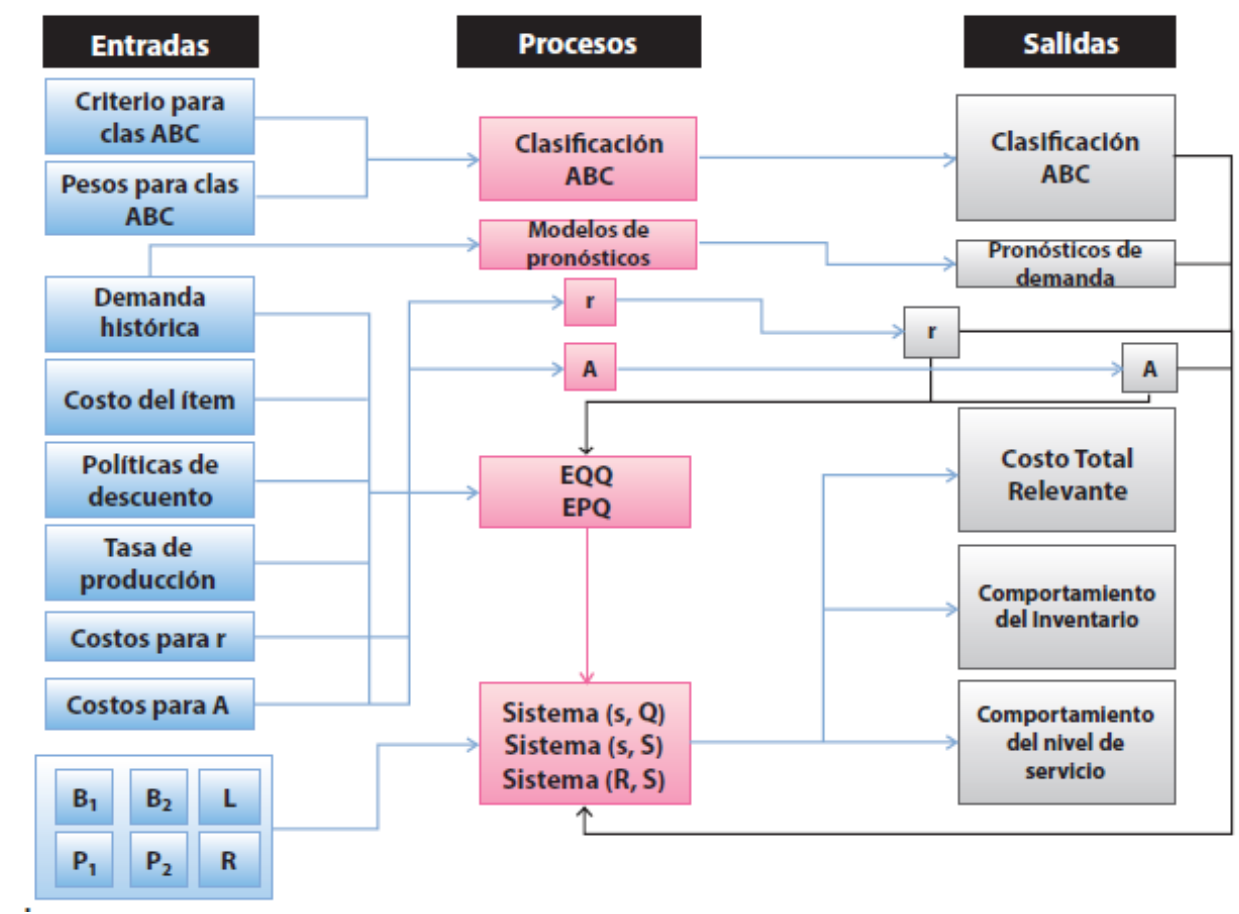

Figura 48. Perfil de modelo de Castro para DSS. Castro y Otros, 2014

En la figura 46 se presenta el perfil de modelo propuesto en el caso de éxito de Castro. El perfil es adaptable y puede ser usado en revisiones continuas o periódicas. Así, el autor sugiere hacer las adaptaciones necesarias para adecuarse a la realidad de la empresa. En la figura 47 , se presenta el perfil de modelo propuesto para la política de stocks. 


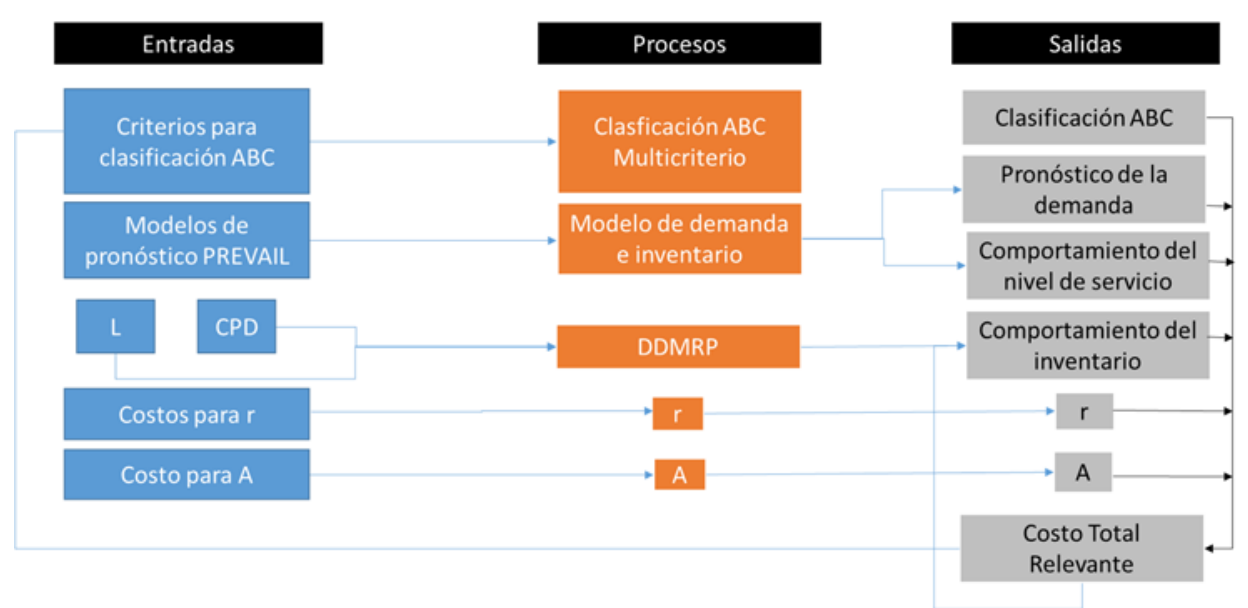

Figura 49. Perfil de modelo propuesto para niveles de inventario

El modelo ha sido adaptado de acuerdo al perfil tecnológico de la empresa y la complejidad de la red de distribución. Se han incluido las herramientas con las que actualmente se cuenta y se han estructurado en el modelo de manera que se presente información relevante para evaluar la política de inventario en términos de:

- Objetivos comerciales -> Clasificación ABC, Pronóstico de la demanda, Nivel de servicio

- Objetivos financieros -> Costos totales de los inventarios

El modelo de política de inventarios está diseñado de manera que sea un proceso donde existe una base científica/teórica para el cálculo de cada punto en el nivel de inventarios, y también se permita un feedback y ajuste dinámico sobre criterios con una base objetiva y alineada a los objetivos comerciales y no a metas individuales.

\section{Modelo de Reposición de Pedido}

Como se explicó en el capítulo anterior, la gestión de inventarios de la empresa. Se realiza en el sistema AV. Este sistema trabaja con niveles de inventario segmentados en estados de alerta partir de los cuales se realiza la programación. Si un nivel de inventario está en inseguro o crítico se dispara la necesidad enviar inventario hasta llegar a un nivel seguro. En la figura 48 se visualiza todos los estados que actualmente se tienen en la empresa. 
Para poder diseñar el modelo de inventarios se proponen 2 tipos de modelos que serán

\begin{tabular}{|l|l|l|l|l|}
\hline \multicolumn{2}{|c|}{ Punto Crítico } & \multicolumn{2}{c}{ Punto Seguro } & Punto Parar \\
\hline Crítico & Inseguro & Seguro & Parar \\
\hline
\end{tabular}

Figura 50. Estados de alerta de inventarios. Derechos reservados, Vilela

contrastados en una simulación, para determinar el mejor. A continuación, en la tabla 20, de acuerdo a la definición de cada punto en el capítulo 2, se hace una reinterpretación de la metodología original y la metodología propuesta para adaptarlos a cada uno de los puntos definidos en el sistema.

Tabla 20.

Adaptación de modelos de inventarios

Nota: Derechos reservados Vilela, 2017.

\section{Niveles de Alerta \\ Actual \\ Metodología EOQ Original}

Lead days al

CDA o 1

Crítico +

Seguro

\section{Metodología DDMRP Propuesto}

Base $=$ Lead time $\mathrm{x}$ Demanda $\mathrm{x}$ Factor de Lead time

Base $\mathrm{x} \%$ Factor Variabilidad

Crítico +Demanda Promedio x Lead Time

Mínima cantidad + Crítico + Seguro + Crítico

A decisión del programador o

Parar

Mínima

cantidad de

EOQ

Frecuencia x Demanda + Crítico +

Seguro + Crítico

envío

Demanda x \%Consumo lead + seguro +

Crítico

\begin{tabular}{lcl}
\hline Alto & $\begin{array}{c}\text { A decisión del } \\
\text { programador }\end{array}$ & Exceso EOQ \\
\hline
\end{tabular}

El modelo original de Castro (2014) propone la metodología EOQ para ser aplicada en la empresa, pues uno de los métodos más extendidos y tradicionales para ser aplicados por primera vez con una menor capacidad tecnológica. El experimento de Miclo (2016) argumenta que el modelo EOQ está muy desfasado y genera mejores resultados en términos del inventario balanceado. 


\section{$\underline{\text { Planteamiento del modelo de inventario }}$}

Considerando la complejidad de la red de distribución de la empresa y el perfil tecnológico de la empresa se ha escogido la metodología DDMRP para determinar los niveles de inventario. El comportamiento del nivel de servicio y la demanda estará dado por las herramientas de los sistemas Areté que tiene la empresa. Los costos se basarán en las fórmulas del modelo original. Con estas salidas se llevará seguimiento a la política. A continuación, se presentan el diseño de cada uno de los procesos:

\section{Clasificación ABC multicriterio:}

Como primer paso se debe hacer una segmentación de los productos que se manejan en la locación. Esta segmentación estará basada en tres criterios alineados a los objetivos de la empresa y servirá para segmentar el nivel de servicio que se debe tener cada producto.

- Cobertura de SKUS estratégicos: La empresa maneja una lista de SKUS que siempre deben estar en la bodega de un cliente. Esta lista se divide en distintos tipos de portafolio, el estratégico (lista de imperdonables), complementario y sin portafolio. Para poder permitir la cobertura y venta de estos SKUS, no debe haber desabastecimientos en los almacenes.

- Ventas: Se separarán los productos de acuerdo a su participación en las ventas en CU. Para esto se utilizará el historial de año 2017 de las ventas para cada sku de MEPA. Se separarán en tres grupos a los productos por rango de venta

- Márgenes de venta por SKU: Se clasificarán los SKUS en tres percentiles estableciendo un rango de aquellos que aportan más ganancias por venta de SKU.

Se realizará esta clasificación estableciendo pesos para cada una de las variables y segmentando finalmente los SKUS en tres grupos. Estos grupos servirán para hacer las adecuaciones de los rangos de la política de stocks.

\section{Modelo de demanda y nivel de servicio}

Para obtener el comportamiento de la demanda y los niveles de servicio se utilizarán las dos herramientas que actualmente posee la empresa de la compañía Areté. Estos dos sistemas nos dan el pronóstico de la demanda a nivel de día-locación-sku, la cual servirá para hacer la simulación de cada SKU y presentar los resultados. El sistema da detalle de 
cada curva de pronóstico que se ajuste mejor a la venta histórica del producto con un método patentado. Con esta curva de pronóstico y el input de lead time, hace el cálculo de nivel de servicio por cada punto de seguridad. La consulta donde se hace el cálculo de nivel de servicio, no es flexible para incluirla fuera del programa. Por lo tanto, se realizará una estimación lineal con la información obtenida del programa para hallar la curva de los pronósticos y poder usarla en las simulaciones de niveles de servicio y toma de decisiones.

\begin{tabular}{|c|c|c|c|c|c|c|c|c|c|}
\hline \multicolumn{10}{|c|}{ Whse-Products } \\
\hline Whse & Method & Prod & $*$ & Lead Days & Plan Freq & Reac Days & Targ SL & Targ Safe DS & Targ Avg DS \\
\hline MEPA & Deploy & 255367 & & 1 & 1 & 2 & 98.0 & 4.37 & 4.37 \\
\hline MEPA & Deploy & 255369 & & 1 & 1 & 2 & 98.0 & 4.48 & 4.48 \\
\hline MEPA & Deploy & 255389 & & 1 & 1 & 2 & 98.0 & 5.73 & 5.73 \\
\hline MEPA & Deploy & 255390 & & 1 & 1 & 2 & 98.0 & 6.41 & 6.41 \\
\hline MEPA & Deploy & 255391 & & 1 & 1 & 2 & 98.0 & 4.20 & 4.20 \\
\hline MEPA & Deploy & 255392 & & 1 & 1 & 2 & 98.0 & 4.25 & 4.25 \\
\hline MEPA & Deploy & 255403 & & 4 & 1 & 5 & 98.0 & 11.06 & 8.06 \\
\hline MEPA & Deploy & 255404 & & 4 & 1 & 5 & 98.0 & 9.73 & 6.73 \\
\hline MEPA & Deploy & 255405 & & 4 & 1 & 5 & 98.0 & 43.04 & 40.04 \\
\hline MEPA & Deploy & 255414 & & 4 & 1 & 5 & 98.0 & 60.00 & 57.00 \\
\hline
\end{tabular}

Figura 51. Imagen del editor de nivel de servicio

\section{Metodología DDMRP}

Para este caso, se utilizará las fórmulas descritas en el capítulo 1 para los buffers del DDRP, que clasifican al inventario en tres zonas, las cuales se han adaptado al sistema que utiliza el software AV:

\section{Nivel Crítico}

Para el nivel crítico, que indica un despacho inmediato para no generar desabastecimiento se ha elegido la fórmula de la zona roja la cual es descrita a continuación

$$
\begin{gathered}
\text { Crítico }=\text { Zona roja base }+ \text { Zona roja segura } \\
\text { Zona roja base }: d \times L x f l
\end{gathered}
$$

Zona roja segura: zona roja base $x f v$ 
Donde

d: demanda promedio diaria

L: lead time expresado en días

fl: factor de lead time

fv: factor de variabilidad de la demanda

\section{Nivel Seguro}

El nivel seguro es aquel punto que, al cumplirse, cubre todas las variabilidades y permite lograr un adecuado nivel de servicio. Está dado por la siguiente fórmula:

$$
\text { Nivel Seguro }=\text { Crítico }+ \text { Zona Amarilla }
$$

$$
\text { Zona Amarilla }=d \times L \times 100 \%
$$

Donde:

d: demanda promedio diaria

L: lead time expresado en días

\section{Nivel Alto}

El nivel alto determina hasta cuánto se debe enviarse a la locación, a través de la siguiente fórmula

$$
\begin{gathered}
\text { Alto }=\text { Crítico }+ \text { Seguro }+ \text { Zona verde } \\
\text { Zona verde }=d x L \times f l
\end{gathered}
$$

$\mathrm{O}$

Zona verde $=M O Q$

$\mathrm{O}$

Zona verde $=$ Ciclo de pedido 
Donde:

d: demanda diaria promedio

fl: factor de lead time

MOQ: cantidad mínima de pedido

Ciclo de pedido: Establecida por una frecuencia de días a la que debe abastecerse un SKU

En el caso del modelo DDMRP es necesario realizar una segmentación de los productos más detallada que permita elegir los factores de lead time y variabilidad, así como el método para calcular la zona verde.

\section{Costo de ordenar un pedido}

$$
\boldsymbol{A}=\frac{\text { costo de ordenar en el periodo }}{\# \text { ordenes generadas en el periodo }}
$$

Los costos de ordenar un pedido incluirán los siguiente:

- Insumos: Costo de la materia prima utilizada por elaborar una caja física de un SKU. El costo varía por planta y se expresa como un factor del volumen.

- Concentrado: Costo de elaborar un producto con un jarabe de la marca del consorcio es expresado como un porcentaje de precio bruto de venta.

- Costo de Fabricación (energía): La energía que se utiliza para la fabricación por cada SKU.

- Costo de Flete: Costo por caja física del transporte y operación de carga a los trailers para su despacho a los almacenes. 


\section{Costo de mantener el Inventario}

La empresa posee almacenes propios y almacenes terciarizados. En el caso de estudio, se trata de un almacén terciarizado, al cual se le paga por el servicio de almacén, distribución y venta una tarifa (Fee de distribución) por cada caja física transportada. Por ello, solo este dato se considerará como costo de mantenimiento

$$
r=\frac{\text { costos anuales }}{\text { inventario anual valorizado al costo }}
$$

Donde costo anual incluye:

- Fee de distribución: Pago por caja transportada al CDA.

\section{Costo total de relevante}

$$
\text { Costo de ordenar }+ \text { Conste de mantener }=\text { Costo total }
$$

Para el costo total del inventario se sumarán ambos costos, los cuales se mostrarán en la herramienta DSS para poder tomar decisiones en base a los costos generados en la simulación.

\subsection{Hacer}

$\underline{\text { Lineamientos de la política }}$

Objetivo de la política:

Para la propuesta se han traducido los principales objetivos de la actual coyuntura al modelo. 
Tabla 21.

Objetivos del modelo

\begin{tabular}{lll}
\hline Área & Objetivo de la empresa & Objetivos del modelo \\
\hline Supply & $\begin{array}{l}\text { Asegurar la satisfacción de los } \\
\text { clientes disminuyendo los } \\
\text { desabastecimientos }\end{array}$ & $\begin{array}{l}\text { Lograr niveles de servicio aceptables } \\
\text { por locación } \\
\text { Reducir los costos de inventario y } \\
\text { Comercial }\end{array}$ \\
\cline { 2 - 2 } & $\begin{array}{l}\text { Aumentar los márgenes de } \\
\text { ganancia sobre las ventas }\end{array}$ & $\begin{array}{l}\text { inventario que satisfaga las } \\
\text { necesidades }\end{array}$ \\
& Asegurar la cobertura de los & $\begin{array}{l}\text { Priorizar niveles de servicio por } \\
\text { segmentación de SKUS }\end{array}$ \\
\hline
\end{tabular}

Nota: Resumen de los resultados obtenidos en el focus group del área de abastecimiento. Derechos reservados Vilela, 2017

Naturaleza de la política:

- La política de stocks hace referencia al nivel de inventario que cada locación debe tener para alcanzar las metas de la empresa.

- La política no es estática y debe estar sujeta a revisiones constantes. Inicialmente, se debe manejar al menos dos revisiones, una para la temporada alta y otra para la temporada baja.

- Solo debe existir una política establecida por locación en el periodo que se defina. Inicialmente, se manejará la política de la temporada y la política de largo plazo.

Alcance de la política:

- La política está a nivel de locación - segmento de productos y es aplicable solo a la locación para la cual está definida y en el periodo especificado. Cuando se requiera de una política a un nivel mayor (Región, Planta) se debe realizar el cálculo a través de la actividad llamada "Niveles de proceso"

Responsabilidades:

- La política es centralizada solo por el área de Abastecimiento, recibiendo retroalimentación de los gestores de almacén, equipo de demanda, producción y los planificadores de las áreas comercial y de marketing. 


\section{$\underline{\text { Mapa de procesos }}$}

La demanda de largo plazo es llevada por el Gerencia de planeamiento estratégico bajo un proceso estándar y riguroso. La política de stocks es un dato que no está normalizado y no es llevado oficialmente aún por el área de abastecimiento. Actualmente, el área de abastecimiento solo lleva el control del abastecimiento, proceso resaltado en amarillo, que es una tarea de soporte a las funciones operativas de la cadena. En la figura 38, se presenta la propuesta sobre la política de stocks en la empresa. Se crea un proceso de planificación de la política stocks como ámbito estratégico de Supply Chain. Este nuevo proceso, deberá ser llevado por el área de abastecimiento junto su proceso actual de control.

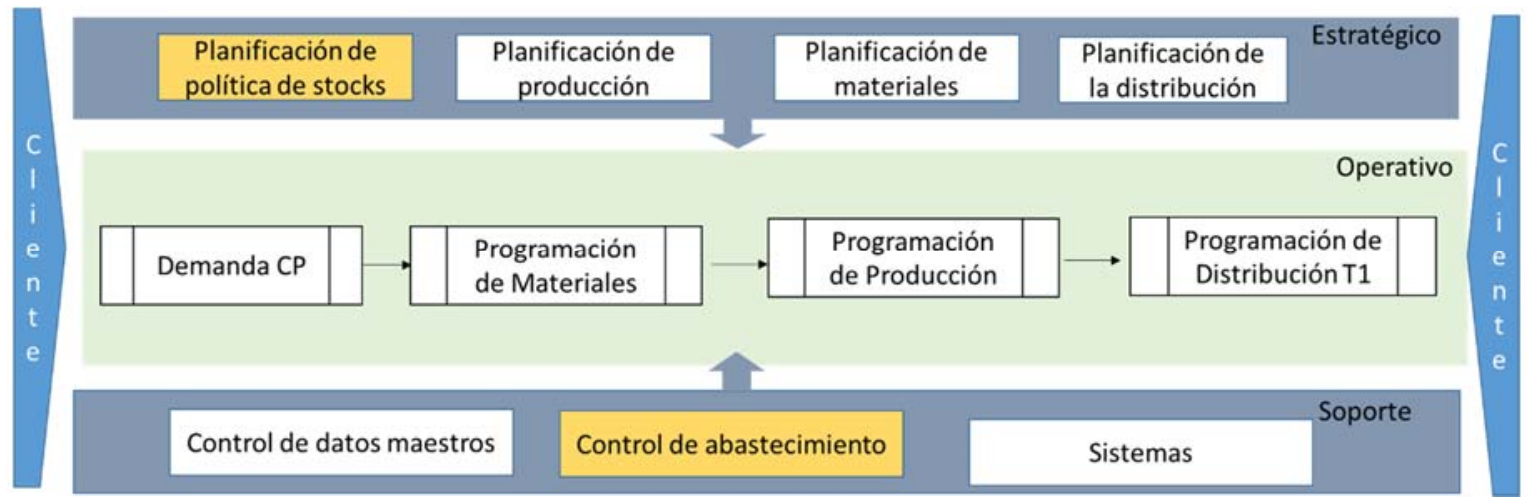

Figura 52. Mapa de procesos principales propuesto para el área de Supply Chain. Derechos reservados Vilela, 2017

De esta manera, la política de stocks deberá tener consideraciones especiales cuando se trate de planificaciones a largo plazo (anuales, semestrales, etc.) el stock de seguridad. Al tratarse de un proceso estratégico, se lleva como una actividad transversal que debe de recoger información de todos los procesos operativos de la cadena para asegurar su correcto funcionamiento y alineación a objetivos. 


\section{$\underline{\text { SIPOC de proceso de planificación de stocks }}$}

En la figura 39, se presenta el diagrama SIPOC del proceso de definición de la política de stocks. En primer lugar, se tiene la lista de proveedores, con sus respectivas entradas. Así también, se indican el orden de cada subproceso y el output final de cada uno. Así también, se presenta un cuadro de factores críticos por cada sub proceso para asegurar la calidad del resultado.

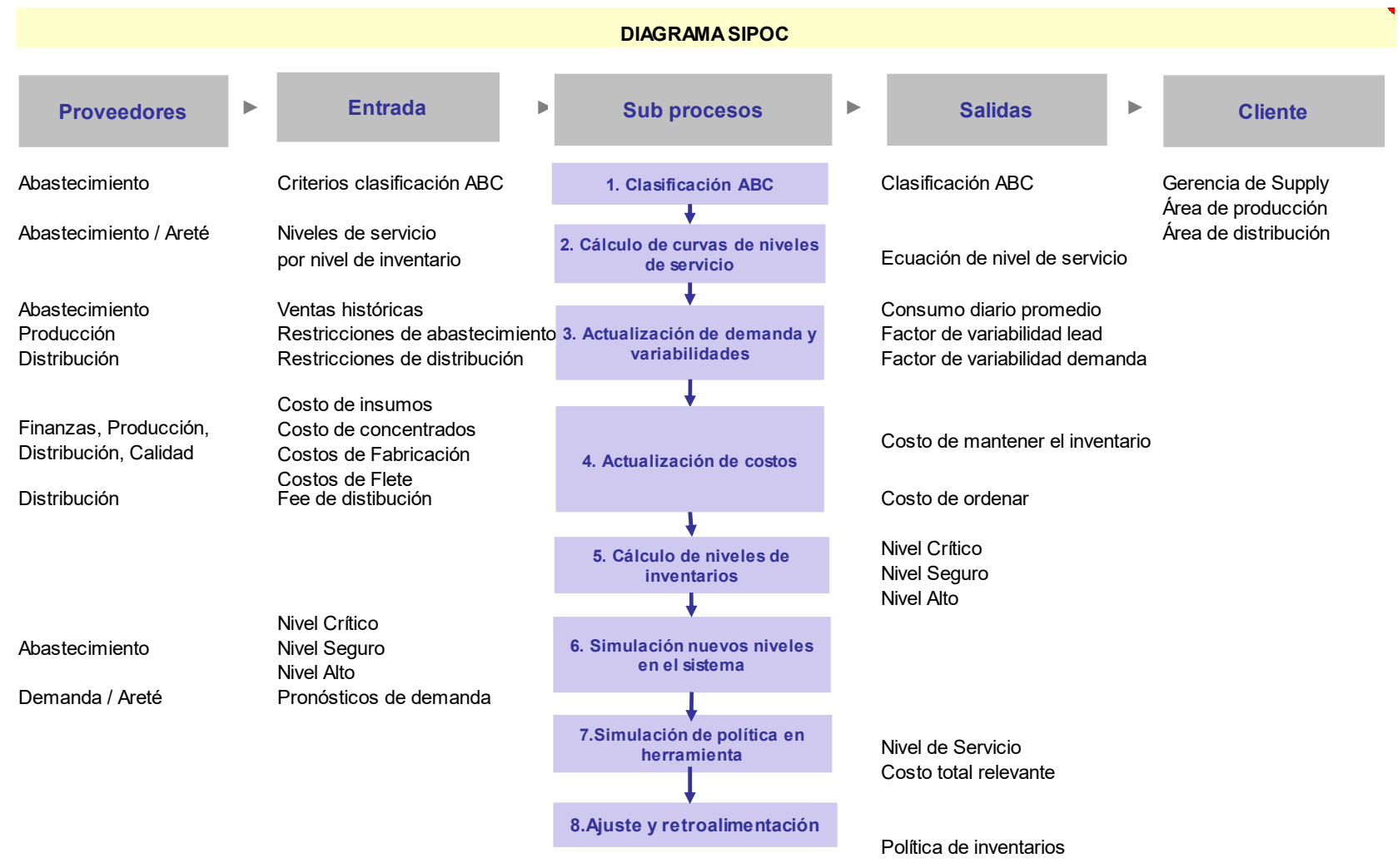

Figura 53. SIPOC del proceso de definición de la política de inventarios

A continuación, se detalla cada uno de las actividades que se deben realizar. Para cada actividad se presentará lo siguiente:

- Definición de la actividad

- Instructivo

- Resultados del ejercicio 


\section{Clasificación $\mathrm{ABC}$}

En primer lugar, se realiza la clasificación $\mathrm{ABC}$ para determinar los niveles de servicio que se manejarán en la política de stocks. Sobre esta definición se pondrán los rangos de niveles de servicio que servirán para tomar decisiones sobre los niveles de inventarios.

\begin{tabular}{|c|c|}
\hline & Pautas para la Clasificación $A B C$ \\
\hline Procedimiento: & 1. Definir los actores involucrados en la aprobación \\
\hline & $\begin{array}{l}\text { Se debe definir con aprobación de la gerencia de Supply, las áreas claves } \\
\text { que deben involucrarse en la validación y aprobación de los niveles de } \\
\text { servicios.. }\end{array}$ \\
\hline & 2. Definir los indicadores claves \\
\hline & $\begin{array}{l}\text { Se deben definir } 3 \text { indicadores claves para la compañía, incluyendo los } \\
\text { objetivos de cobertura comerciales y objetivos de finanzas. } \\
\text { 3. Definir la asignación de valores para cada indicador }\end{array}$ \\
\hline & $\begin{array}{l}\text { Cada indicador debe separarse en tres segmentos y colocar un puntaje del } \\
1-3 \text {, el cual servirá de base para medir un puntaje total. Se debe definir que } \\
\text { método se usa para separar en segmentos (paretos, segmentos } \\
\text { preexistentes, etc.) }\end{array}$ \\
\hline & 4. Definir los niveles de servicio por cada categoría \\
\hline & $\begin{array}{l}\text { En conjunto con todos los actores involucrados, se debe definir el nivel de } \\
\text { servicio por cada categoría, considerando niveles de servicio históricos a } \\
\text { nivel SKU_Locación } \\
5 . \text { Recopilación de información de indicadores }\end{array}$ \\
\hline & $\begin{array}{l}\text { Se debe recopilar información de vigente de cada indicador elegido. Si se } \\
\text { trata de históricos de venta. La información debe ser por año } \\
6 \text {. Cálculo y aprobación. }\end{array}$ \\
\hline & $\begin{array}{l}\text { Se calcula el puntaje de cada SKU por indicador y se clasifica en su } \\
\text { segmento ABC. Se deja constancia de la aprobación con el equipo } \\
\text { involucrado en el portal de Abastecimiento. }\end{array}$ \\
\hline
\end{tabular}

Figura 54. Pautas para el procedimiento ABC

Resultados del ejercicio:

Esta clasificación fue realizada en conjunto con los analistas del área de abastecimiento.

1. Clasificación ABC Multicriterio

Para la clasificación $\mathrm{ABC}$ multicriterio se utilizaron los siguientes criterios ponderados en la tabla 21. La lógica utilizada para esta clasificación se basa en que aquellos SKUS que deban tener mayor cobertura en el punto de venta, 
participación de volumen, y margen de venta, deberán tener el nivel de servicio más alto, pues son los SKUS de mayor valor para la compañía.

Tabla 22.

Asignación de valores $A B C$ por indicador

\begin{tabular}{cclc}
\hline Indicador & Características & \multicolumn{1}{c}{ Definición } & Valor \\
\hline \multirow{2}{*}{$\begin{array}{c}\text { Cobertura en el } \\
\text { punto de venta }\end{array}$} & A & En la lista cobertura estratégica & 3 \\
& B & En la lista Cobertura complementaria & 2 \\
Participación en & C & Sin lista & 1 \\
ventas & A & Participación pareto 0\%-80\% & 3 \\
& B & Participación pareto 80\%-97\% & 2 \\
Márgenes de Venta & C & Participación pareto 97\%-100\% & 1 \\
& A & Top & 3 \\
& B & Avg & 2 \\
\hline
\end{tabular}

Nota: Dererechos reservados Vilela, 2017.

A continuación, se explican los pasos seguidos en la metodología:

- Se recopila la historia del año 2017 (Enero- Noviembre) de ventas de la locación MEPA

- Se calculan los indicadores por cada SKU. El indicador de coberturas es una clasificación hecha directamente con la lista de criterios de coberturas presentada en el ANEXO 1. Si el SKU no se encuentra en esa lista, es clasificado como C. Para la participación de volumen de ventas. Se realiza un análisis Pareto presentado en el ANEXO 2, con el cual se clasifican los skus con cada criterio. Los resultados se muestran en la tabla 25. Para los márgenes de venta, se utiliza la segmentación clasificada de finanzas sobre los skus que tienen un margen de contribución más alto.

- Se suman los resultados obtenidos en los tres indicadores según la tabla 26. 
Tabla 23.

Categorías de suma $A B C$

\begin{tabular}{ccc}
\hline Categoría & Suma ABC & $\begin{array}{c}\text { Nivel de } \\
\text { Servicio }\end{array}$ \\
\hline A & $9-7$ & $95 \%$ \\
B & $6-5$ & $90 \%$ \\
C & $4-3$ & $85 \%$ \\
\hline
\end{tabular}

Nota: Los niveles de servicio fueron consensuados con el área de abastecimiento. Derechos Reservados Vilela, 2017.

Como el universo total de SKUS analizados considera las ventas históricas, muchos de ellos están descontinuados. Por ello, el resultado final se cruza con el portafolio activo para el 2018. De esta manera, los resultados obtenidos se muestran en la siguiente tabla:

Tabla 24.

Resultados de la clasificación ABC multicriterio

\begin{tabular}{cc}
\hline Categoría multicriterio & Cantidad de SKUS \\
\hline A & 32 \\
B & 68 \\
C & 41 \\
\hline
\end{tabular}

Nota: Derechos reservados Vilela, 2017.

2. Cálculo de curvas de niveles de servicio

El modelo de inventarios tiene como una de las salidas principales el nivel de servicio para poder evaluar los niveles de inventario. Esta salida requiere un cálculo dinámico del nivel de servicio. Para ello, se usa el sistema de planeamiento AV/PV, en el módulo IP Flat Editor. 


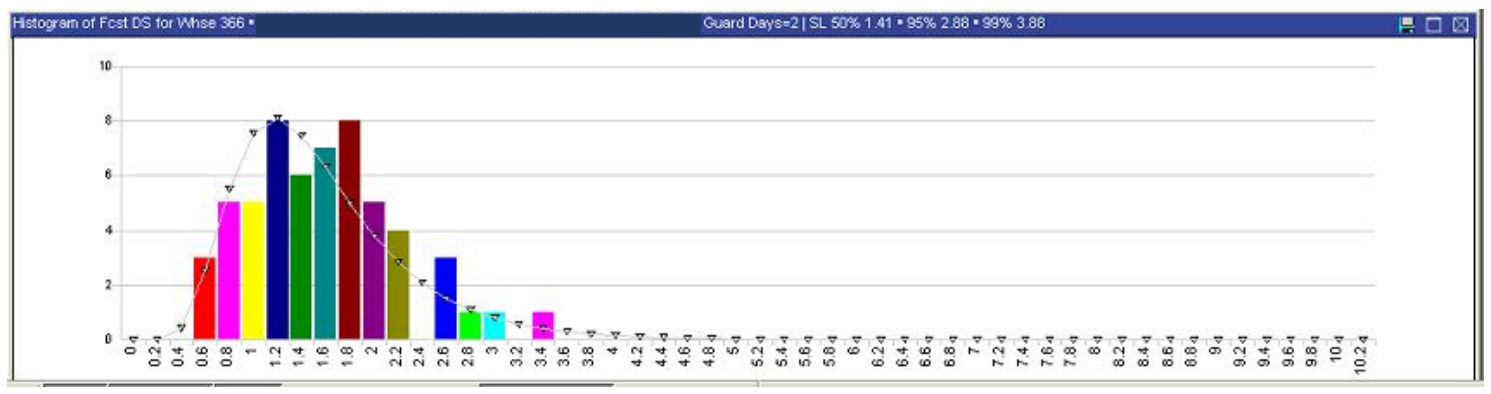

Figura 55. Curva de nivel de servicio de un SKU

En la figura 53, podemos observar que el sistema genera una curva con las ventas reales y la demanda proyectada histórica. A través de esta curva el sistema puede calcular por cuál es el nivel de inventario que debería tener cada el SKU para llegar a cierto nivel de servicio. El sistema permite que los usuarios puedan jugar con estos niveles de servicio en la ventana "IP Flat editor" mostrado en la figura 54. Resaltado en rojo se puede ver que por cada "Targ SL" Nivel de servicio inputado, el sistema da como resultado un "Targ DS" días de venta objetivo para llegar a ese nivel de servicio.

\begin{tabular}{|c|c|c|c|c|c|c|c|}
\hline \multicolumn{6}{|c|}{ Whse-Products } & \multirow[b]{2}{*}{ Targ SL } & \multirow[b]{2}{*}{ Targ Safe DS } \\
\hline Whse & Source & Method & Prod & Pkg & * Reac Day & & \\
\hline MEPA & MEPA & Make & 254849 & PET1500x02 & & 80.0 & 3.16 \\
\hline MEPA & MEPA & Make & 251406 & PET1500 $\times 02$ & & 80.0 & 2.48 \\
\hline MEPA & MEPA & Make & 254851 & PET1500x02 & & 80.0 & 3.57 \\
\hline MEPA & MEPA & Make & 254954 & PET1500 $\times 02$ & & 80.0 & 2.94 \\
\hline MEPA & MEPA & Make & 254950 & PET1500x02 & & 80.0 & 3.61 \\
\hline MEPA & MEPA & Make & 254853 & PET1500x02 & & 80.0 & 3.09 \\
\hline MEPA & MEPA & Make & 251429 & PET2500x6S & & 80.0 & 6.59 \\
\hline MEPA & MEPA & Make & 251196 & PET $3000 \times 02$ & & 80.0 & 2.88 \\
\hline MEPA & MEPA & Make & 250524 & PET $3000 \times 02$ & & 80.0 & 2.79 \\
\hline MEPA & MEPA & Make & 251385 & PET3000x02 & & 98.0 & 12.68 \\
\hline
\end{tabular}

Figura 56. IP Flat Editor para niveles de servicio

El sistema no da revela el tipo de curva o ecuación de cada SKU; sin embargo, da los resultados necesarios para poder hacer una estimación de esa curva. con las coordenadas $(\mathrm{x} ; \mathrm{y})$ / nivel de servicio - días de piso objetivo. Por ello, con esta información se ejecuta una estimación lineal en Excel para generar un polinomio de grado 4.

Con este polinomio se puede calcular el nivel de servicio de algún nivel de inventario propuesto o viceversa. 
En la figura 55, se muestran todos los pasos a segui $+\mathrm{r}$ para poder obtener las ecuaciones polinómicas del nivel de servicio que luego se añadirán a la herramienta.

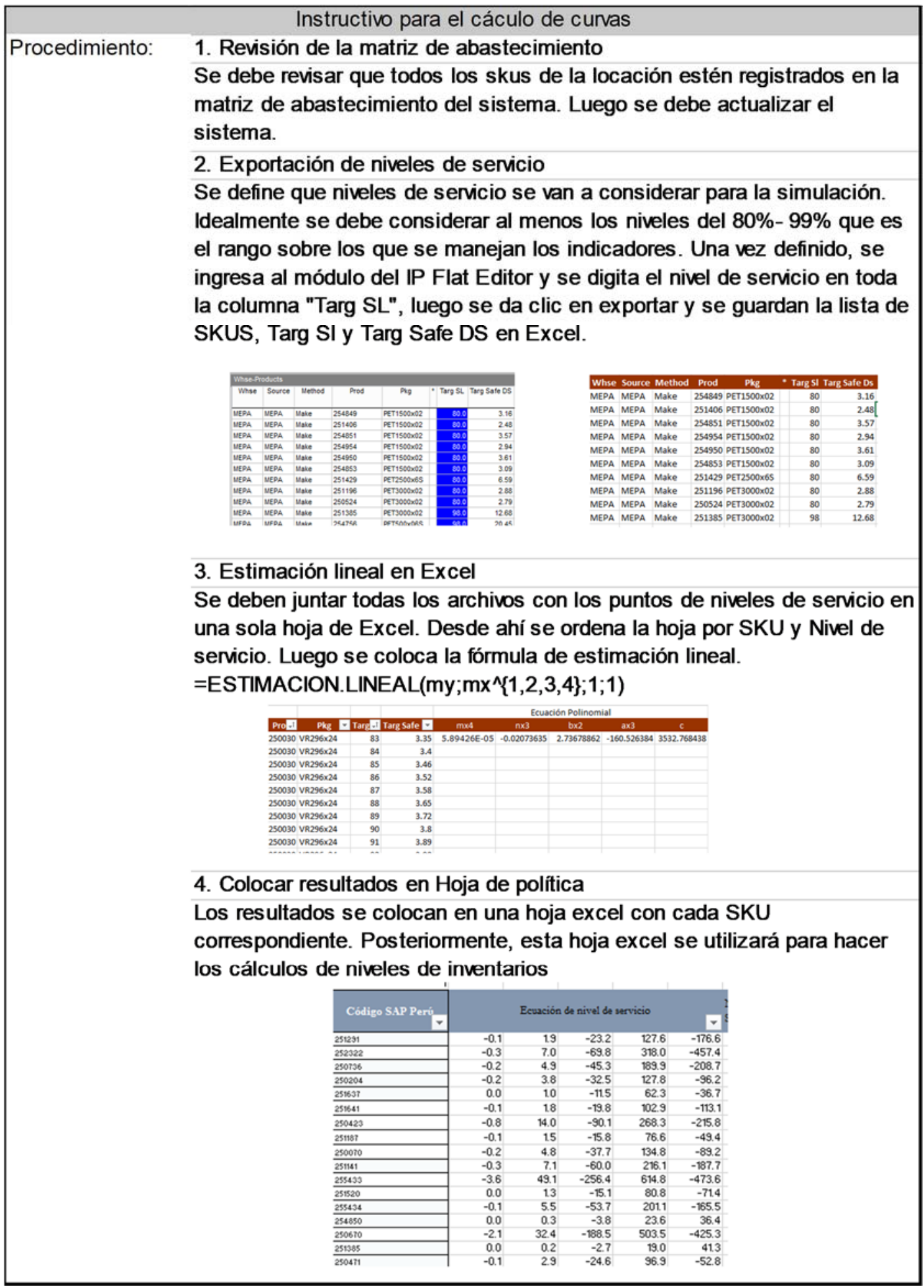

Figura 57. Instructivo para cálculo de curvas de nivel de servicio. Derechos reservados Vilela, 2017.

Resultados del ejercicio: 
Se realizó el ejercicio con todos los SKUS que abastece la locación MEPA. Los resultados se colocaron en la tabla de niveles de inventarios. En la figura 56, se muestra parte de la tabla seleccionado. Por ejemplo, para el SKU 251291 se obtiene la siguiente ecuación para el nivel de servicio dado $\mathrm{x}$ ( días de piso) :

$$
\begin{gathered}
F(x)=-0.1 x^{4}+1.9 x^{3}-23.2 x^{2}+127.6 x-176.6 \\
\text { donde } x=6.3 \\
F(x)=94.2
\end{gathered}
$$

\begin{tabular}{|c|c|c|c|c|c|c|c|}
\hline Código SAP Perú & Verde & \multicolumn{4}{|c|}{ Ecuación de nivel de servicio } & \multicolumn{2}{|c|}{$\begin{array}{l}\text { Nivel de } \\
\text { Servicio }\end{array}$} \\
\hline 251291 & 6.3 & -0.1 & 1.9 & -23.2 & 127.6 & -176.6 & 94.2 \\
\hline 252322 & 5.5 & -0.3 & 7.0 & -69.8 & 318.0 & -457.4 & 96.1 \\
\hline
\end{tabular}

Figura 58. Muestra de tabla de niveles de servicio. Derechos reservados Vilela, 2017.

Los resultados completos de niveles de ecuaciones de niveles de servicio se encuentran en el ANEXO 2.

3. Actualización de demanda y sus variabilidades

El tercer paso está enfocado en obtener los inputs para el cálculo de los niveles de

\begin{tabular}{|c|c|c|}
\hline \multicolumn{3}{|c|}{ Cálculo de CPD } \\
\hline \multirow[t]{6}{*}{ Procedimiento: } & \multicolumn{2}{|l|}{ 1. Definir el periodo del CPD } \\
\hline & \multicolumn{2}{|c|}{$\begin{array}{l}\text { Para calcular el consumo promedio diario se debe considerar las ventas } \\
\text { históricas del SKU. Es necesario considerar al menos } 4 \text { meses de } \\
\text { historia. Se consideran } 3 \text { meses anteriores para la tendencia y el mes a } \\
\text { proyectar del año pasado. } \\
\text { 2. Extracción de la información y cálculo } \\
\text { Se extrae la información histórica a nivel fecha de sistema SAP BO para } \\
\text { cada sku y se calcula el promedio. Los resultados se colocan en la Hoja } \\
\text { de trabajo de la política de stocks }\end{array}$} \\
\hline & Código SAP Perú & ${ }^{\mathrm{CPD}} \nabla$ \\
\hline & $\frac{251291}{252323}$ & 2802 \\
\hline & 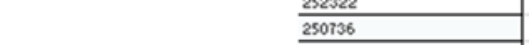 & \\
\hline & $\mid \frac{250204}{251637}$ & $\begin{array}{l}3899 \\
3343\end{array}$ \\
\hline
\end{tabular}
inventario para el DDMRP. Se calcula el CPD (Consumo diario promedio) y las variabilidades de demanda y de lead time.

Figura 59. Procedimiento para el cálculo del consumo promedio diario 
Resultado del ejercicio:

Se extrajo la venta histórica en cajas físicas de los meses de setiembre, octubre, noviembre del 2017 y la demanda de diciembre 2016. Con esto se calcula el CPD diario para cada SKU de la matriz de abastecimiento. Parte de los resultados se muestran en la figura 58.

\begin{tabular}{l|r}
\hline Código SAP Perú & CPD \\
\hline 251291 & \\
\hline 252322 & 2802 \\
\hline 250736 & 3960 \\
\hline 250204 & 1442 \\
\hline 251637 & 3899 \\
\hline 251641 & 3343 \\
\hline 250423 & 915 \\
\hline 251187 & 1865 \\
\hline 250070 & 2038 \\
\hline
\end{tabular}

Figura 60. Resultados del CPD

Variabilidad:

Para el cálculo de las variabilidades de demanda. Se utiliza el Coeficiente de variación dado en la siguiente fórmula:

$$
C V=\frac{\delta}{x}
$$

Donde:

$\delta$ : Desviación estándar

$\mathrm{x}$ : media aritmética

Sobre el resultado del CV de cada SKU. Se elige el mayor de todos y se clasifica como $100 \%$ en factor de variabilidad. Con esta relación se calculan los otros porcentajes de variabilidad mediante interpolación.

Resultados del ejercicio:

Se analizaron los 143 SKUS de MEPA. El mayor CV fue de 4.35 que se encuentra dentro del rango de productos pronosticables. A partir de ello se interpolaron los otros factores variabilidad. Una muestra de este resultado se presenta en la siguiente figura. 


\begin{tabular}{|l|r|r|r|}
\hline Código SAP Perú & $\begin{array}{c}\text { Factor } \\
\text { variabilid } \\
\text { ad } \%\end{array}$ & \multicolumn{1}{c|}{ CV } & \multicolumn{2}{c|}{ CPD } \\
\hline 251291 & $36 \%$ & 1.55 & 2802 \\
\hline 252322 & $68 \%$ & 2.94 & 3960 \\
\hline 250736 & $27 \%$ & 1.17 & 1442 \\
\hline 250204 & $61 \%$ & 2.63 & 3899 \\
\hline 251637 & $22 \%$ & 0.94 & 3343 \\
\hline 251641 & $26 \%$ & 1.14 & 915 \\
\hline 250423 & $58 \%$ & 2.51 & 1865 \\
\hline
\end{tabular}

Figura 61. Muestra resultado de factor de variabilidad

Actualización de Lead Time

Para la actualización del lead time se considera como base la unidad de medida de días.

El lead time definido considera que los productos tienen inventario disponible en 1 planta de producción. Como base para todos los SKUS se consideran como mínimo 2 días de lead time, 1 por producción y 1 por distribución. Para el caso de retornables, se añade 1 día más por el recojo de envases. En el caso de productos con cuarentena, se añade los días base más los días de cuarentena. El resumen de esta definición se muestra en la tabla 25.

\section{Tabla 25.}

Definición de lead time

\begin{tabular}{ll}
\hline Segmentación & Lead time \\
\hline Base SKUS & 2 días \\
Retornables & 3 días \\
Productos con cuarentena & Días base + días cuarentena \\
\hline
\end{tabular}

Nota: Derechos reservados Vilela, 2017.

Factor de lead time

Otro punto a calcular es el factor de lead time, el cual sirve para poder aplicar un porcentaje de seguridad sobre el consumo diario. Para los factores de lead time se utilizaron las siguientes definiciones

Tabla 26.

Definiciones para los factores de lead time

\begin{tabular}{|c|c|c|}
\hline Categoría & Factor & Segmentación de SKUS \\
\hline Lead time largo & $20 \%-40 \%$ & Productos retornables \\
\hline Lead time medio & $41 \%-60 \%$ & $\begin{array}{l}\text { Productos complementarios } \\
\text { Productos de las líneas de } \\
\text { producción de concentrados }\end{array}$ \\
\hline Lead time corto & $61 \%-100 \%$ & $\begin{array}{l}\text { Productos core no retornables, } \\
\text { Productos multipuntos }\end{array}$ \\
\hline
\end{tabular}

Nota: Derechos reservados Vilela, 2017. 
Se realizó un grupo de trabajo con un analista de abastecimiento y producción para la definición y valoración de cada SKU de acuerdo a los grupos segmentados definidos.

\begin{tabular}{|l|rr|}
\multicolumn{1}{|c|}{ Código SAP Perú } & \multicolumn{1}{|c|}{$\begin{array}{r}\text { Factor } \\
\text { Lea }\end{array}$} & \multicolumn{2}{l|}{$\begin{array}{l}\text { Lead } \\
\text { Time }\end{array}$} \\
\hline 251291 & $80 \%$ & 3 \\
\hline 252322 & $50 \%$ & 3 \\
\hline 250736 & $50 \%$ & 3 \\
\hline 250204 & $40 \%$ & 3 \\
\hline 251637 & $40 \%$ & 3 \\
\hline
\end{tabular}

Figura 62. Muestra de los factores de lead time. Derechos reservado Vilela, 2017.

4. Actualización de costos

Para la simulación y como soporte a la toma de decisiones se deben actualizar los costos de ordenar y mantener el inventario. Para esto se presenta el siguiente procedimiento para obtener los costos en la figura 61 .

\begin{tabular}{|c|c|c|c|c|c|c|}
\hline \multicolumn{7}{|c|}{ Pautas para la actualización de costos } \\
\hline \multirow[t]{25}{*}{ Procedimiento: } & \multicolumn{6}{|l|}{ 1.Cálculo de ordenar } \\
\hline & \multicolumn{6}{|c|}{$\begin{array}{l}\text { Los costos indirectos de fabricación se calculan con la información de } \\
\text { finanzas de las siguiente forma: } \\
\text {->Insumos: Costo por SKU y planta. Este costo se asocia a cada SKU por }\end{array}$} \\
\hline & \multirow[t]{2}{*}{ planta de procedencia } & \multirow{2}{*}{\multicolumn{5}{|c|}{$\begin{array}{l}\text { Costo Indirecto de Fabricación } \\
\text { Cd Planta ClF S/. }\end{array}$}} \\
\hline & & & & & & \\
\hline & \multirow{6}{*}{\multicolumn{2}{|c|}{ 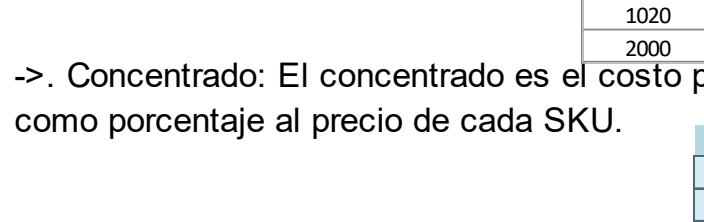 }} & \multicolumn{4}{|c|}{0.32} \\
\hline & & & \multicolumn{4}{|c|}{0.58} \\
\hline & & & Ut malca & a veriu & ma y se & ipical \\
\hline & & & Marca & & $\%$ & \\
\hline & & & MARCA 1 & & $20.00 \%$ & \\
\hline & & & MARCA 2 & & $25.00 \%$ & \\
\hline & ->Costo de de fabricación: Incluye el & costos de & Mano d & de obr & a directa & a y el \\
\hline & costo de energía & Energ & & $\begin{array}{l}\text { Energia } x \\
\text { CF (S/.) } \\
\text { SLXCF }\end{array}$ & MODS/. & \\
\hline & & $\frac{\text { Cd Plar }}{1020}$ & $\begin{array}{c}\text { anta Cod SKU } \\
250041\end{array}$ & \begin{tabular}{|c|c|} 
SI. X CF \\
0.15
\end{tabular} & $\begin{array}{c}\mathrm{S} / \mathrm{x} \mathrm{CF} \\
0.18\end{array}$ & \\
\hline & & 1020 & \begin{tabular}{|l|}
250204 \\
\end{tabular} & 0.23 & 0.27 & \\
\hline & $\begin{array}{l}\text {-> Costo de Flete: El costo del flete, } \\
\text { pickear los productos desde la planta } \\
\text { locación y planta de origen }\end{array}$ & $\begin{array}{l}\text { es el cost } \\
\text { a al alamce }\end{array}$ & $\begin{array}{l}\text { to de trar } \\
\text { én. Está }\end{array}$ & nsport & $\begin{array}{l}\text { tar, carg } \\
\text { por SK }\end{array}$ & $\begin{array}{l}\text { gar y } \\
\text { iU, }\end{array}$ \\
\hline & & \begin{tabular}{|c|} 
Código de Planta \\
SAP
\end{tabular} & \begin{tabular}{|l}
$\begin{array}{l}\text { Código de De } \\
\text { dígitos -forma }\end{array}$ \\
\end{tabular} & $\begin{array}{l}\text { epósito (2 } \\
\text { lato texto) }\end{array}$ & Código SAP & Soles/cu \\
\hline & & $\begin{array}{l}\text { Cd Planta } \\
\quad y\end{array}$ & Cd Deposito & & Cd SKU & $10 / 201=$ \\
\hline & & 1020 & 6 & & 250204 & 1.90 \\
\hline & & 1020 & 6 & & 250431 & 4.42 \\
\hline & $\begin{array}{l}\text { 2. Se suman todos los costos y se c } \\
\text { herramienta a nivel. SKII } \\
\text { 2. Calculo de mantener el inventario }\end{array}$ & colocan en & la planti & illa de & & \\
\hline & $\begin{array}{l}\text { Para el cálculo de mantener el invent } \\
\text { a los almacenes. Esta información s }\end{array}$ & $\begin{array}{l}\text { tario se cor } \\
\text { e coloca } p\end{array}$ & $\begin{array}{l}\text { nsidera } € \\
\text { or CF }\end{array}$ & el Fee & e que se & paga \\
\hline & $\mathrm{Fe}$ & & & & & \\
\hline & & Locacion & $=\operatorname{cod} \mathrm{Sr}=$ & & & ifa $\times 0$ \\
\hline & 40 & & 250039 & & & -1.512 \\
\hline & 22 & & 250039 & & & -1.296 \\
\hline
\end{tabular}

Figura 63. Procedimiento de actualización de costos. Derechos reservados Vilela, 2017 
Resultados del ejercicio:

Se obtuvo para cada SKU los costos de mantener y ordenar por CF. Este costo en soles será multiplicado por cada volumen durante la simulación. No se muestran los costos completos por confidencialidad en la figura 62.

\begin{tabular}{|l|r|r|}
\hline $\begin{array}{c}\text { Código } \\
\text { SAP Per }\end{array}$ & $\begin{array}{r}\text { Costo de } \\
\text { mantenei }\end{array}$ & $\begin{array}{c}\text { Costo de } \\
\text { ordenar }\end{array}$ \\
\hline 251291 & 1.671 & 4.35 \\
\hline 252322 & 1.215 & 3.34 \\
\hline 250736 & 1.367 & 4.20 \\
\hline
\end{tabular}

Figura 64. Muestra de costos por volumen y SKU

5. Cálculo de los niveles de inventario

Para el cálculo de niveles de inventario se utiliza las fórmulas presentadas en la tabla 27, de acuerdo a lo revisado para el DDMRP.

Tabla 27.

Cálculo de los niveles de inventario

\begin{tabular}{cr}
\hline Niveles de inventario & Cálculo \\
\hline Zona Rojo Base & CPD x LT X \% FL \\
Zona Rojo Seguro & Zona roja base x \%Variabilidad \\
Nivel Crítico & Zona roja base + Zona Roja segura \\
Zona Amarilla & CPD x LT \\
Nivel Seguro & Nivel crítico + Zona Amarilla \\
Zona Verde & Cantidad mínima de pedido (si aplica) o CPD x LT X\%FL \\
Nivel Parar & Nivel Seguro + Zona Verde \\
\hline
\end{tabular}

Nota: Derechos reservados Vilela, 2017.

Las variables necesarias para el cálculo de cada nivel se obtuvieron en los pasos 3 y 4. CPD (Consumo diario promedio), LT ( lead time), FL ( factor de lead), \% variabilidad. Luego que se calcula cada nivel, este es divido por el CPD para obtener una aproximación en días de venta. Se ilustra los pasos seguidos en el siguiente ejemplo:

\section{SKU 251291}

Factor de variabilidad: 36\% -Coeficiente de Variación 1.54

Factor de Lead: $80 \%$ - Producto multipunto

Lead Time: 3 días $\quad$ - Retornable

CPD: $\quad 2802 \mathrm{CF}$ 
Tabla 28.

Ejemplo de cálculo de niveles de inventario para SKU 251291

\begin{tabular}{lr}
\hline Niveles de inventario Cálculo & \\
\hline Zona Rojo Base & $2802 \times 3 \times \% 80=6724$ \\
Zona Rojo Seguro & $6724 \times 36 \%=2395$ \\
Nivel Crítico & $6274+2395=9120$ \\
Zona Amarilla & $2802 \times 3=8405$ \\
Nivel Seguro & $9120+8405=17525$ \\
Zona Verde & $2802 \times 2 \times 80 \%=6724$ \\
Nivel Parar & $17525+6724=24249$ \\
\hline
\end{tabular}

Nota: Derechos reservados Vilela, 2017

Una vez obtenidos los niveles de inventarios de cada SKU, estos son convertidos a sus equivalentes en días de venta con la siguiente ecuación:

$$
\text { Días de venta }=\frac{\text { Nivel de inventario }}{C P D}
$$

De esta manera los niveles de inventario calculados pasan a ser los siguientes presentados en la figura 63.

\begin{tabular}{lrc}
\hline & $\begin{array}{c}\text { Niveles de } \\
\text { inventario }\end{array}$ & Días de venta \\
\hline Nivel Crítico & 9120 & 3.15 \\
Nivel Seguro & 17525 & 6.06 \\
Nivel Parar & 24249 & 8.38 \\
\hline
\end{tabular}

Figura 65. Días de venta del SKU 251291. Derechos reservados Vilela, 2017

Finalmente, se obtienen todos los niveles de inventario mostrados en la figura 64. La totalidad de los niveles de inventario obtenidos se muestra en el Anexo 2.

\begin{tabular}{|l|r|r|r|}
\hline $\begin{array}{l}\text { Código SAP } \\
\text { Perú }\end{array}$ & \multicolumn{2}{|c|}{ Crítico } & \multicolumn{2}{|c|}{ Verde } & \multicolumn{1}{c|}{ Parar } \\
\hline 251291 & 3.3 & 6.3 & 8.7 \\
\hline 252322 & 2.5 & 5.5 & 7 \\
\hline 250736 & 1.9 & 4.9 & 6.4 \\
\hline 251637 & 1.5 & 4.5 & 5.7 \\
\hline 251641 & 1.9 & 4.9 & 6.4 \\
\hline 251141 & 1.2 & 3.2 & 4 \\
\hline 255433 & 1 & 3 & 3.5 \\
\hline 251520 & 1.9 & 4.9 & 6.4 \\
\hline
\end{tabular}

Figura 66. Niveles de Inventario.

Derechos reservados Vilela, 2017. 
6. Simulación en el sistema

Una vez determinada los niveles de inventarios, estos deben pasar el sistema en el modo de prueba para realizar la simulación de posiciones de inventario y reordenes durante un periodo.

Como este es un paso que depende del sistema se necesita cumplir con un checklist de mantenimiento para asegurar el buen funcionamiento de la simulación. Este checklist se muestra en la figura 65 .

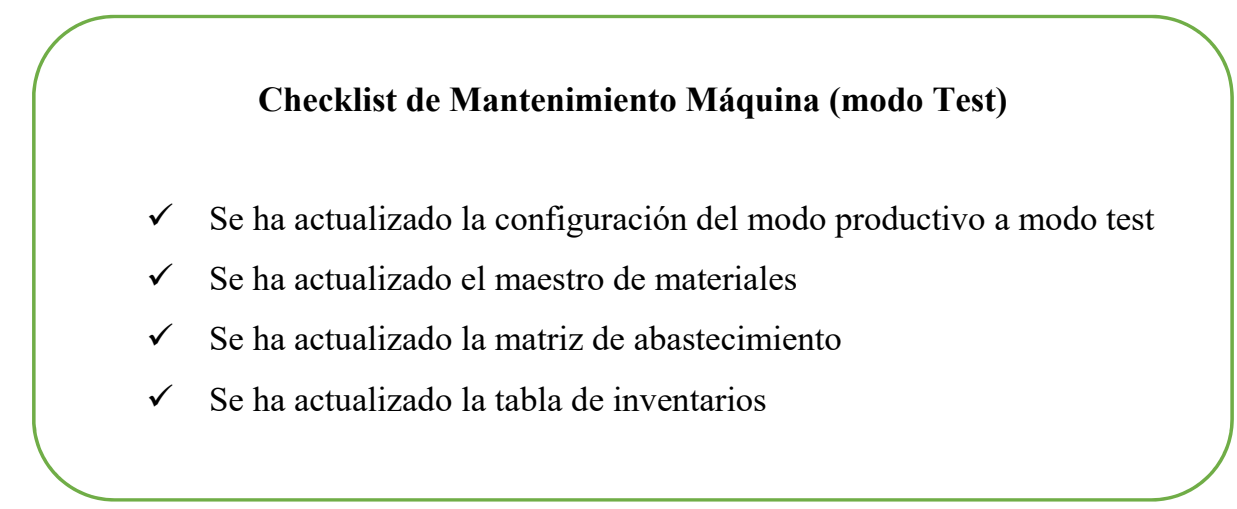

Figura 67. Checklist para mantenimiento del Programa AV en el Modo Test

Cuando se han cumplido todos los pasos del checklist, se procede a ingresar los niveles de inventario al sistema en el módulo Edit Whse -Prod Settings mostrado en la figura 66.

\begin{tabular}{l||l|r|r|r|}
\multicolumn{1}{r|}{ Prod } & To Loc & \multicolumn{1}{c}{ Crit DS } & Safe DS & \multicolumn{1}{c|}{ Stop DS } \\
\hline 256369 & MEPA & 1.20 & 5.20 & 7.50 \\
\hline 256368 & MEPA & 1.20 & 5.20 & 7.50 \\
\hline 256360 & MEPA & 1.20 & 5.20 & 7.50 \\
\hline 256355 & MEPA & 1.20 & 5.20 & 7.50 \\
\hline 256358 & MEPA & 1.20 & 5.20 & 7.50 \\
\hline 256359 & MEPA & 1.20 & 5.20 & 7.50 \\
\hline 256357 & MEPA & 1.20 & 5.20 & 7.50 \\
\hline 256332 & MEPA & 0.70 & 1.70 & 2.70 \\
\hline
\end{tabular}

Figura 68. Edición de inventario en sistema. Derechos reservados Vilela, 2017

Una vez editado en el sistema el nivel de inventario se procede a realizar la simulación en el módulo de deployment scheduling, con la opción de Export 1. 


\begin{tabular}{|c|c|c|c|c|c|c|c|}
\hline & & Today's & Scheduled & Today's & End of Day & Deploy & \\
\hline Product & Date & Inventory & InTransits & Demand & Inventory & Quantity & Demand \\
\hline$========$ & $=======$ = & $=========$ & $==========$ & $=========$ = & $=========$ & $:==========$ & $===========$ \\
\hline 252312 & Dic-15 & 1395 & 0 & 1286 & 109 & 1296 & 0 \\
\hline 253568 & Dic-15 & 546 & 0 & 163 & 383 & 0 & 0 \\
\hline 253311 & Dic-15 & 91 & 0 & 4 & 87 & 13 & 0 \\
\hline 253312 & Dic-15 & 695 & 0 & 16 & 679 & 0 & 0 \\
\hline 252312 & Dic-16 & & & & 1405 & 249 & 127 \\
\hline 253568 & Dic-16 & & & & 383 & 0 & 25 \\
\hline 253311 & Dic-16 & & & & 100 & 5 & 4 \\
\hline 253312 & Dic-16 & & & & 679 & 0 & 15 \\
\hline
\end{tabular}

Figura 69. Resultado de simulación en el sistema. Derechos reservados Vilela, 2017.

En la figura 67 se muestra el resultado de la simulación de abastecimiento con los nuevos niveles de inventarios. Las columnas de "End of day Inventory" ( Posición de inventarios) y "Deploy Quantity" (Cantidad de envío) y demanda son las 3 columnas que servirán como input para el siguiente paso donde se utiliza la herramienta de validación del sistema.

\section{Simulación en la herramienta}

Para presentar la herramienta final. Se agregan los costos de ordenar y de mantener, así como las ecuaciones de nivel de servicio a la simulación del sistema. Se multiplican cada uno de estos por la cantidad que se envía al almacén y la posición de inventario estimada.

Este cuadro se puede llevar una tabla dinámica para mostrar los costos finales por cada SKU en el periodo así como un promedio del nivel de servicio que se tendrá de cada uno. En la figura 68, se muestra un ejemplo de la simulación final con los costos niveles de servicio finales.

\begin{tabular}{|c|c|c|c|c|c|c|c|c|c|c|c|c|}
\hline Product & Date & Inventory & Quantity & & & $\begin{array}{l}\text { Total Costo } \\
\text { de mantenr }\end{array}$ & & & $\begin{array}{l}\text { Tota } \\
\text { de C }\end{array}$ & $\begin{array}{l}\text { Costo } \\
\text { denar }\end{array}$ & Total Costo & $\begin{array}{l}\text { Nivel de } \\
\text { servicio }\end{array}$ \\
\hline$=======$ & $======-=$ & & $========$ & & & & & & & & & \\
\hline 252312 & Dic-15 & 109 & 1296 & $\mathrm{~S} /$. & 2 & 188 & $\mathrm{~S} /$. & 2 & $\mathrm{~S} /$. & 2,812 & S/. $\quad 3,000$ & $93 \%$ \\
\hline 253568 & Dic-15 & 383 & 0 & S/. & 1 & 503 & $\mathrm{~S} / \mathrm{.}$ & 3 & $\mathrm{~S} /$ & - & 503 & $85 \%$ \\
\hline 253311 & Dic-15 & 87 & 13 & $\mathrm{~S} /$. & 1 & 119 & S/. & 4 & S/. & 55 & 174 & $97 \%$ \\
\hline 253312 & Dic-15 & 679 & 0 & $\mathrm{~S} /$. & 1 & 989 & S/. & 3 & S/. & - & 989 & $90 \%$ \\
\hline 252312 & Dic-16 & 1405 & 249 & S/. & 2 & S/. $\quad 2,418$ & $\mathrm{~S} /$. & 2 & $\mathrm{~S} /$. & 540 & $\mathrm{~S} / . \quad 2,958$ & $92 \%$ \\
\hline 253568 & Dic-16 & 383 & 0 & S/. & 1 & 503 & $\mathrm{~S} /$. & 3 & $\mathrm{~S} /$. & - & 503 & $86 \%$ \\
\hline 253311 & Dic-16 & 100 & 5 & $S /$. & 1 & 137 & $\mathrm{~S} /$. & 4 & $\mathrm{~S} /$. & 21 & 158 & $95 \%$ \\
\hline
\end{tabular}

Figura 70. Muestra simulación con costos y niveles de servicio en la herramienta 
8. Ajuste dinámico y feedback

Con los resultados del paso 7 se presenta una tabla final con la política de stock con sus costos, niveles de servicio y clasificación ABC, como se muestra en la figura 69.

\begin{tabular}{|c|c|c|c|}
\hline Product & - Clasificación & Suma de Total Costo & Promedio de Nivel de servicio \\
\hline-25231 & $12 \mathrm{~B}$ & $5,958.24$ & $93 \%$ \\
\hline$\boxminus 25331$ & $11 \mathrm{~A}$ & 331.23 & $96 \%$ \\
\hline-25331 & $12 \mathrm{~A}$ & $1,977.25$ & $91 \%$ \\
\hline$\theta 25356$ & $68 \mathrm{~B}$ & $1,006.52$ & $86 \%$ \\
\hline
\end{tabular}

Figura 71. Ejemplo simulación en herramienta. Derechos reservados Vilela, 2017

Con estos datos el equipo de abastecimiento debe hacer un análisis de cada SKU para determinar si el nivel de inventario escogido es el correcto. Se proponen tres preguntas básicas para hacer el análisis de acuerdo a la clasificación $\mathrm{ABC}$ en la figura 70:

\begin{tabular}{l|l|llll|}
\hline Categoría & Pregunta Clave & Acción & & \\
\hline Productos A & $\begin{array}{l}\text { ¿Se ha llegado al nivel de } \\
\text { servicio adecuado? }\end{array}$ & $\begin{array}{l}\text { Aumentar el nivel de } \\
\text { inventarios }\end{array}$ & & \\
& $\begin{array}{l}\text { ¿Los costos justifican el } \\
\text { nivel de servicio? }\end{array}$ & Disminuir el nivel de & servicio & & \\
\hline Productos B & $\begin{array}{l}\text { ¿Los costos justifican el } \\
\text { nivel de servicio? }\end{array}$ & Disminuir el nivel de & servicio & & \\
\hline Productos C & & & & \\
\hline
\end{tabular}

Figura 72 Checklist para clasificación $\mathrm{ABC}$

Si es necesario, se pueden volver a hacer simulaciones con los nuevos niveles de inventario hasta determinar la política adecuada. 
Diseño del nuevo flujo de planeamiento de la cadena de abastecimiento estratégico y operativo

La empresa cuenta con una red distribución compleja ilustrada en la figura 71. Esta situación presenta un problema al traducir la política de stocks del almacén hacia el nivel de planta para poder cubrir los requerimientos. Por ello, se ha rediseñado el proceso de planeamiento de las áreas, para que la política de stocks definida por abastecimiento, pueda desplegarse correctamente también hacia las áreas de producción y distribución. Para esto se presentará el nuevo flujo y herramienta de soporte en los cálculos.

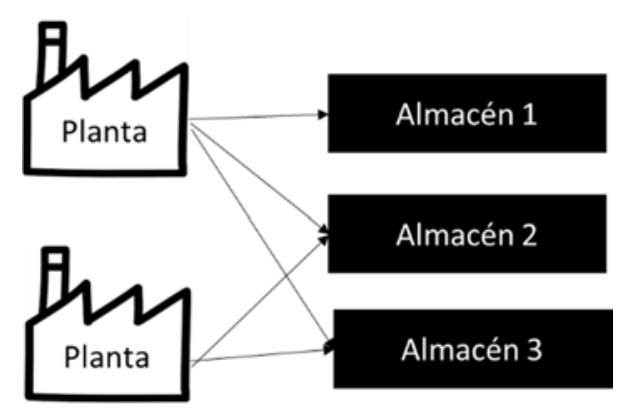

Figura 73. Red de abastecimiento. Derechos reservados Vilela, 2017.

Existen tres tipos de planeamiento en la cadena de abastecimiento. Estratégico (referido a los planes mensuales o semestrales), operativo (referido a los planes semanales) y diario (ajustes diarios a los planes semanales). Como se detalló en el anterior capítulo es el planeamiento estratégico y operativo el que presenta mayores deficiencias. 
En la figura 72, se detalla el nuevo flujo que tendrá el planeamiento estratégico. Los cambios hechos corresponden a los ítems resaltados en azul.

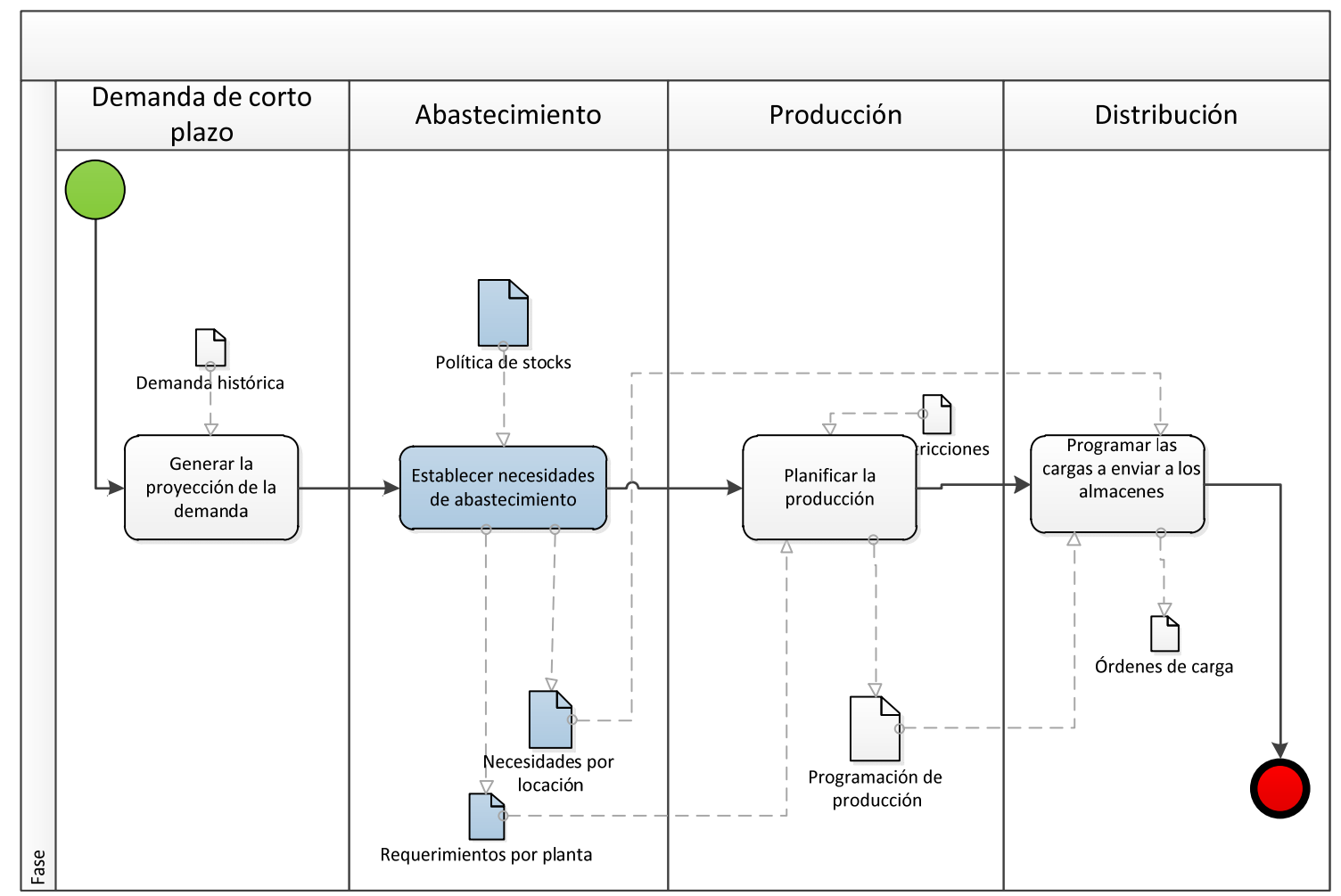

Figura 74. Diagrama de flujo de la nueva planificación de la cadena de abastecimiento.

Derechos reservados Vilela, 2017.

La primera modificación, es la creación de una única política de stocks que sirve de input para establecer la necesidad de inventario en toda la cadena. Se ha agregado un proceso de "establecimiento de necesidades de abastecimiento “. Esta nueva actividad permite definir la cantidad que requiere cada locación considerando el stock seguro establecido en la política, este es un input directo para el área de distribución. Con esta necesidad por cada locación el área sabe hasta cuánto debe subir los niveles de inventario. Así también, un proceso de traducción de esta política a nivel de sistema de abastecimiento (requerimientos por planta). Este documento detalla la cantidad de inventarios que debe producir como mínimo una planta para satisfacer las necesidades de las locaciones de su red de abastecimiento. Con los "requerimientos por planta" el área de producción elabora su plan considerando las restricciones que se tienen por planta. Este plan debe cumplir con el mínimo de requerimientos definidos y si existen grandes gaps entre los requisitos y lo planificado se deben levantar las restricciones para replantear mejoras en la cadena. 


\section{Diseño de la actividad "necesidades de abastecimiento"}

La actividad de "establecer necesidades de abastecimiento" estará soportada en una herramienta temporal que reemplaza a las hojas de Excel que actualmente se utiliza. Con esta herramienta, el área de abastecimiento deberá ejecutar las siguientes actividades: Actualizar parámetros, centralizar la información necesaria de cada área y actualizarla en la herramienta. Luego deberá correr la herramienta con los parámetros actualizados y generar el reporte de requerimientos para distribución y el reporte de requerimiento por planta para producción. Finalmente, el área envía los reportes.

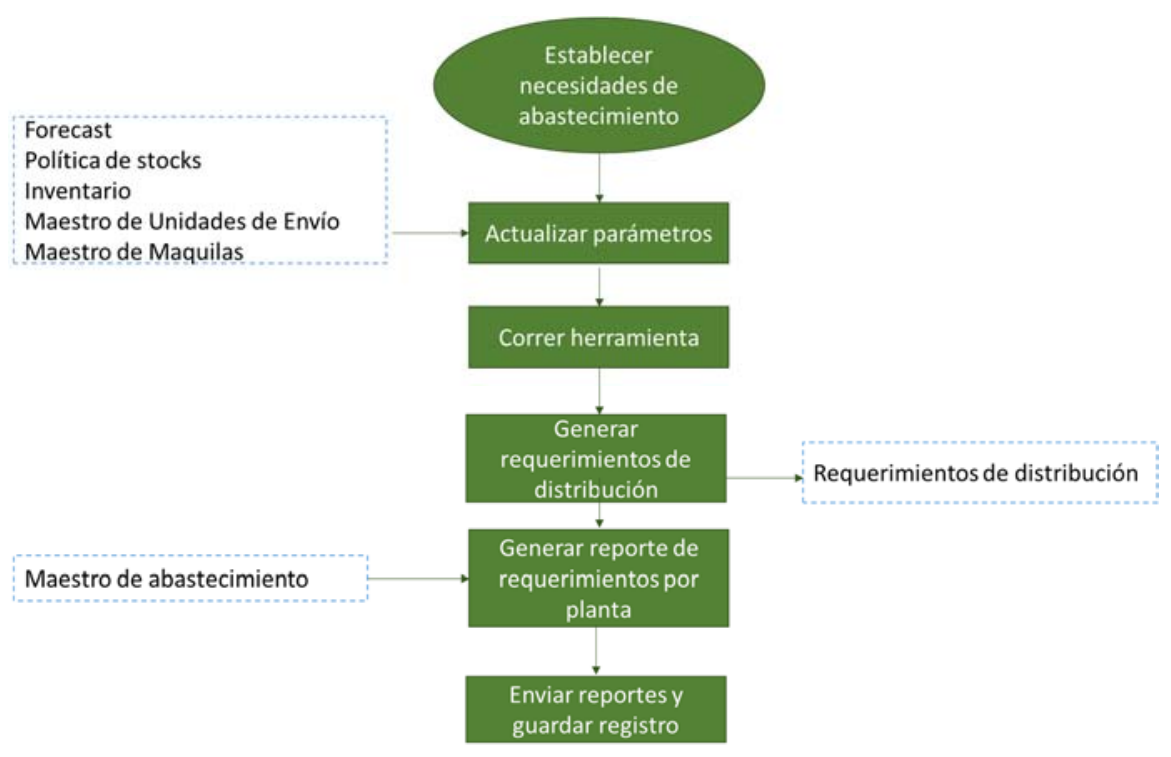

Figura 75. Diagrama de bloques para establecer necesidades de abastecimiento. Derechos reservados Vilela, 2017.

\section{Presentación de Maestros para la herramienta temporal}

En la tabla 29 se resume cada uno de los inputs (bases de dato) necesarios para el cálculo de la herramienta. El seguimiento y control de calidad de la entrega de cada uno de estos es responsabilidad del área de abastecimiento 
Tabla 29.

Inputs para el cálculo de necesidades

\begin{tabular}{|c|c|c|}
\hline Input & Proveedor & Observaciones \\
\hline Forecast & $\begin{array}{l}\text { Demanda de corto } \\
\text { plazo }\end{array}$ & $\begin{array}{l}\text { Demanda debe estar a nivel SKU-Locación y } \\
\text { sumarizada por periodo mensual o semanal. }\end{array}$ \\
\hline Política de Stocks & Abastecimiento & Política por Locación-SKU \\
\hline Inventario & $\begin{array}{l}\text { SAP - Plantas } \\
\text { AV- CDAS }\end{array}$ & Inventario actualizado de planta-sku y locación -sku \\
\hline $\begin{array}{l}\text { Maestro de unidades } \\
\text { de envío }\end{array}$ & Distribución - AV & Maestro actualizado del sistema AV por SKU \\
\hline Maestro de maquilas & Producción & $\begin{array}{l}\text { Maestro actualizado con componentes de maquila } \\
\text { a nivel SKU }\end{array}$ \\
\hline $\begin{array}{l}\text { Matriz de } \\
\text { abastecimiento }\end{array}$ & Distribución -AV & Maestro a nivel Planta-Locación-SKU \\
\hline Maestro de SKUS & Producción - PV & $\begin{array}{l}\text { Maestro con el detalle de jerarquía de producto } \\
\text { para todos los SKUS vigentes }\end{array}$ \\
\hline $\begin{array}{l}\text { Maestro de } \\
\text { Locaciones }\end{array}$ & Distribución - AV & Muestra la región y códigos de locaciones \\
\hline
\end{tabular}

Nota: Derechos reservados Vilela , 2017

A continuación, en las figuras $71-75$, se presenta las fichas detalladas para cada uno de los inputs que se necesita para la herramienta. Para cada uno de estos inputs se ha parametrizado cómo debe entregarse cada input de acuerdo a las siguientes secciones: Título, descripción del contenido, Fuente y Observaciones 


\begin{tabular}{|c|c|c|c|}
\hline \multicolumn{4}{|l|}{ Ficha del Maestro: } \\
\hline Título & \multicolumn{3}{|l|}{ Maestro de SKUS } \\
\hline $\begin{array}{l}\text { Descripción del } \\
\text { contenido: }\end{array}$ & \multicolumn{3}{|l|}{ Descripción de todos los SKUS, } \\
\hline \multirow{2}{*}{\multicolumn{4}{|c|}{$\begin{array}{l}\text { Fuente: } \\
\text { Observaciones }\end{array}$}} \\
\hline & & & \\
\hline & \multicolumn{3}{|l|}{ Maestro debe ser actualizado por el área de producción } \\
\hline Campos & Descripción & Fuente & Ejemplo \\
\hline Código SAP & Código SAP del SKU & Maestro Prevail & 254893 \\
\hline Descripción & Descripción SAP del SKU & Maestro Prevail & FR TPA 1 LT $\times 12$ \\
\hline Línea & $\begin{array}{c}\text { Línea del producto ( CORE; SABORES; NECTAR ..) Cruzar } \\
\text { con Maestros de Abastecimientos? }\end{array}$ & Maestro Prevail & BEBIDAS \\
\hline Marca & Marca del SKU & Maestro Prevail & FR \\
\hline Factor de Conversión d & $\begin{array}{c}\text { Factor de conversión de CU a CF (Sistema SIPAN y/o Sistema } \\
\text { PREVAIL) }\end{array}$ & Maestro Prevail & 0.473 \\
\hline Tipo Retornable & NO RETORNABLE; RETORNABLE & Maestro Prevail & NO RETORNABLE \\
\hline Tipo de Envase & Single Serve, Multi Serve & Maestro Prevail & MULTI SERVE \\
\hline Flag Región & $\begin{array}{c}\text { Se distingue los SKUS exclusivos del SUR con el valor (SUR) } \\
\text { los demás llevan el valor (GEN) }\end{array}$ & Campo Manual & GEN \\
\hline
\end{tabular}

Figura 77. Ficha para el Maestro de SKUS. Derechos Reservados Vilela, 2017.

\begin{tabular}{|c|c|c|c|}
\hline \multicolumn{4}{|l|}{ Ficha del Maestro: } \\
\hline Título & \multirow{3}{*}{\multicolumn{3}{|c|}{$\begin{array}{l}\text { Maestro de Maquilas y Componentes } \\
\text { Relaciones entre maquilas y sus componentes madres. } \\
\text { Relaciones entre los códigos MERC de Iquitos con sus componente } \\
\text { madre PTER (Lima) }\end{array}$}} \\
\hline & & & \\
\hline $\begin{array}{l}\text { Descripcion del } \\
\text { contenido: }\end{array}$ & & & \\
\hline Fuente: & \multicolumn{3}{|c|}{$\begin{array}{l}\text { Recopilación de Excels de MEPA, IQUITOS y SUR del área de } \\
\text { Producción }\end{array}$} \\
\hline Observaciones & \multicolumn{3}{|c|}{$\begin{array}{l}\text { Requiere de un Flag por región. Un código de maquila puede tener } \\
\text { componentes madre distintos en la región abastecimiento LIMA } \\
\text { (GEN) y en la región abastecimiento el SUR (SUR) }\end{array}$} \\
\hline \multicolumn{4}{|l|}{ Descripción de Campos: } \\
\hline Campos & Descripción & Fuente & Ejemplo \\
\hline Código SAP Maquila & Código SAP de Maquila & $\begin{array}{l}\text { Archivo de MEPA / } \\
\text { SUR/IQUITOS }\end{array}$ & 250524 \\
\hline Código SAP Madre & Código SAP del componente Madre & $\begin{array}{l}\text { Archivo de MEPA / } \\
\text { SUR/IQUITOS }\end{array}$ & 251637 \\
\hline Factor de maquilado & $\begin{array}{l}\text { Proporción de uso de las CF componente } \\
\text { madre en la maquila: } \\
0.5=\text { Se necesita la mitad de una CF del } \\
\text { comnonente nara la manuila }\end{array}$ & $\begin{array}{l}\text { Archivo de MEPA / } \\
\text { SUR/IQUITOS }\end{array}$ & 0.50 \\
\hline Flag Región & $\begin{array}{l}\text { Distinsor de componente de región } \\
\text { abastecimiento SUR vs. LIMA (GEN) }\end{array}$ & Campo MANUAL & GEN \\
\hline
\end{tabular}

Figura 76. Ficha para el Maestro de Maquilas. Derechos reservados Vilela, 2017 


\begin{tabular}{|c|c|c|c|}
\hline \multicolumn{4}{|l|}{ Ficha del Maestro: } \\
\hline TítuloO6:R17 & \multicolumn{3}{|l|}{ Maestro de Unidad de Envío } \\
\hline $\begin{array}{l}\text { Descripción del } \\
\text { contenido: }\end{array}$ & \multicolumn{3}{|c|}{ Paletaje de cada SKU de acuerdo a la planta productora } \\
\hline Fuente: & \multicolumn{3}{|c|}{$\begin{array}{l}\text { AVAIL } \\
\text { ( Tabla nDs -> Hub Product Settings - Campos (From Loc y Bases/pal) } \\
\text { Filtrar los paletajes de los "From Loc": Plantas. Actualizado por } \\
\text { distribución }\end{array}$} \\
\hline Observaciones & \multicolumn{3}{|c|}{$\begin{array}{l}\text { Falta trabajo de revisión de alineamiento entre tabla maestra de SAP y } \\
\text { AVAIL de Paletajes por planta }\end{array}$} \\
\hline \multicolumn{4}{|c|}{ Descripción de Campos: } \\
\hline Campos & Descripción & Fuente & Ejemplo \\
\hline Código SAP & Código SAP de PTER & $\begin{array}{l}\text { AVAIL: Menú nDs-> Tabla Hub } \\
\text { Product Settings-> Campo Prod }\end{array}$ & 254849 \\
\hline PLANTA & Nombre AVAIL de Planta & $\begin{array}{l}\text { AVAIL: Menú nDs-> Tabla Hub } \\
\text { Product Settings-> Campo } \\
\text { "From Loc" }\end{array}$ & PLAQP \\
\hline ódigo SAP PLANT & Código SAP del campo PLANTA. & $\begin{array}{l}\text { Campo Externo del maestro de } \\
\text { locaciones }\end{array}$ & 1080 \\
\hline Paletaje & CF / Paleta de envío & $\begin{array}{l}\text { AVAIL: Menú nDs-> Tabla Hub } \\
\text { Product Settings-> Campo } \\
\text { "Bases/Pal" }\end{array}$ & 180 \\
\hline
\end{tabular}

Figura 78. Ficha del Maestro de Unidad de Envío. Derechos reservados Vilela, 2017.

\begin{tabular}{|c|c|c|c|}
\hline \multicolumn{4}{|l|}{ Ficha del Maestro: } \\
\hline Título & \multicolumn{3}{|l|}{ Maestro de Política de Inventarios } \\
\hline $\begin{array}{l}\text { Descripción del } \\
\text { contenido: }\end{array}$ & \multicolumn{3}{|c|}{ Días de Piso Seguro por cada SKU_Locación de Venta } \\
\hline Fuente: & \multicolumn{3}{|l|}{$\begin{array}{l}\text { AVAIL } \\
\text { ( Tabla nDs -> Edit Whse-Product ) } \\
\text { Bajar Campos Prod, To Loc, Safe DS }\end{array}$} \\
\hline Observaciones & \multicolumn{3}{|c|}{$\begin{array}{l}\text { Utilizar la política de stock que defina abastecimiento de acuerdo a la } \\
\text { temporada a analizar }\end{array}$} \\
\hline \multicolumn{4}{|c|}{ Descripción de Campos: } \\
\hline Campos & Descripción & Fuente & Ejemplo \\
\hline Código SAP & Código SAP de PTER & $\begin{array}{l}\text { AVAIL: Menú nDs- }>\text { Tabla } \\
\text { Hub Whse-Product }>\text { Campo } \\
\text { Prod }\end{array}$ & 751080 \\
\hline WHSE & Nombre AVAIL de la locación & $\begin{array}{l}\text { AVAIL: Menú nDs-> Tabla } \\
\text { Hub Whse-Product> Campo } \\
\text { "To Loc" }\end{array}$ & AQPNO \\
\hline Código de depósito & Código de Depósito de la locación & $\begin{array}{l}\text { Campo externo del Maestro de } \\
\text { locaciones para unir con los } \\
\text { archivos de demanda }\end{array}$ & 54 \\
\hline Días Seguro & $\begin{array}{l}\text { Días de Piso para llegar al nivel serguro } \\
\text { de inventarios }\end{array}$ & $\begin{array}{l}\text { AVAIL: Menú nDs-> Tabla } \\
\text { Hub Whse-Product> Campo } \\
\text { "Safe DS" }\end{array}$ & 4 \\
\hline
\end{tabular}

Figura 79. Ficha del maestro de política de Inventarios. Derechos Reservados Vilela, 2017. 


\begin{tabular}{|c|c|c|c|}
\hline \multicolumn{4}{|l|}{ Ficha del Maestro: } \\
\hline Título & \multicolumn{3}{|l|}{ Maestro de Locaciones } \\
\hline $\begin{array}{l}\text { Descripción del } \\
\text { contenido: }\end{array}$ & \multicolumn{3}{|c|}{$\begin{array}{l}\text { Descripción de cada Locación (PLANTA; PULMON; CDA/OL), códigos en el sistema comercial, SAP } \\
\text { y AVAIL. Región Comercial de cada Locación }\end{array}$} \\
\hline Fuente: & \multicolumn{3}{|c|}{$\begin{array}{l}\text { AVAIL - Actualizado por Distribución } \\
\text { Tabla Set-Up }>\text { Edit Locations }>\text { All Locations } \\
\text { Bajar campos Loc, }<<\text { Loc }>> \\
\text { Recopilar Tabla SAP de equivalencias de código Comercial con código SAP } \\
\text { Recopilar Tablas de Descripción de Locaciones del equipo de Abastecimiento }\end{array}$} \\
\hline Observaciones & \multicolumn{3}{|c|}{$\begin{array}{l}\text { El }<<\text { Loc }>>\text { de la tabla Avail contiene el código de Depósito del sistema comercial de las locaciones, en } \\
\text { el caso de MEPA cambiar el código MA por el código } 29 .\end{array}$} \\
\hline \multicolumn{4}{|l|}{ Descripción de Campos: } \\
\hline Campos & Descripción & Fuente & Ejemplo \\
\hline Código de depósito & Código de locación Comercial (Sistema SIPAN/BASIS) & $\begin{array}{c}\text { Up-> Table Edit } \\
\text { Locations-> } \\
\text { Opción All } \\
\end{array}$ & ABANC \\
\hline Código SAP & $\begin{array}{c}\text { Código de locación en SAP (Fuente: Tabla de equivalencias de } \\
\text { SAP/SIPAN) }\end{array}$ & $\begin{array}{c}\text { Archivo de } \\
\text { equivalencias de } \\
\text { SAP }\end{array}$ & 91 \\
\hline Nombre AVAIL & $\begin{array}{l}\text { Descripción de la Locación en AVAIL } \\
\text { Campo Loc }\end{array}$ & $\begin{array}{c}\text { Up-> Table Edit } \\
\text { Locations-> } \\
\text { Opción All } \\
\text { Locacations -> }\end{array}$ & 8091 \\
\hline Descripción & $\begin{array}{c}\text { Descripción completa del CDA (Definir el nombre que se quiere } \\
\text { mostrar) }\end{array}$ & Campo Manual & $x x x$ \\
\hline Región Comercial & Región Comercial de la Locación & $\begin{array}{l}\text { locaciones de } \\
\text { SIPAN }\end{array}$ & Sur \\
\hline Tipo de Locación & $\begin{array}{c}\text { Descripción; Consignación, Venta Directa, OL, Planta, Pulmón } \\
\text { (Definir el tipo que se quiere segmentar) }\end{array}$ & Campo Manual & Consignación \\
\hline
\end{tabular}

Figura 80. Ficha de Maestro de Locaciones. Derechos reservados, 2017.

\section{$\underline{\text { Lógica de cálculo }}$}

La herramienta temporal que soportará el proceso de planeamiento estratégico y operativo será realizada en el aplicativo de Microsoft Power Pivot. La lógica de cálculo que deberá seguir para poder calcular los requerimientos de distribución y producción es el siguiente: 
Para cada locación a nivel SKU o componentes se calcula el requerimiento de distribución siguiendo la siguiente lógica:

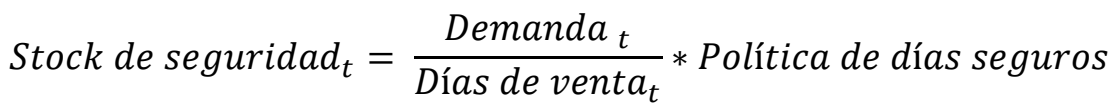

Necesidad de distribución $n_{t}=$ Demanda $_{t}+$ Stock de Seguridad $_{t}$

Stock de Proyectado $_{t}=$ Requerimiento $_{t-1}+$ Stock $_{\text {proyectado }}$ Re-1 $_{- \text {Demanda }_{t-1}}$

Necesidad de distribución $n_{t}=\left(\right.$ Inventario $_{t-1}-$ Demand $\left._{t}\right)+$ Stock de Seguridad

$\rightarrow$ Requerimiento de distribución $_{t}=$ Necesidad $_{t}-$ Stock Proyectado $_{t}$

Si el requerimiento de distribución es menor a la mitad de una unidad de envío se redondea al mayor.

Con el requerimiento de distribución de calcula el requerimiento de producción considerando la suma de los componentes de maquilas a los SKUS de línea y sumando el tota de necesidades en una Planta o región de abastecimiento:

A nivel SKU se calcula para todas las locaciones de una planta el requerimiento:

Requerimiento de Producción $n_{t}$

$=$ Requerimiento de distribución $_{t}+$ Requerimiento de componentes $_{t}$ 


\begin{tabular}{|c|c|c|c|c|c|c|c|c|c|c|c|c|c|}
\hline CAMPOS & Mes & SKU & LOC & FORECAST ( CF) & \begin{tabular}{|c|}
$\begin{array}{c}\text { Stocks proyectado en } \\
\text { Locación a cierre de } \\
\text { mes }\end{array}$ \\
\end{tabular} & \begin{tabular}{|c|} 
Política de \\
Stock \\
Seguro \\
\end{tabular} & Paletaje & Forecast Promedio Diario & \begin{tabular}{|c}
$\begin{array}{c}\text { Forecast Diario } \\
\text { con Stock de } \\
\text { seguridad }\end{array}$ \\
\end{tabular} & Seguro del Mes & Necesidad & Stock Proyectado & $\begin{array}{l}\text { Requerimiento de } \\
\text { distribución }\end{array}$ \\
\hline \multirow{8}{*}{ Datos de ejemplo } & Junio & 250039 & 29 & 500 & \begin{tabular}{|c|}
300 \\
\end{tabular} & \begin{tabular}{|c|}
4.5 \\
\end{tabular} & 60 & 19 & \begin{tabular}{|c|}
87 \\
\end{tabular} & 52 & 552 & 300 & 252 \\
\hline & Julio & 250039 & 29 & 300 & & 4.5 & 60 & 12 & 52 & & 300 & 52 & 248 \\
\hline & $\begin{array}{l}\text { Junio } \\
\end{array}$ & 251185 & 29 & 100 & 50 & 2.7 & 120 & 4 & 10 & 21 & 121 & 50 & 120 \\
\hline & Julio & 251185 & 29 & 200 & & 2.7 & 120 & 8 & 21 & & 200 & 70 & 130 \\
\hline & $\begin{array}{l}\text { Junio } \\
\end{array}$ & 250382 & 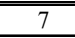 & 200 & 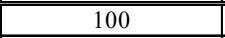 & 3.1 & 80 & 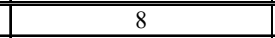 & 24 & 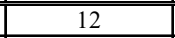 & 2212 & 100 & $\overline{1112}$ \\
\hline & Julio & 250382 & 7 & 100 & & 3.1 & 80 & 4 & 12 & & 100 & 12 & 88 \\
\hline & Junio & 251185 & $\overline{77}$ & 100 & 80 & 3.7 & $\overline{120}$ & $\overline{44}$ & 14 & 21 & 121 & 80 & 120 \\
\hline & Julio & 251185 & 7 & 150 & & 3.7 & 120 & 6 & 21 & & 150 & 100 & 120 \\
\hline Fuente & \multicolumn{4}{|c|}{ Archivo demanda de largo plazo } & Archivo de Coberturas & \multicolumn{2}{|c|}{ Maestros Genéricos } & \multicolumn{6}{|c|}{ Cálculos de Requerimiento } \\
\hline Observaciones & & & & \begin{tabular}{|c|} 
Se transforma el \\
Forecast de CU a CF \\
con el Factor de \\
conversión
\end{tabular} & \begin{tabular}{|c|} 
Se calcula un inventario \\
proyectado de acuerdo al \\
último stock y los dias \\
faltantes para el cierre
\end{tabular} & & \begin{tabular}{|c|} 
El paletaje está dado de \\
acuerdo a la planta de \\
asignada para el SKU- \\
LOCACIÖN
\end{tabular} & $\begin{array}{c}\text { Se ha considerado } 26 \text { dias para } \\
\text { el cálculo. } \\
\text { Se podría utilizar un maestro de } \\
\text { dias de venta efectivo (BP) }\end{array}$ & & \begin{tabular}{|c|} 
Se considera seguro \\
del mes al forecast \\
diario con dias \\
seguro del mes \\
siguiente:
\end{tabular} & & $\begin{array}{l}\text { Para el primer Mes se utiliza el dato ded } \\
\text { stock del proyectado del archivo de } \\
\text { coberturas. Para los meses siguientes se } \\
\text { calcula de acuerdo a la formula. }\end{array}$ & $\begin{array}{c}\text { Si el Requerimiento es } \\
\text { menor a a unidad de Envío } \\
\text { (Pallet) Se considera a la } \\
\text { Pallet (paletaje) como } \\
\text { requerimiento. }\end{array}$ \\
\hline Fórmulas & & & & $\begin{array}{c}\text { Forecast (CU) } \\
\text { x Factor de Conversión } \\
\text { (CF/CU) }\end{array}$ & $\begin{array}{l}\text { Inventarios (CF) } \\
\text { - Forecast (CF) }\end{array}$ & & & $\frac{\text { Forecast Mensual }}{\text { Cantidad de días del Mes }}$ & $\begin{array}{l}\text { Forecast Promedio } \\
\text { Diario x } \\
\text { Días Seguro }\end{array}$ & & $\begin{array}{l}\text { Seguro del Mes } \\
+ \text { Forecast }\end{array}$ & $\begin{array}{c}\text { Cálculo con datos del Mes Anterior } \\
\text { Requerimiento } \\
\text { + Stock Proyectado } \\
\text { - Forecast }\end{array}$ & $\begin{array}{l}\text { Necesidad - } \\
\text { Stock Proyectado }\end{array}$ \\
\hline
\end{tabular}

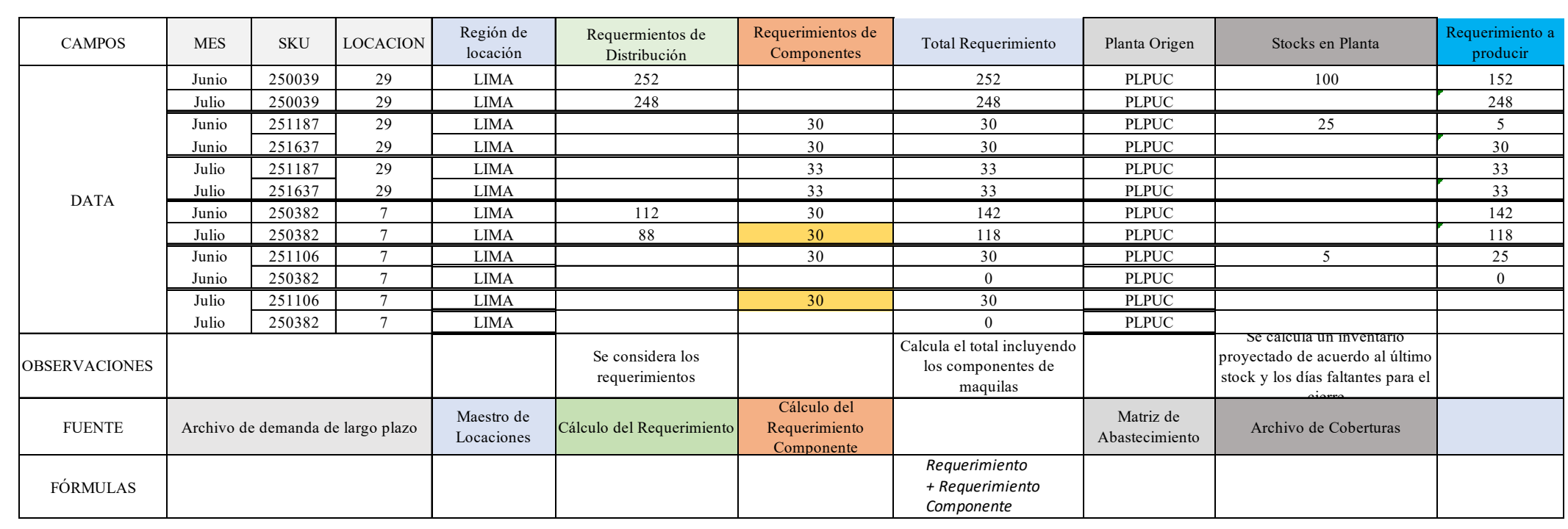




\subsection{Estudiar}

El proceso definido necesita de un seguimiento continuo para poder establecer mejoras al proceso. En esa línea se proponen dos tipos de seguimientos:

- Análisis del comportamiento de los niveles de inventario

- Seguimiento a objetivos

\section{$\underline{\text { Análisis del comportamiento de los niveles de inventario }}$}

De acuerdo a las simulaciones y teoría de la metodología DDMRP el inventario debe pasar de una distribución bimodal del inventario con excesos y faltantes, a una distribución normal con media en el nivel Seguro.

Para esto se debe realizar mensualmente un análisis de la distribución mediante el conteo de incidencias de los niveles a cada SKU. En la figura 64, se muestra un ejemplo del análisis con la situación actual de la empresa. Se debe hacer un seguimiento a este comportamiento una vez implementada la propuesta. A medida que pasan los meses debería haber mejoras en el estado de los inventarios.

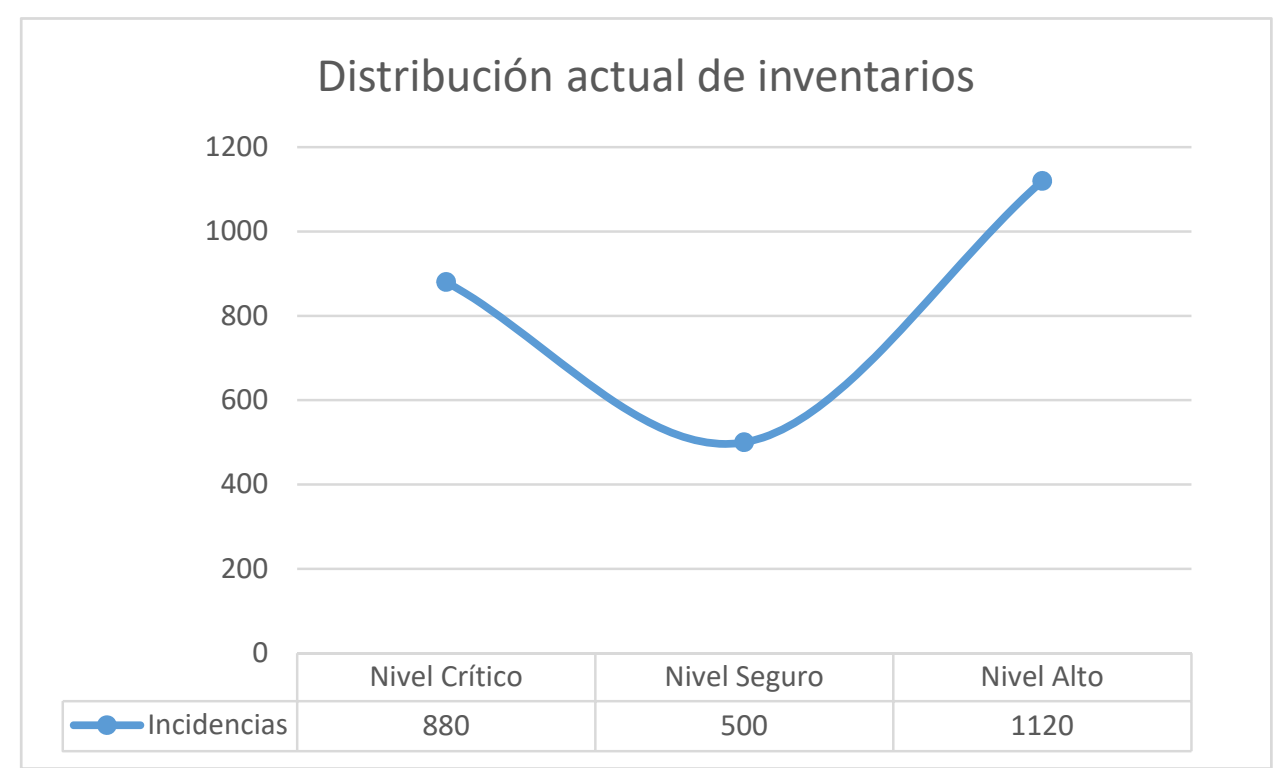

Figura 81. Ejemplo análisis de distribución de inventarios. Derechos reservados Vilela, 2017. 
$\underline{\text { Seguimiento a objetivos }}$

Para el seguimiento a objetivos se han definido los siguientes indicadores basados en los tres objetivos fundamentales:

1. Vencimientos del almacén: Se debe controlar que la nueva política de inventarios disminuye la cantidad de vencimientos generados en el almacén.

2. Desabastecimientos: La nueva política debe reducir el porcentaje de desabastecimientos de la locación

3. Costo total de inventarios: La nueva política debe reducir el costo total de inventarios

A continuación, se presentan cada una de las fichas de los indicadores: 


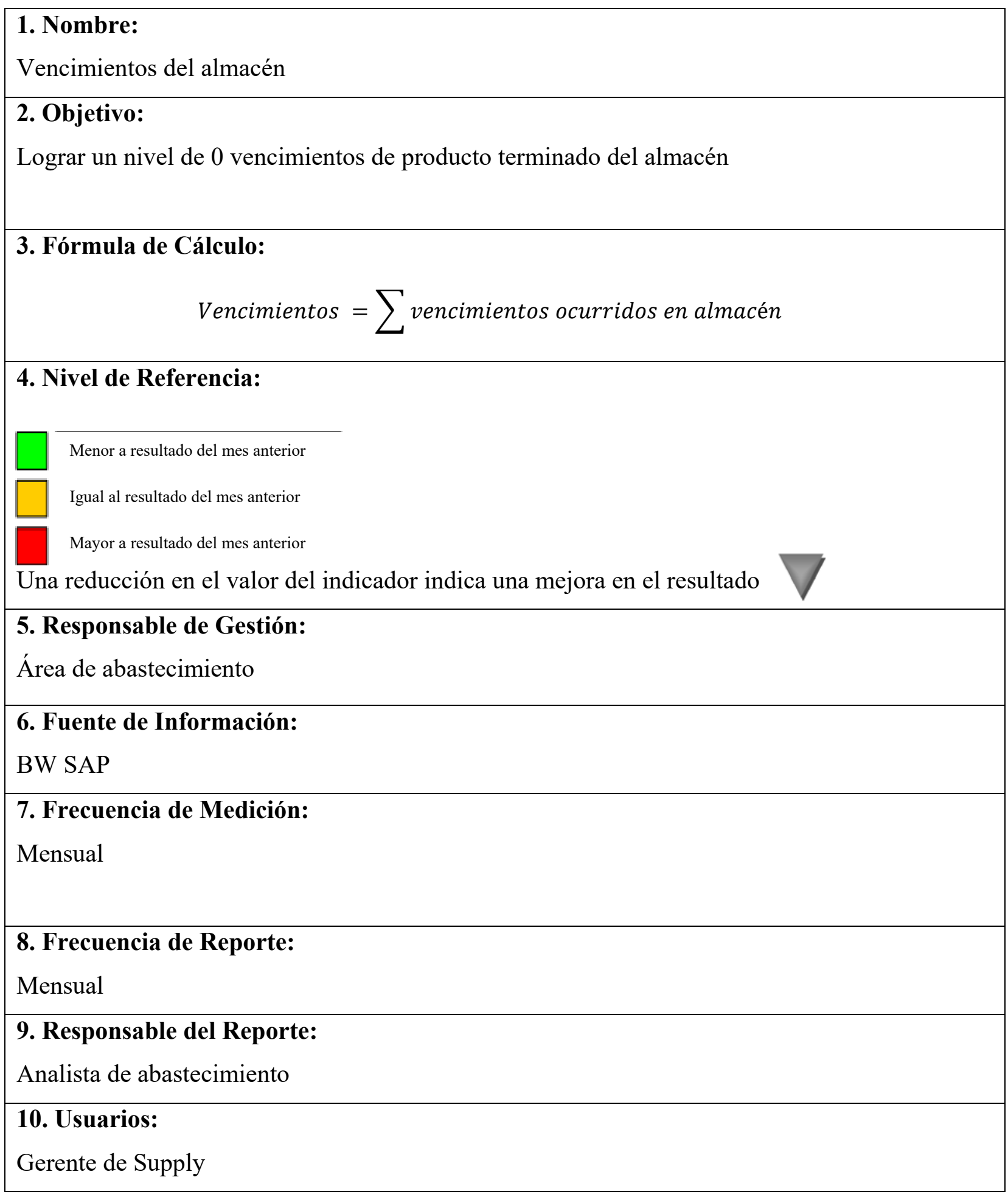




\section{Nombre:}

Desabastecimientos

\section{Objetivo:}

Lograr un nivel de $2 \%$ de desabastecimientos sobre la demanda mensual.

\section{Fórmula de Cálculo:}

$$
\text { Desabastecimientos }=\frac{\text { Desabastecimientos }}{\text { Demanda }}
$$

\section{Nivel de Referencia:}

$$
<4 \%
$$

$4 \%-6 \%$

$>6 \%$

Una reducción en el valor del indicador indica una mejora en el resultado

\section{Responsable de Gestión:}

Área de abastecimiento

\section{Fuente de Información:}

BW SAP

\section{Frecuencia de Medición:}

Mensual

\section{Frecuencia de Reporte:}

Mensual

\section{Responsable del Reporte:}

Analista de abastecimiento

10. Usuarios:

Gerente de Supply 


\section{Nombre:}

Costo Total de inventario

\section{Objetivo:}

Reducir el costo total de inventarios

3. Fórmula de Cálculo:

$$
\text { Dif Costo Total de inventarios }=\frac{\text { Costo stk año actual }}{\text { Costo stk año anterior }}
$$

\section{Nivel de Referencia:}

$$
<1 \%
$$

$1 \%-0 \%$

$>0 \%$

Una reducción en el valor del indicador indica una mejora en el resultado

\section{Responsable de Gestión:}

Área de abastecimiento

\section{Fuente de Información:}

Herramienta de cálculo de costos

7. Frecuencia de Medición:

Mensual

\section{Frecuencia de Reporte:}

Mensual

\section{Responsable del Reporte:}

Analista de abastecimiento

10. Usuarios:

Gerente de Supply 


\subsection{Plan de implementación}

La implementación de la propuesta se debe basar en dos fases. La primera fase incluye el piloto y la salida en productivo de una locación con el nuevo modelo de política de stocks. Una vez que esta locación haya implementado el modelo, se procederá a definir los grupos de locaciones en los cuales se implementará la herramienta como segunda fase.

Se espera que la herramienta pueda ser implementada en todas las locaciones de una sola región para poder pasar a una tercera fase que sería incluir la política de producción como parte del proceso.

En la figura 80, se muestra a detalle las tareas que se deben ejecutar para implementar el proyecto. El periodo de la primera fase dura 4 meses.

Proyecto Política de Stocks

Fase 1:

Defnición de roles

Presentación del proyecto Conformación del equipo de trabajo Armado de plan de trabajo

Construcción de herramienta

Anáslis de SKUS para clasificación ABC Recolección data ventas y costos Estudio de lead times

Recolección de curvas de nivel de servicio Armado de definiciones de la herramienta Construcción de la herramienta Implementación del Plan Piloto

Capacitación a Analistas de abastecimiento y producción Cambio de parámetros en los sistemas Inicio de Piloto Validación de resultados Retroalimentación y gestión de cambios Extensión de la herramienta

Definición de grupos de locaciones

Definición de gantt de implementación

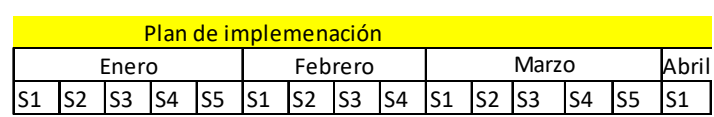

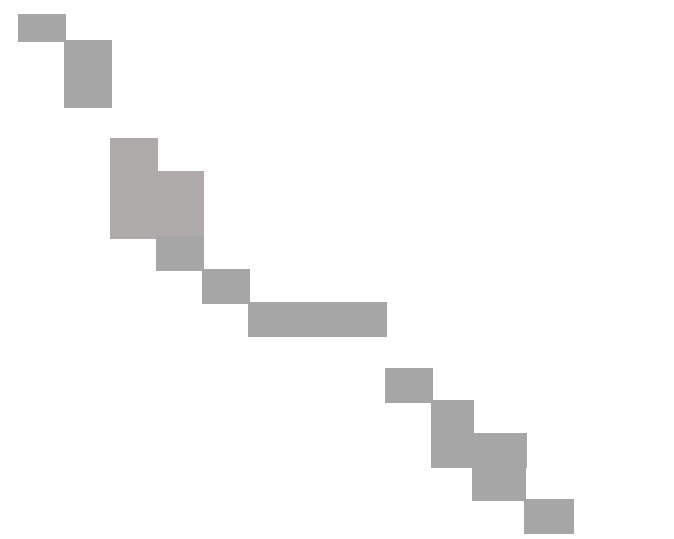

Figura 82. Gantt de implementación en fase 1 


\section{Capítulo IV: Evaluación y validación de la propuesta}

En este capítulo se procederá a evaluar la efectividad de la propuesta mediante una simulación piloto. Así, también se presentarán los indicadores económicos y los impactos de la propuesta.

\subsection{Validación de la propuesta}

Para validar la propuesta de solución se realizó una corrida con los resultados obtenidos en el proceso de definición de políticas de stocks. Este resultado fue comparado versus la política de stocks anterior de la locación y se comprueba la reducción de costos e inventario. A continuación, se explicará paso a paso el método utilizado para la simulación.

\subsubsection{Método para la simulación}

Se ha utilizado el programa de simulación del sistema AV de Areté INC. Este sistema de planificación contiene toda la data maestra y transaccional de la empresa y es capaz de realizar una simulación completa de los envíos y posiciones de inventarios para un periodo de tiempos.

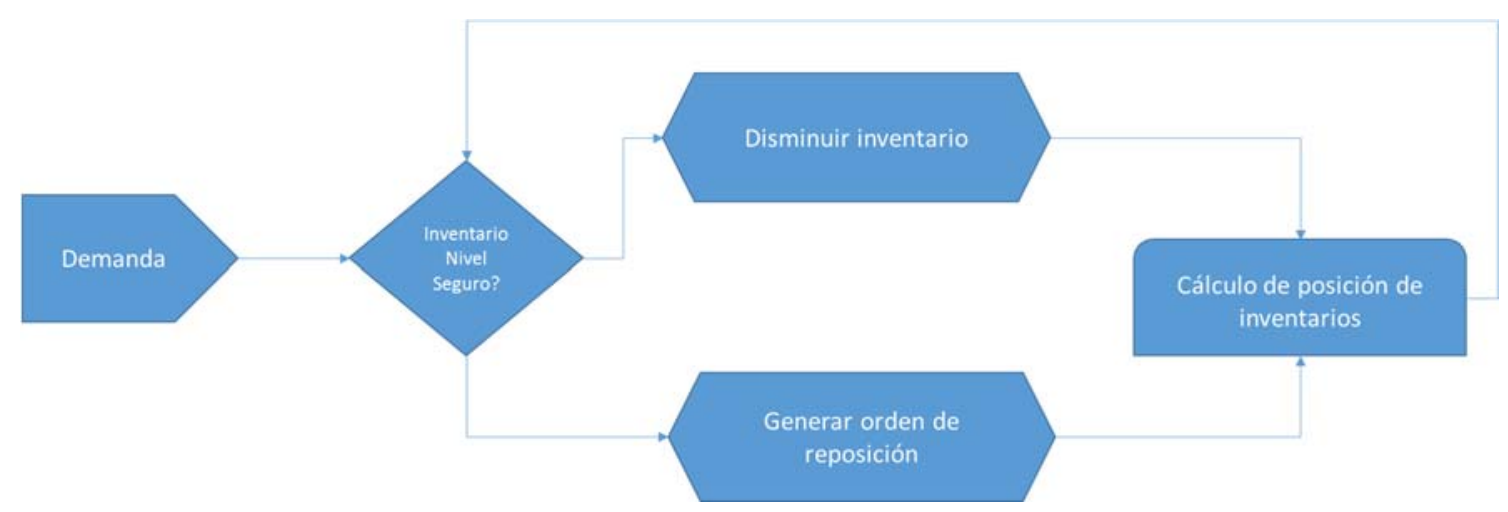

Figura 83. Esquema de la simulación en AV

En la figura 81 se muestra un esquema de la simulación en el sistema, para calcular las posiciones de inventarios en la locación. El sistema considera el ingreso de una demanda al almacén, basado en los pronósticos de su módulo PV, a partir de esta, se revisan los inventarios de la locación basada inicialmente el stock declarado en el sistema el día de 
la simulación. Si los inventarios no llegan a nivel seguro de la política se genera una orden de reposición, con la cual se vuelve a calcular la posición del inventario en la locación.

Esta simulación del sistema se cruza con los costos de ordenar y de mantener el inventario y los niveles de servicio, obtenidos en el capítulo 3. Esto permite traducir la posición del inventario de la locación a términos cuantificables para un análisis de resultados sobre costos y niveles de servicios.

\begin{tabular}{|c|c|c|c|c|c|c|c|}
\hline & |---.--- & & $12 / 15$ & -..---o- & |--.--..- & Sat $12 / 16$ & $|-\cdots---|$ \\
\hline & Today's & Scheduled & Today's & End of Day & Deploy & & End of Day \\
\hline Product & Inventory & InTransits & Demand & Inventory & Quantity & Demand & Inventory \\
\hline ="==="=="==" & $=========$ & ="==="===" & =="==="=== & =="=="=="== & ="==="===" & ="==="=="== & $=========$ \\
\hline 250070 & 1395 & 0 & 1286 & 109 & 1296 & 0 & 1405 \\
\hline 250070 & 546 & 0 & 163 & 383 & 0 & 0 & 383 \\
\hline 250070 & 91 & 0 & 4 & 87 & 13 & 0 & 100 \\
\hline 250070 & 695 & 0 & 16 & 679 & 0 & 0 & 679 \\
\hline 250070 & 101 & 0 & 5 & 96 & 0 & 0 & 96 \\
\hline 250070 & 41 & 0 & 2 & 39 & 0 & 0 & 39 \\
\hline 250070 & 152 & 0 & 8 & 144 & 0 & 0 & 144 \\
\hline 250070 & 216 & 0 & 90 & 126 & 108 & 0 & 234 \\
\hline
\end{tabular}

Figura 84. Resultado de la simulación en el sistema

En la figura 82 se muestra el resultado de la simulación en el sistema. Las primeras columnas hacen la proyección de la posición del inventario con el stock cargado al día de hoy la demanda ingresada. Para los siguientes días, se utiliza la demanda pronosticada y con ello se calcula el envío de carga a la locación y su posición de inventario cada día. En la tabla 30 , se presentó cómo a este resultado del sistema se le puede agregar los costos y la fórmula de nivel de servicio. El resultado de la simulación se muestra en la tabla 30. 
Tabla 30.

Resultados de la simulación

\begin{tabular}{|c|c|c|c|c|c|c|c|}
\hline Código SAP Perú & Crítico & Verde & Parar & $\begin{array}{l}\text { Nivel de } \\
\text { servicio }\end{array}$ & $\begin{array}{l}\text { Nivel de } \\
\text { servicio }\end{array}$ & Costo & Total \\
\hline 252322 & 2.5 & 5.5 & 7.0 & A & 96 & S/. & 60,123 \\
\hline 250736 & 1.9 & 4.9 & 6.4 & $A$ & 95 & $\mathrm{~S} /$. & 82,304 \\
\hline 250204 & 1.9 & 4.9 & 6.1 & $A$ & 94 & $\mathrm{~S} / \mathrm{.}$ & 70,345 \\
\hline 251637 & 1.5 & 4.5 & 5.7 & $A$ & 97 & $\mathrm{~S} /$. & 78,597 \\
\hline 251641 & 1.9 & 4.9 & 6.4 & $A$ & 94 & $\mathrm{~S} /$. & 79,345 \\
\hline 251187 & 1.4 & 4.4 & 5.6 & $A$ & 95 & $\mathrm{~S} / \mathrm{.}$ & 84,560 \\
\hline 251520 & 1.9 & 4.9 & 6.4 & $A$ & 97 & $\mathrm{~S} /$. & 79,323 \\
\hline 254850 & 1.8 & 4.8 & 6.3 & $A$ & 97 & $\mathrm{~S} /$. & 65,736 \\
\hline 251385 & 1.8 & 4.8 & 6.3 & $A$ & 94 & $\mathrm{~S} / \mathrm{.}$ & 68,934 \\
\hline 251301 & 1.5 & 4.5 & 5.7 & $A$ & 95 & $\mathrm{~S} /$. & 50,342 \\
\hline 252527 & 1.1 & 4.1 & 4.8 & $A$ & 94 & $\mathrm{~S} /$. & 45,986 \\
\hline 251620 & 1.1 & 4.1 & 4.8 & B & 90 & $\mathrm{~S} /$. & 40,668 \\
\hline 252618 & 1.1 & 4.1 & 4.8 & B & 89 & $\mathrm{~S} /$. & 44,578 \\
\hline 250411 & 1.1 & 4.1 & 4.8 & B & 92 & $\mathrm{~S} /$. & 41,086 \\
\hline 254734 & 1.1 & 4.1 & 4.8 & B & 91 & $\mathrm{~S} /$. & 57,890 \\
\hline 250041 & 1.2 & 4.2 & 4.8 & B & 91 & $\mathrm{~S} /$. & 52,356 \\
\hline 251570 & 1.1 & 4.1 & 4.8 & B & 90 & $\mathrm{~S} /$. & 53,250 \\
\hline 254742 & 1.0 & 4.0 & 4.8 & B & 90 & $\mathrm{~S} /$. & 85,708 \\
\hline 254706 & 1.0 & 4.0 & 4.8 & B & 91 & $\mathrm{~S} /$. & 88,965 \\
\hline 255331 & 1.4 & 4.4 & 5.6 & B & 94 & $\mathrm{~S} /$. & 89,042 \\
\hline 254853 & 1.5 & 4.5 & 5.7 & B & 92 & $\mathrm{~S} /$. & 98,765 \\
\hline 254786 & 1.9 & 4.9 & 6.4 & B & 93 & $\mathrm{~S} /$. & 90,234 \\
\hline 255332 & 1.5 & 4.5 & 5.7 & B & 89 & $\mathrm{~S} /$. & 84,312 \\
\hline 254733 & 1.1 & 4.1 & 4.8 & B & 90 & $\mathrm{~S} /$. & 82,345 \\
\hline 254930 & 1.0 & 4.0 & 4.8 & B & 93 & $\mathrm{~S} /$. & 80,972 \\
\hline 254849 & 1.5 & 4.5 & 5.7 & B & 91 & $\mathrm{~S} /$. & 74,352 \\
\hline 254843 & 1.0 & 4.0 & 4.8 & $C$ & 85 & $\mathrm{~S} /$. & 65,334 \\
\hline 254842 & 1.0 & 4.0 & 4.8 & $C$ & 87 & $\mathrm{~S} /$. & 89,435 \\
\hline 254851 & 1.5 & 4.5 & 5.7 & $\mathrm{C}$ & 88 & $\mathrm{~S} /$. & 63,582 \\
\hline 254950 & 1.7 & 4.7 & 6.2 & $C$ & 86 & $\mathrm{~S} /$. & 71,204 \\
\hline 254954 & 1.7 & 4.7 & 6.2 & C & 89 & S/. & 78,903 \\
\hline 255440 & 1.0 & 4.0 & 4.8 & $\mathrm{C}$ & 84 & $\mathrm{~S} /$. & 79,043 \\
\hline 255382 & 1.8 & 4.8 & 6.3 & $C$ & 88 & $\mathrm{~S} /$. & 71,235 \\
\hline 256285 & 1.4 & 4.4 & 5.6 & C & 85 & $\mathrm{~S} /$. & 79,345 \\
\hline 256330 & 1.4 & 4.4 & 5.6 & $\mathrm{C}$ & 80 & $\mathrm{~S} /$. & 69,045 \\
\hline 254885 & 1.5 & 4.5 & 5.7 & $C$ & 84 & $\mathrm{~S} /$. & 85,678 \\
\hline 256332 & 1.4 & 4.4 & 5.6 & C & 88 & $\mathrm{~S} /$. & 81,045 \\
\hline 256357 & 1.5 & 4.5 & 5.7 & C & 89 & $\mathrm{~S} /$. & 79,352 \\
\hline 256355 & 1.4 & 4.4 & 5.6 & $\mathrm{C}$ & 87 & $\mathrm{~S} /$. & 79,567 \\
\hline 256369 & 1.4 & 4.4 & 5.6 & C & 88 & $\mathrm{~S} /$ & 97,593 \\
\hline
\end{tabular}

Nota: Derechos reservados Vilela, 2017.

\subsubsection{Análisis de resultados}

A continuación, se presentan los resultados de los resultados totales después de la simulación de la propuesta de solución, se realizó el análisis de resultados en base a la medición de los indicadores propuestos en el capítulo 3. 


\section{Comparativo de costos de stock:}

Este indicador comparativo es el diferencial porcentual del costo de stock comparando el mismo periodo en el año anterior. Se calculará de la siguiente forma:

$$
\text { DifCosto }=\frac{\text { Costo stk política actual }}{\text { Costo stk política anterior }}
$$

La siguiente ilustración muestra el total de costos del mes de noviembre con la política actual y sus costos esperados con la nueva política de inventarios. La reducción del costo total de inventarios fue de $1.4 \mathrm{M}$ soles para la locación MEPA, con esto se obtuvo una reducción de $68 \%$ de los costos totales respecto a la política anterior. Por lo tanto,

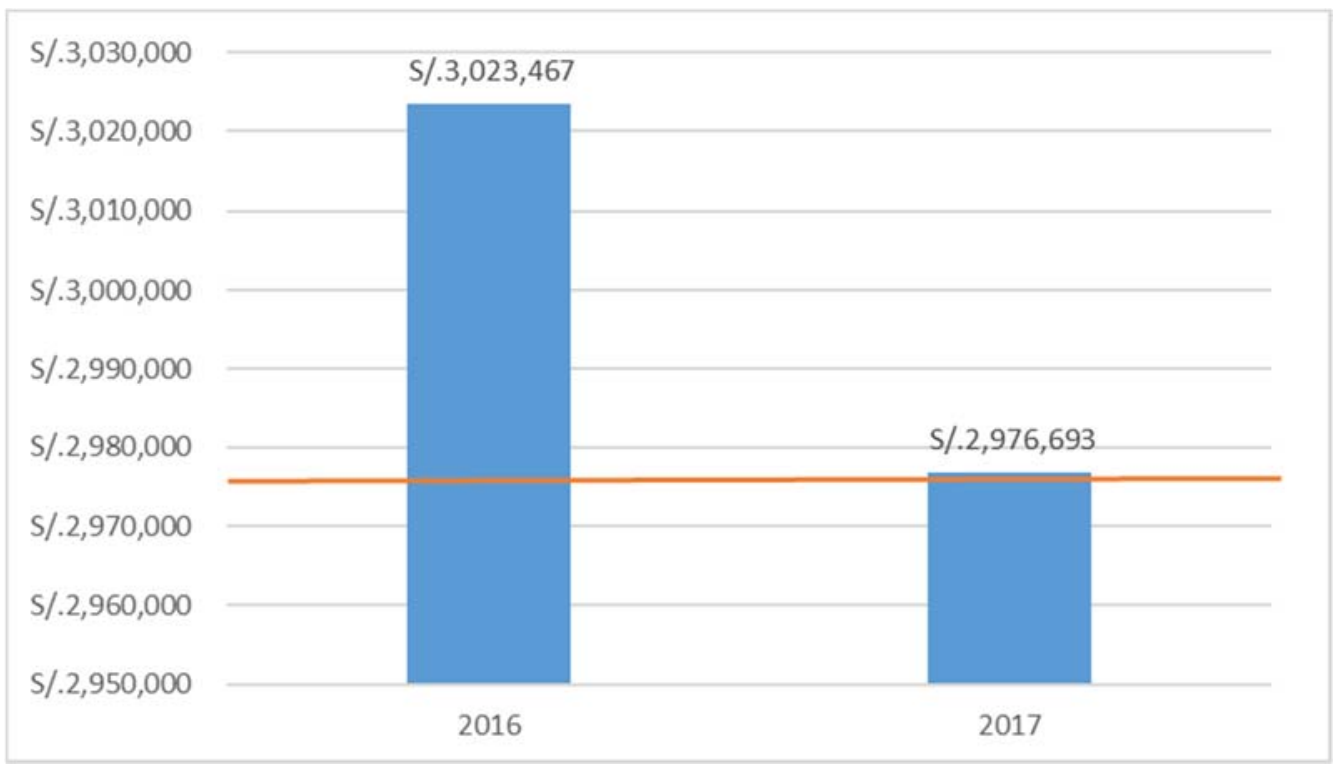

Figura 83. Comparativo de costos de stock. Derechos Vilela, 2017.

\section{$>$ Comparativo de niveles de servicio}

Este indicador comparativo es el diferencial porcentual de los niveles de servicio comparando el mismo periodo con la política de la propuesta y la política actual. Se calculará de la siguiente forma: 
En la siguiente tabla podemos observar que el nivel de servicio ha mejorado con la nueva propuesta de inventarios en las categorías A y C. La categoría B disminuyó en nivel de servicio por 3 puntos porcentuales; sin embargo aún sigue dentro del rango de nivel de servicio objetivo. En general, se observa una mejor distribución de los niveles de servicio, de acuerdo a su clasificación ABC. Por lo tanto, el indicador fue exitoso.

Tabla 31.

Comparación de niveles de servicio promedio

\begin{tabular}{ccccc}
\hline Categoría & $\begin{array}{c}\text { Objetivo de NS } \\
\text { por categoría }\end{array}$ & $\begin{array}{c}\text { Nivel de servicio } \\
\text { promedio } \\
\text { actual }\end{array}$ & $\begin{array}{c}\text { Nivel de } \\
\text { servicio } \\
\text { promedio } \\
\text { propuesto }\end{array}$ & $\begin{array}{c}\text { Diferencia } \\
\text { Niveles de } \\
\text { servicio }\end{array}$ \\
\hline A & $95 \%$ & $90 \%$ & $96 \%$ & $6 \mathrm{pp}$ \\
B & $90 \%$ & $96 \%$ & $93 \%$ & $-3 p p$ \\
C & $85 \%$ & $90 \%$ & $87 \%$ & $-3 p p$ \\
\hline
\end{tabular}

Nota: Información de Noviembre 2017, Derechos reservado Vilela, 2017.

\title{
4.2 Evaluación económica
}

\author{
DifNiveles de servicio \\ $=$ Nivel de servicio promedio propuesto \\ - Nivel de servicio promedio anterior
}

Se realizó la validación económica en base al uso de indicadores financieros tales como el VAN, TIR y el Costo Beneficio. Para ello, se elaboró un flujo de caja resumen para el escenario esperado

- El escenario esperado: Es el escenario que se propuso en el capítulo anterior, como situación esperada después de la implementación de la propuesta de solución.

La siguiente tabla muestra el flujo de caja resumido para el escenario real. En ella se toma el dato de simulación del mes de noviembre y se proyecta el ahorro para los siguientes meses con un porcentaje proporcional al crecimiento de la demanda para cada mes respecto al año pasado

Según este flujo de caja se calculan los siguientes indicadores financieros: 
- El VAN, sería aproximadamente de S/. 333,005. Esto quiere decir que se obtendrá una ganancia respecto a la alternativa que representa el costo de oportunidad. Por ello, según este indicador sigue siendo recomendable realizar la inversión.

- $\quad$ El TIR es de 911\%. Es elevado debido a que las utilidades son altas y la inversión es pequeña. Como se obtiene mayor interés por la inversión en el proyecto que por la tasa de descuento, este indicador valida la rentabilidad del proyecto.

- La Razón costo beneficio es de 103.9. Esto quiere decir que por cada sol invertido se recupera S/. 103.9. Por ello, según este indicador la inversión es recomendable.

Con este análisis concluimos después de un mes del inicio de la puesta en marcha del proyecto, que este es válido económicamente. Esto comprueba la veracidad de la hipótesis planteada en el segundo capítulo. 


\subsection{Impacto de la Solución}

Para concluir con la validación de la respuesta, se realizó el estudio de los impactos relevantes. Se clasificaron dichos impactos por cada interesado: impacto en los trabajadores, en la organización, en los clientes, en los competidores y en el ambiente. Finalmente, se analizaron los riesgos mediante una matriz de probabilidad - impacto, relacionando cada riesgo con los objetivos del proyecto planteados en el capítulo anterior.

\subsubsection{Impacto Interno}

El impacto interno se refiere al impacto que tendrá la propuesta en la compañía, tanto en sus procesos como en sus empleados.

\subsubsection{Impacto en los trabajadores}

El impacto en los trabajadores se divide en los siguientes puntos:

- Impacto positivo:

- Menos horas extra y mejora de la comunicación por funciones definidas y pautas objetivas para la toma de decisiones.

- Mayor eficiencia en el flujo de distribución por la automatización de los reportes enviados a las áreas.

- Mayor integración entre las áreas de abastecimiento, producción y distribución por flujo de planeamiento cohesionado.

- Impacto negativo:

- Resistencia al cambio: Los trabajadores que antiguamente llevaban esta función pueden resistirse al cambio e imposición de una nueva forma de trabajo, debido a que se trata de trabajadores antiguos con muchos años de experiencia. Por ello, se propone introducir a propuesta mostrando los beneficios en los temas de ahorro de tiempo y mejora en la integración de las áreas. Así también, se propone integrar a la validación de la política de stocks a toda la gerencia de supply para concertar como equipo la nueva propuesta. 
- Abandono del proyecto: Un riesgo sobre la propuesta es que no se implemente como un proceso regular y se realice con la frecuencia adecuada. El área de abastecimiento es altamente dinámica, por lo que agregar nuevas tareas podría generar una sobrecarga en el trabajo y que la propuesta solo se ejecute una vez y luego se abandone. Por ello, la propuesta incluye la automatización de la herramienta con un programador de visual basic. De esta manera, se buscan acortar los tiempos de las tareas. Así también, se han incluido procedimientos resumidos para que el despliegue del proyecto sea entendible y fácil.

\subsubsection{Impacto en la compañía}

El impacto en la compañía se ha divido en los siguientes puntos:

- Impacto Positivo:

- Mayor rentabilidad por reducción de costos de stocks y menor riesgo de vencimiento

- Mayor nivel de servicio. Mejor imagen hacia el cliente.

- Procesos estructurados con bases objetivas y separación de funciones. Aumenta la madurez como compañía porque se tienen menos procesos empíricos y no controlables.

- Impacto Negativo:

- Es posible que apenas se implemente la propuesta exista una pequeña desviación en el nivel de servicio porque se debe implementar por partes. Primero el área de abastecimiento y luego todo el sistema de producción. Por ello, para mitigar cualquier desabastecimiento que pueda ocurrir es necesario estar preparados con stock de emergencia.

- Es posible que exista una falta de interés de la Alta dirección y opten cambiar por otro sistema de planificación para resolver las deficiencias. Esto cambiaría parte de la propuesta. Sin embargo; la propuesta es adaptable a cualquier nuevo sistema de planificación pues se ha puesto énfasis en estructurarla como un proceso estratégico. Por ello, cuando se presente el proyecto se debe hacer énfasis en que la propuesta no está ligada a resolver solo las deficiencias del sistema sino del proceso en sí y que es adaptable y relevante en cualquier tipo de contexto. 


\subsubsection{Impacto Externo}

El impacto externo está relacionado a cómo se ven afectados los interesados que no están implicados en el funcionamiento interno de la compañía. Este se refleja en los siguientes interesados: impacto en los clientes y en los competidores.

\subsubsection{Impacto en los clientes}

El impacto de los clientes se ha clasificado en los siguientes puntos:

- Impacto positivo:

- Aumenta el nivel de servicio en los skus clave para la compañía. Esto aumenta la confianza y fidelización de los clientes

- Impacto negativo:

- Se ha disminuido el nivel de servicio de los SKUS complementarios en los clientes, por lo que puede existir mayor riesgo de desabastecimiento en estos. Sin embargo, el nivel de servicio propuesto sigue dentro de los objetivos establecidos por la compañía.

\subsubsection{Impacto en el ambiente}

El impacto en el ambiente está medido por los siguientes puntos:

- Impacto positivo:

- La propuesta de solución está ligada a la reducción de recursos y procesos en exceso que pueden ocasionar contaminación indirectamente por los procesos de fabricación y distribución

- Impacto negativo:

- No existe un impacto negativo directo o indirecto en el ambiente al implementarse la propuesta. 


\subsubsection{Impacto en los competidores}

El impacto en los competidores está medido por los siguientes puntos:

- Impacto positivo:

- Mejora en los niveles de servicio de la compañía, mayor cobertura de los productos en las bodegas implica mayor participación en el mercado.

- Impacto negativo:

- Es posible que la reacción de los competidores sea un riesgo, pues puede mejorar en la lección de sus modelos, atendiendo de una manera más eficiente los inventarios en sus almacenes.

En la figura 85, se presenta a manera de resumen la matriz de mitigación de riesgos con cada uno de los riesgos identificados por stakeholders y sus acciones mitigantes.

\begin{tabular}{|c|c|l|c|c|c|c|l|}
\hline Stakeholders & Riesgo & \multicolumn{1}{|c|}{ Concepto } & Probabilidad & Impacto & Categoría & $\begin{array}{c}\text { Valor de } \\
\text { riesgo bruto }\end{array}$ & \multicolumn{1}{|c|}{$\begin{array}{c}\text { Acciones mitigantes (indicar la acción, frecuencia y } \\
\text { responsable) }\end{array}$} \\
\hline \multirow{2}{*}{ Trabajadores } & AS01 & Resistencia al cambio & D & 3 & D3 & Moderado & $\begin{array}{l}\text { Inclusión de todo el equipo en la validación final de la política de } \\
\text { stocks }\end{array}$ \\
\cline { 2 - 7 } & AS02 & $\begin{array}{l}\text { Abandono del proyecto por pocos } \\
\text { recursos }\end{array}$ & B & 4 & B4 & Extremo & $\begin{array}{l}\text { Automatización de la herramienta y proceso para disminuir los } \\
\text { tiempos de trabajo }\end{array}$ \\
\hline \multirow{2}{*}{ Compañía } & AS03 & Desviación de nivel de servicio en piloto & C & 2 & C2 & Moderado & $\begin{array}{l}\text { Tener un stock de reserva durante los meses de prueba de la } \\
\text { propuesta }\end{array}$ \\
\cline { 2 - 7 } & AS04 & $\begin{array}{l}\text { Desinterés en el proyecto por alta } \\
\text { dirección por implementación de otros } \\
\text { sistema }\end{array}$ & C & 3 & C3 & Alto & $\begin{array}{l}\text { Impulsar el proyecto como un proceso adaptable a cualquier } \\
\text { sistema }\end{array}$ \\
\hline Clientes & AS05 & $\begin{array}{l}\text { Reducción de nivel servicio en SKUS } \\
\text { complementarios }\end{array}$ & D & 3 & D3 & Moderado & $\begin{array}{l}\text { Analizar con Marketing si se deben subir los niveles de servicio a } \\
\text { los productos complementarios }\end{array}$ \\
\hline Competidores & AS06 & Reacción de los competidores & D & 1 & D1 & Bajo & Realizar un benchmarking \\
\hline
\end{tabular}

Figura 84. Matriz de mitigación de riesgos. Derechos reservados Vilela, 2017. 


\section{Capítulo V: Conclusiones y Recomendaciones}

\subsection{Conclusiones}

La gestión de inventarios en las compañías está generalmente soportada en un sistema que limita y define el modelo de inventarios que se debe seguir. Es difícil que un sistema se adapte por completo a la situación de una compañía y los métodos usados en los sistemas pueden ser complejos de entender. Esta limitación puede generar que los planificadores cuestionen y modifiquen la política de inventarios muchas veces sin una base teórica, lo que finalmente puede repercutir en desabastos o excesos de inventarios. En esta tesis, se propone un proceso estructurado para la definición de la política de inventarios que sea un soporte para la toma de decisiones sobre el inventario y reduzca los niveles de inventarios para reducir los vencimientos. Asimismo, se presenta un modelo detallado con parámetros basados en la metodología DDMRP y una herramienta de simulación construida bajo el marco teórico de gestión de inventarios.

Mediante la simulación en el sistema de planificación utilizado se ha comprobado que es necesaria la implementación de un modelo de inventarios como marco de referencia para poder controlar la variabilidad de los inventarios en los almacenes. Los sistemas de planificación, si bien son de gran ayuda, no se adaptan a todas las situaciones y cuando se requiere tomar decisiones que salgan de la norma, la única manera de comprobar si se está tomando una decisión correcta sobre la política de stocks, es un modelo estructurado.

Por otro lado, la política de stocks debe estar siempre soportada por un proceso estratégico que involucre e integre los objetivos de compañía a nivel. Se ha podido comprobar que solo definiendo y segmentando los productos de acuerdo a las metas de la compañía, se puede visualizar cuáles niveles de inventarios no están generando un verdadero valor agregado a la empresa.

Finalmente, es importante resaltar que la definición de la política es un proceso que está siempre en mejora continua y requiere de retroalimentación. Se necesita facilitar el proceso de modificación y cambios. La política de stocks no puede ser estática sino debe estar en constante revisión para adaptarse a las nuevas necesidades de la empresa. 


\subsection{Recomendaciones}

- Se recomienda elaborar como una segunda fase una propuesta que integre el proceso completo de producción desde el planeamiento de stocks con los proveedores, para así reducir los inventarios en toda la cadena. Esta propuesta debe estar dirigida a todas las plantas a nivel nacional y considerar las complejidades de la matriz de abastecimiento.

- Se recomienda investigar y reducir la unidad mínima de envío en los SKUS de clasificación C. Permitir la entrega de paletas pickeadas a los almacenes permite aumentar la velocidad del flujo de materiales y reducir el inventario.

- Se recomienda realizar un estudio sobre los beneficios de usar días de inventario o un punto de reorden fijo, si en el futuro se cambiara de sistema.

-Se recomienda implementar la metodología del DDMRP en su toda la cadena para poder acelerar el flujo de materiales y reducir los buffers de los centros de distribución.

-Se recomienda analizar las otras causas de vencimientos en patio (8\%) para finalizar por completo con el problema de desmedro. Se hizo un pre análisis de las posibles causas y entre ellas se encuentra un descontrol en el proceso de maquilas. Este debería ser uno de los temas principales para continuar con la reducción del indicador. 


\section{REFERENCIAS}

\section{Libros}

Demand Driven Institute (2016) The Demand Driven Planner Program. Lima : Flowing Consultoría.

Pérez, José Antonio (2010) Gestión por procesos. Madrid: ESIC Editorial.

Smith, Chad y Ptak, Carol (2011) Orlicky's Material Requirement Planning. New York: McGraw-Hill Education.

\section{Fuentes electrónicas}

Assawawongmethee, W., \& Laosiritaworn, W. (2015). Application of Neural Networks in Perishable Inventories Management. Applied Mechanics \& Materials.

Retrieved from :

http://search.ebscohost.com/login.aspx?direct=true\&db=egs\&AN=10219

2405\&lang=es [Consulta: 22 de julio 2017]

Castro, Carlos y Otros (2014) Marco de referencia para el desarrollo de un sistema de apoyo para la toma de decisiones para la gestión de inventarios : Retrieved from :

http://web.a.ebscohost.com/ehost/pdfviewer/pdfviewer?vid=1\&sid=ed7a22d7-641a$\underline{4 \text { ece-b15e-78391ffbf7d5\%40sessionmgr4007 }}$

Deloitte University Press (2015) Consumer product trends. Navigating 2020 . Retrieved from: https://www2.deloitte.com/pe/es/pages/consumerbusiness/articles/tendenciasconsumomasivo.html\# 
Díaz-Batista, José y Pérez-Armayor, Dania (2012) Optimización de los niveles de inventario en una cadena de suministro. Retrieved from: http://scielo.sld.cu/pdf/rii/v33n2/rii04212.pdf

Fernández, Joaquim (2015) Lean production planning and control in semi-process industries (tesis de maestría). Universidad noruega de ciencia y tecnología, Noruega.

Gupta, Amit y otros (2012) Inventroy selection criteria: A proposed classification. Retrieved from : https://search.proquest.com/docview/1241017989/fulltextPDF/F288F57374C14F44PQ/ $\underline{4 ? \text { accountid }=43860}$

Gutierrez, Valentina y Vidal, Carlos (2008). Modelo de Gestión de Inventarios en Cadena de Abastecimiento: Revisión de la Literatura. Retrieved julio 15, 2017 from www.scielo.org.co/pdf/rfiua/n43/n43a12.pdf

Hernández, Julia A. (2009) La gestión por proceso vinculada con la NC ISO 9001 en un hotel. Retrieved from : http://web.ebscohost.com/ehost/detail?vid=7\&sid=be5f7bc233eb-41f5-bb50d99a85aba565\%40sessionmgr1 13\&hid=24\&bdata $=$ Jmxhbmc9ZXM\%3d\#db=a9h\&AN $=52656886$

Jones, Malcom (2015). Can we be too lean?. Lean Management Journal, 5(9), 12-14. Retrieved from : http://web.a.ebscohost.com/ehost/pdfviewer/pdfviewer?vid=2\&sid=2e219805-d297430a-be26-03d982dc9552\%40sessionmgr4008

Kulahng, Peter y otros (2014) Further development of value stream mapping to design $\begin{array}{llll}\text { work } & \text { systems. } & \text { Retrieved : }\end{array}$ https://www.researchgate.net/publication/289655460_Further_development of Value Stream_Mapping to design_work_systems 
Lyons, A. C., Vidamour, K., Jain, R., \& Sutherland, M. (2013). Developing an understanding of lean thinking in process industries. Production Planning \& Control, 24(6), 475-494. doi: 10.1080/09537287.2011.633576

Luján, Darkys y otros (2009) El diseño organizacional basado en la gestión por proceso. Un reto para las instalaciones turísticas. Retrieved from : http://web.ebscohost.com/ehost/detail?vid=7\&sid=be5f7bc2-33eb-41f5-bb50d99a85aba565\%40sessionmgr113\&hid=117\&bdata $=$ Jmxhbmc9ZXM\%3d\#db=a9h\&A $\mathrm{N}=52685031$

Ma, J., Lei, T., \& Okudan, G. (2013). EOQ-based inventory control policies for perishable items: The case of blood plasma inventory management. IIE Annual Conference.Proceedings, , 1683-1692. Retrieved from: https://search.proquest.com/docview/1471959491?accountid=43860

Miclo, R y otros (2016) An empirical comparison of MRPII and Demand-Driven MRP. Retrieved from: https://www.sciencedirect.com/science/article/pii/S2405896316311144

Orozco, Maydelín y otros (2013, Julio) Perfeccionamiento de la gestión de inventario de lento movimiento $\mathrm{y}$ perecederos. Retrieved from : http://web.a.ebscohost.com/ehost/pdfviewer/pdfviewer?vid=1\&sid=3d20333b-04a3$\underline{47 \mathrm{dd}-\mathrm{a} 225-41 \mathrm{c} 435 \mathrm{e} 5 \mathrm{da} 15 \% 40 \text { sessionmgr4008 }}$

Przemyslaw, Korytkowski- (2014) Exponential smoothing for multi-product lot-sizing wiith heijunka and varying demand. Retrieve from : http://mper.org/mper/images/archiwum/2014/nr2/3-korytkowski.pdf

Román, Rodrigo (2017) Estudio del DDMRP (Demand Driven materials Requirement Planning) Proyecto fin Máster en logística. Universidad de Valladolid. Retrieved from:

Saleeshya, P., Raghuram, P., \& Vamsi, N. (2012). Lean manufacturing practices in textile industries-a case study. International Journal of Collaborative Enterprise, 3(1), 18-37. 
Tanel, T. L. (2012). How to make EOQ relevant again. SDCExec.Com, Retrieved from https://search.proquest.com/docview/1422206871 accountid $=43860$

Valdés, Tatiana (2009) Características de la gestión por proceso y la necesidad de su implementación en una empresa cubana. En: Ingeniería Industrial, Vol. 30. Retrieved from : $\quad$ http://web.ebscohost.com/ehost/detail?sid=69eefb2c-360d-43d4-bdf67ala82b6494e \%40sessionmgr14\&vid=3\&bk=1\&hid=20\&bdata=Jmxhbmc9ZXM\%3d\# $\mathrm{db}=\mathrm{a} 9 \mathrm{~h} \& \mathrm{AN}=60258536$

Van Goubergen, Dirk (2013) Developing a volume/mix capability model based on lean principles for a beverage company.

Veléz, Richard y Pérez, Giovanni (2013, Mayo. Propuesta metodológica para la gestión de inventarios en una empresa de bebidas por el método justo a tiempo caso de estudio : Abastecimiento de Azúcar. from: http://web.a.ebscohost.com/ehost/pdfviewer/pdfviewer?vid=1\&sid=926aaa46-91e64fc9-b8e5-e8fd9cd11826\%40sessionmgr4010

Viera, Emil y Otros (2017) Diagnóstico de los modelos de gestión de inventarios de alimentos en hoteleras. Retrieved from: https://search.proquest.com/docview/1908311957/fulltextPDF/DE48E1EA01AC483CP $\underline{Q} / 1$ ?accountid $=43860$ 


\section{ANEXOS}

\section{Anexo 1}

Lista de criterios para el ABC de coberturas

\begin{tabular}{|c|c|c|c|}
\hline Marca & Empaque & Retornabilidad & Tipo \\
\hline SL & 2.5 & NO RET & complementario \\
\hline SL & 625 & NO RET & complementario \\
\hline SL SAB. & 500 & NO RET & complementario \\
\hline $\mathrm{CCZ}$ & 1.5 & NO RET & estratégico \\
\hline $\mathrm{CCZ}$ & $400 / 450 / 500 \mathrm{ML}$ & NO RET & estratégico \\
\hline $\mathrm{CCZ}$ & 300/330 ML & NO RET & estratégico \\
\hline $\mathrm{CC}$ & 1.5 & RET & estratégico \\
\hline $\mathrm{CC}$ & 2.25 & NO RET & estratégico \\
\hline $\mathrm{CC}$ & 2.5 & RET & estratégico \\
\hline $\mathrm{CC}$ & 192 & RET & estratégico \\
\hline $\mathrm{CC}$ & 296 & RET & estratégico \\
\hline $\mathrm{CC}$ & $300 / 330 \mathrm{ML}$ & NO RET & estratégico \\
\hline $\mathrm{CC}$ & $400 / 450 / 500 \mathrm{ML}$ & NO RET & estratégico \\
\hline FT & $400 / 450 / 500 \mathrm{ML}$ & NO RET & estratégico \\
\hline SP & $400 / 450 / 500 \mathrm{ML}$ & NO RET & estratégico \\
\hline $\mathrm{IK}$ & 1.5 & NO RET & estratégico \\
\hline $\mathrm{IK}$ & 1.5 & RET & estratégico \\
\hline $\mathrm{IK}$ & 2.25 & NO RET & estratégico \\
\hline $\mathrm{IK}$ & 192 & RET & estratégico \\
\hline $\mathrm{IK}$ & 296 & RET & estratégico \\
\hline $\mathrm{IK}$ & $300 / 330 \mathrm{ML}$ & NO RET & estratégico \\
\hline $\mathrm{IK}$ & $400 / 450 / 500 \mathrm{ML}$ & NO RET & estratégico \\
\hline IKZ & 1.5 & NO RET & estratégico \\
\hline IKZ & $400 / 450 / 500 \mathrm{ML}$ & NO RET & estratégico \\
\hline IKZ & $300 / 330 \mathrm{ML}$ & NO RET & estratégico \\
\hline FR & 1 & NO RET & complementario \\
\hline FR & 1.5 & NO RET & complementario \\
\hline
\end{tabular}




\section{Anexo 2}

Clasificación ABC de Volumen de Venta

\begin{tabular}{|c|c|c|c|c|}
\hline Código SAP Perú & $\begin{array}{c}\text { Volumen Venta en CU } \\
2017 \\
\end{array}$ & Participación & $\begin{array}{c}\text { Participación } \\
\text { Acumulada }\end{array}$ & Clasificación \\
\hline 251291 & $3,438,514$ & $10.9 \%$ & $10.9 \%$ & A \\
\hline 252322 & $2,354,587$ & $7.5 \%$ & $18.4 \%$ & $A$ \\
\hline 250736 & $1,990,875$ & $6.3 \%$ & $24.8 \%$ & A \\
\hline 250204 & $1,791,900$ & $5.7 \%$ & $30.4 \%$ & $A$ \\
\hline 250039 & $1,759,404$ & $5.6 \%$ & $36.0 \%$ & A \\
\hline 250422 & $1,587,517$ & $5.0 \%$ & $41.1 \%$ & A \\
\hline 251637 & $1,359,700$ & $4.3 \%$ & $45.4 \%$ & $A$ \\
\hline 251641 & $1,234,221$ & $3.9 \%$ & $49.3 \%$ & A \\
\hline 250423 & 873,600 & $2.8 \%$ & $52.1 \%$ & A \\
\hline 251187 & 826,984 & $2.6 \%$ & $54.7 \%$ & $A$ \\
\hline 250070 & 695,939 & $2.2 \%$ & $57.0 \%$ & A \\
\hline 251141 & 639,824 & $2.0 \%$ & $59.0 \%$ & A \\
\hline 255433 & 637,239 & $2.0 \%$ & $61.0 \%$ & $A$ \\
\hline 251520 & 625,629 & $2.0 \%$ & $63.0 \%$ & A \\
\hline 255434 & 569,095 & $1.8 \%$ & $64.8 \%$ & A \\
\hline 254850 & 511,264 & $1.6 \%$ & $66.4 \%$ & A \\
\hline 250670 & 476,808 & $1.5 \%$ & $68.0 \%$ & A \\
\hline 251385 & 420,266 & $1.3 \%$ & $69.3 \%$ & A \\
\hline 250471 & 352,530 & $1.1 \%$ & $70.4 \%$ & A \\
\hline 252348 & 351,215 & $1.1 \%$ & $71.5 \%$ & A \\
\hline 254898 & 176,306 & $0.6 \%$ & $83.4 \%$ & B \\
\hline 254703 & 171,751 & $0.5 \%$ & $83.9 \%$ & B \\
\hline 250311 & 163,978 & $0.5 \%$ & $84.4 \%$ & $B$ \\
\hline 250411 & 154,019 & $0.5 \%$ & $84.9 \%$ & B \\
\hline 254700 & 146,725 & $0.5 \%$ & $85.4 \%$ & B \\
\hline 254915 & 143,375 & $0.5 \%$ & $85.9 \%$ & B \\
\hline 254904 & 124,409 & $0.4 \%$ & $86.3 \%$ & B \\
\hline 254974 & 120,773 & $0.4 \%$ & $86.6 \%$ & B \\
\hline 255369 & 114,569 & $0.4 \%$ & $87.0 \%$ & $B$ \\
\hline 255390 & 109,992 & $0.3 \%$ & $87.4 \%$ & B \\
\hline 254894 & 107,622 & $0.3 \%$ & $87.7 \%$ & B \\
\hline 252507 & 62,896 & $0.2 \%$ & $92.7 \%$ & $B$ \\
\hline 254901 & 62,161 & $0.2 \%$ & $92.9 \%$ & B \\
\hline 251394 & 60,382 & $0.2 \%$ & $93.1 \%$ & $B$ \\
\hline 251570 & 56,612 & $0.2 \%$ & $93.3 \%$ & $B$ \\
\hline 252436 & 55,990 & $0.2 \%$ & $93.4 \%$ & B \\
\hline 252629 & 54,611 & $0.2 \%$ & $93.6 \%$ & B \\
\hline 254732 & 54,576 & $0.2 \%$ & $93.8 \%$ & B \\
\hline 254742 & 49,338 & $0.2 \%$ & $94.0 \%$ & $B$ \\
\hline
\end{tabular}




\begin{tabular}{|c|c|c|c|c|}
\hline 254895 & 48,574 & $0.2 \%$ & $94.1 \%$ & B \\
\hline 252331 & 44,670 & $0.1 \%$ & $94.3 \%$ & $B$ \\
\hline 254706 & 44,460 & $0.1 \%$ & $94.4 \%$ & B \\
\hline 255352 & 43,320 & $0.1 \%$ & $94.5 \%$ & B \\
\hline 255351 & 43,149 & $0.1 \%$ & $94.7 \%$ & B \\
\hline 254741 & 39,411 & $0.1 \%$ & $94.8 \%$ & B \\
\hline 252508 & 38,566 & $0.1 \%$ & $94.9 \%$ & $B$ \\
\hline 254899 & 38,324 & $0.1 \%$ & $95.0 \%$ & B \\
\hline 255331 & 38,193 & $0.1 \%$ & $95.2 \%$ & B \\
\hline 251126 & 37,147 & $0.1 \%$ & $95.3 \%$ & B \\
\hline 254888 & 37,142 & $0.1 \%$ & $95.4 \%$ & $B$ \\
\hline 252533 & 36,156 & $0.1 \%$ & $95.5 \%$ & $B$ \\
\hline 254853 & 35,336 & $0.1 \%$ & $95.6 \%$ & B \\
\hline 251406 & 34,808 & $0.1 \%$ & $95.7 \%$ & B \\
\hline 254786 & 34,185 & $0.1 \%$ & $95.8 \%$ & $B$ \\
\hline 254702 & 34,041 & $0.1 \%$ & $95.9 \%$ & B \\
\hline 252333 & 33,420 & $0.1 \%$ & $96.1 \%$ & $B$ \\
\hline 255332 & 32,893 & $0.1 \%$ & $96.2 \%$ & $B$ \\
\hline 254733 & 30,878 & $0.1 \%$ & $96.3 \%$ & B \\
\hline 254729 & 29,894 & $0.1 \%$ & $96.4 \%$ & $B$ \\
\hline 250541 & 29,448 & $0.1 \%$ & $96.4 \%$ & $B$ \\
\hline 251633 & 28,523 & $0.1 \%$ & $96.5 \%$ & B \\
\hline 254916 & 28,164 & $0.1 \%$ & $96.6 \%$ & $B$ \\
\hline 250669 & 27,198 & $0.1 \%$ & $96.7 \%$ & $B$ \\
\hline 254930 & 26,828 & $0.1 \%$ & $96.8 \%$ & B \\
\hline 251151 & 25,800 & $0.1 \%$ & $96.9 \%$ & $B$ \\
\hline 254849 & 25,785 & $0.1 \%$ & $97.0 \%$ & $B$ \\
\hline 255392 & 25,028 & $0.1 \%$ & $97.0 \%$ & B \\
\hline 254843 & 24,465 & $0.1 \%$ & $97.1 \%$ & C \\
\hline 254723 & 24,381 & $0.1 \%$ & $97.2 \%$ & $C$ \\
\hline 255439 & 23,375 & $0.1 \%$ & $97.3 \%$ & C \\
\hline 254842 & 23,372 & $0.1 \%$ & $97.3 \%$ & C \\
\hline 254917 & 22,734 & $0.1 \%$ & $97.4 \%$ & $C$ \\
\hline 254851 & 21,619 & $0.1 \%$ & $97.5 \%$ & C \\
\hline 254958 & 20,312 & $0.1 \%$ & $97.6 \%$ & C \\
\hline 254893 & 19,838 & $0.1 \%$ & $97.6 \%$ & C \\
\hline 254903 & 19,783 & $0.1 \%$ & $97.7 \%$ & $C$ \\
\hline 251145 & 19,207 & $0.1 \%$ & $97.7 \%$ & C \\
\hline 254950 & 19,034 & $0.1 \%$ & $97.8 \%$ & C \\
\hline 254730 & 18,835 & $0.1 \%$ & $97.9 \%$ & $C$ \\
\hline 252460 & 18,438 & $0.1 \%$ & $97.9 \%$ & C \\
\hline 250030 & 18,297 & $0.1 \%$ & $98.0 \%$ & C \\
\hline 255391 & 18,228 & $0.1 \%$ & $98.0 \%$ & C \\
\hline 254892 & 17,884 & $0.1 \%$ & $98.1 \%$ & C \\
\hline 252549 & 17,589 & $0.1 \%$ & $98.1 \%$ & C \\
\hline
\end{tabular}




\begin{tabular}{|c|c|c|c|c|}
\hline 254913 & 16,451 & $0.1 \%$ & $98.2 \%$ & C \\
\hline 254852 & 16,362 & $0.1 \%$ & $98.3 \%$ & C \\
\hline 254954 & 15,776 & $0.1 \%$ & $98.3 \%$ & C \\
\hline 254764 & 15,136 & $0.0 \%$ & $98.4 \%$ & C \\
\hline 254762 & 15,096 & $0.0 \%$ & $98.4 \%$ & C \\
\hline 251253 & 15,026 & $0.0 \%$ & $98.4 \%$ & C \\
\hline 254759 & 14,886 & $0.0 \%$ & $98.5 \%$ & C \\
\hline 254891 & 14,569 & $0.0 \%$ & $98.5 \%$ & C \\
\hline 254749 & 14,479 & $0.0 \%$ & $98.6 \%$ & C \\
\hline 250746 & 14,475 & $0.0 \%$ & $98.6 \%$ & C \\
\hline 254914 & 14,048 & $0.0 \%$ & $98.7 \%$ & C \\
\hline 250418 & 13,930 & $0.0 \%$ & $98.7 \%$ & C \\
\hline 252532 & 13,728 & $0.0 \%$ & $98.8 \%$ & C \\
\hline 254750 & 13,628 & $0.0 \%$ & $98.8 \%$ & C \\
\hline 254889 & 13,348 & $0.0 \%$ & $98.9 \%$ & C \\
\hline 252334 & 12,465 & $0.0 \%$ & $98.9 \%$ & C \\
\hline 255444 & 12,271 & $0.0 \%$ & $98.9 \%$ & C \\
\hline 254900 & 11,951 & $0.0 \%$ & $99.0 \%$ & C \\
\hline 254965 & 11,906 & $0.0 \%$ & $99.0 \%$ & C \\
\hline 751312 & 10,796 & $0.0 \%$ & $99.0 \%$ & C \\
\hline 254964 & 10,362 & $0.0 \%$ & $99.1 \%$ & C \\
\hline 250032 & 9,805 & $0.0 \%$ & $99.1 \%$ & C \\
\hline 250689 & 9,672 & $0.0 \%$ & $99.1 \%$ & C \\
\hline 255429 & 9,491 & $0.0 \%$ & $99.2 \%$ & C \\
\hline 254756 & 8,940 & $0.0 \%$ & $99.2 \%$ & C \\
\hline 256359 & 8,848 & $0.0 \%$ & $99.2 \%$ & C \\
\hline 254993 & 8,536 & $0.0 \%$ & $99.2 \%$ & C \\
\hline 255404 & 8,486 & $0.0 \%$ & $99.3 \%$ & C \\
\hline 254963 & 7,853 & $0.0 \%$ & $99.3 \%$ & C \\
\hline 255430 & 7,554 & $0.0 \%$ & $99.3 \%$ & C \\
\hline 255440 & 7,484 & $0.0 \%$ & $99.3 \%$ & C \\
\hline 255382 & 7,102 & $0.0 \%$ & $99.4 \%$ & C \\
\hline 256320 & 1,867 & $0.0 \%$ & $99.9 \%$ & C \\
\hline 254890 & 1,813 & $0.0 \%$ & $99.9 \%$ & C \\
\hline 255447 & 1,553 & $0.0 \%$ & $99.9 \%$ & C \\
\hline 255449 & 1,461 & $0.0 \%$ & $99.9 \%$ & C \\
\hline 252531 & 1,423 & $0.0 \%$ & $99.9 \%$ & C \\
\hline 254769 & 1,420 & $0.0 \%$ & $99.9 \%$ & C \\
\hline 751360 & 1,334 & $0.0 \%$ & $99.9 \%$ & C \\
\hline 251626 & 1,246 & $0.0 \%$ & $100.0 \%$ & C \\
\hline
\end{tabular}


